\author{
UNIVERSIDADE DE SÃO PAULO \\ FACULDADE DE ECONOMIA, ADMINISTRAÇÃO E CONTABILIDADE \\ DEPARTAMENTO DE ECONOMIA \\ PROGRAMA DE PÓS-GRADUAÇÃO EM ECONOMIA
}

\title{
Política fiscal e ciclo político no Brasil: uma análise empírica
}

Fernando de Faria Siqueira

Orientador: Prof. Dr. Márcio Issao Nakane 


\section{Política fiscal e ciclo político no Brasil: uma análise empírica}

Dissertação apresentada ao Departamento de Economia da Faculdade de Economia, Administração e Contabilidade da Universidade de São Paulo como requisito parcial para a obtenção do título de Mestre em Ciências.

Orientador: Prof. Dr. Márcio Issao Nakane

Versão Corrigida

(Versão Original disponível na Biblioteca da Faculdade de Economia , Administração e Contabildade)

SÃO PAULO

2015 
FICHA CATALOGRÁFICA

Elaborada pela Seção de Processamento Técnico do SBD/FEA/USP

\section{Siqueira, Fernando de Faria}

Política fiscal e ciclo político no Brasil: uma análise empírica / Fernando de Faria Siqueira. - São Paulo, 2015.

$126 \mathrm{p}$.

Dissertação (Mestrado) - Universidade de São Paulo, 2015.

Orientador: Márcio Issao Nakane.

1. Política fiscal 2. Multiplicadores fiscais 3. Ciclo político I. Universidade de São Paulo. Faculdade de Economia, Administração e Contabilidade. II. Título.

CDD -336.3 
Prof. Dr. Marco Antonio Zago

Reitor da Universidade de São Paulo

Prof. Dr. Adalberto Américo Fischmann

Diretor da Faculdade de Economia, Administração e Contabilidade

Prof. Dr. Hélio Nogueira da Cruz

Chefe do Departamento de Economia

Prof. Dr. Márcio Issao Nakane

Coordenador do Programa de Pós-Graduação em Economia 
Aos meus pais 



\section{Agradecimentos}

Dedico esta dissertação especialmente aos meus pais, Kesser e Nelson, que estiveram presentes em todos os momentos, me apoiaram em todas minhas decisões e nunca mediram esforços para sempre me prover o mundo.

À minha irmã Marina, aos meus tios, tias, primos, primas e avós, que sempre me acolheram em tempos difíceis e celebraram as alegrias em tempos de conquistas. Vocês me ajudaram bastante durante este Mestrado e sou eternamente grato por isso. Um agradecimento especial ao meu primo Rafael Faria por sempre me incentivar nos estudos.

Infelizmente não posso compartilhar este momento com o Seu José Faria nem com o Seu Antônio Siqueira. Me alegro de ser neto de dois grandes homens que passaram por Unaí, saibam que eu carrego nossos sobrenomes com muito orgulho.

A todos os amigos de infância, companheiros de intercâmbio, colegas de graduação e mestrado, obrigado pelos bons momentos e pela ajuda indireta nessa caminhada. Fiz bons amigos no IPE-USP, aprendemos muito uns com os outros e espero que essa amizade se prolongue por muitos anos.

Ao meu orientador, Márcio Nakane, pelo conhecimento que me presenteou e pela disponibilidade em me orientar, mesmo à distância. Ao meu coorientador, Rodrigo Orair, por todas as importantes contribuições ao meu trabalho. Aos membros da banca de defesa, Claudio Amitrano e Fabiana Rocha, pelas excelentes observações.

Agradeço o suporte financeiro propiciado pela Coordenação de Aperfeiçoamento de Pessoal de Nível Superior (CAPES). Um muito obrigado aos funcionários e professores da FEA, em especial a Gilberto Tadeu Lima, Pedro Garcia Duarte, Mauro Rodrigues e Carlos Eduardo Soares Gonçalves pelos comentários e críticas relevantes durante o processo de qualificação. 

"Governments never learn. Only people learn." Milton Friedman 



\section{Resumo}

É consensual que questões políticas acarretam impactos econômicos significativos, entretanto, saber a direção e magnitude destes não é trivial. A contribuição desta dissertação ao assunto se divide em duas frentes: verificação da existência de ciclo político-orçamentário na execução de investimentos públicos; e estimação de relações macroeconômicas ao longo do ciclo político. Para o primeiro ponto, utilizou-se um modelo estrutural para a série mensal de investimento das Administrações Públicas (níveis federal, estadual e municipal), encontrando ciclos de curto e médio prazo, com duração de, aproximadamente, 2 e 4 anos, respectivamente. Ademais, os ciclos coincidem com o calendário eleitoral, sendo que suas fases de expansão se encontram no período pré-eleitoral e as de contração, sempre em anos ímpares. Para o segundo ponto, um VAR linear e outro com mudança de regime foram estimados, incorporando neste as informações obtidas pelo Modelo Estrutural. Os resultados do modelo linear indicam que investimento público causa crowding-out sobre investimento privado e que tanto investimento público quanto privado exercem efeito positivo sobre o PIB, a magnitude do segundo, entretanto, é consideravelmente superior à do primeiro. $\mathrm{O}$ modelo não-linear evidencia que os multiplicadores fiscais são distintos para os períodos pré e pós-eleitoral, salientando que o ajuste fiscal não implica redução da atividade econômica, e sim o contrário. O impacto dos investimentos privados sobre o crescimento, por sua vez, é sempre alto, positivo e independente de ciclo político.

Palavras-chaves: Política Fiscal. Multiplicadores fiscais. Ciclo Político. 



\begin{abstract}
There is consensus that political issues carry significant economic impact, however, it's not trivial to determine the direction and magnitude of these ones. The contribution of this thesis to the subject is divided into two fronts: the determination of political budget cycle in the execution of public investments; and estimation of macroeconomic relationships over the political cycle. For the first point, we used a structural model for the general government (federal, state and municipal levels) monthly series of investment, finding short and medium term cycles, with duration of, approximately, 2 and 4 years, respectively. Furthermore, the cycles coincide with the electoral calendar, since phases of expansion are in the pre-election period and the contraction ones, always in odd years. For the second point, a linear and a regime switching VAR were estimated, incorporating in the latter information obtained by the Structural Model. The results of the linear model indicate that public investment causes crowding-out in private investment and that public and private investment has a positive effect on the GDP, the magnitude of the second, however, is considerably higher than the first. The nonlinear model shows that fiscal multipliers are distinct for the pre and post-election period, stressing that the fiscal adjustment does not imply reduction of the economic activity, but otherwise. On the other hand, the impact of private investment on economic growth is always high, positive and independent of the political cycle.
\end{abstract}

Keywords: Fiscal Policy. Fiscal Multipliers. Political Cycle. 



\section{Sumário}

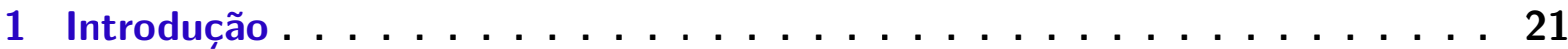

2 Revisão de Literatura . . . . . . . . . . . . . . . . . . . . . . 23

2.1 Ciclo Político . . . . . . . . . . . . . . . . . . . . . 23

2.1.1 Modelos Oportunistas . . . . . . . . . . . . . . . . . . . 24

2.1.2 Modelos Partidários . . . . . . . . . . . . . . . . . . . 27

2.1.3 Modelos de Expectativas Racionais . . . . . . . . . . . . . . 28

2.1 .4 Literatura Empírica . . . . . . . . . . . . . . . . . . . 30

2.2 Política fiscal . . . . . . . . . . . . . . . . . . 38

2.2 .1 Multiplicadores fiscais . . . . . . . . . . . . . . . 38

2.2 .2 Modelos Teóricos . . . . . . . . . . . . . . . . . . . . . . . 39

2.2.2.1 Modelos keynesianos . . . . . . . . . . . . . . . . . . 39

2.2.2.2 Modelos neoclássicos . . . . . . . . . . . . . . . . . . . . 40

2.2.2.3 Modelos novo-keynesianos . . . . . . . . . . . . . . . . 41

2.2 .3 Modelos Empíricos . . . . . . . . . . . . . . . . . . . 42

$2.2 .3 .1 \quad$ VAR/SVAR . . . . . . . . . . . . . . . . . . 43

2.2.3.2 Abordagem Narrativa . . . . . . . . . . . . . . 50

2.2.3.3 Restrição de Sinais . . . . . . . . . . . . . . . . . . . . 54

2.2.3.4 Regime-Switching VAR . . . . . . . . . . . 55

3 Metodologia e Dados . . . . . . . . . . . . . . . . 59

3.1 Construção da série de investimento público . . . . . . . . . . . . . . 59

3.2 Desagregação temporal . . . . . . . . . . . . . . . . . . 64

3.3 Análise Descritiva . . . . . . . . . . . . . . . . . . . . . . 66

3.4 Modelo econométrico . . . . . . . . . . . . . . . . . . . . . . 69

4 Resultados. . . . . . . . . . . . . . . . . . . . 73

4.1 Modelo Estrutural . . . . . . . . . . . . . . . . . . . 73

4.2 Modelo STVAR . . . . . . . . . . . . . . . . . . . . . . . 85

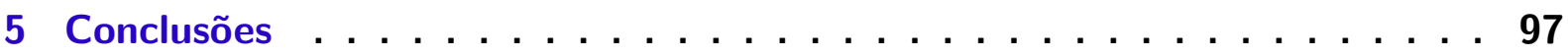

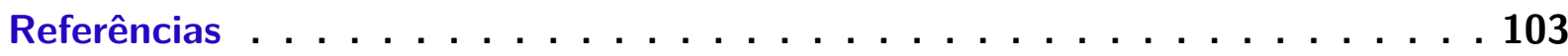

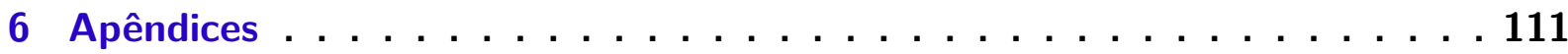

6.1 Testes de Raiz Unitária . . . . . . . . . . . . . . . . . . . . . . . . . . 111

6.2 Modelo linear . . . . . . . . . . . . . . . . . . . . . . . . . . . 118

6.3 Modelo não-linear . . . . . . . . . . . . . . . . . . . . . . . . . . . . . 123 



\section{Lista de ilustrações}

Figura 1 - Ciclo político-econômico de Nordhaus (1975) . . . . . . . . . . . . . 25

Figura 2 - Série Nominal do Investimento Público . . . . . . . . . . . . . 63

Figura 3 - Séries reais mensais de investimento público e privado . . . . . . . . 65

Figura 4 - Comparação de Índices . . . . . . . . . . . . . . . . . 67

Figura 5 - Anos pares e ímpares . . . . . . . . . . . . . . 67 67

Figura 6 - Composição do Investimento Trimestral . . . . . . . . . . . . . . 68

Figura 7 - Investimento privado trimestral . . . . . . . . . . . . 68

Figura 8 - Output do Modelo Estrutural . . . . . . . . . . . . . . 78

Figura 9 - Componentes cíclicos do Modelo Estrutural . . . . . . . . . . . . . 80

Figura 10 - Agregação dos componentes cíclicos . . . . . . . . . . . . . . . . 80

Figura 11 - Modelo 1: Funções de impulso resposta (choque em Ig) . . . . . . . . . 89

Figura 12 - Modelo 1 Funções de impulso resposta (choque em Ip) . . . . . . . . . 90

Figura 13 - Teste de Robustez 1: Funções de impulso resposta (choque em $I g$ ) . . . 91

Figura 14 - Teste de Robustez 2: Funções de impulso resposta (choque em $I g$ ) . . . 92

Figura 15 - Teste de Robustez 3: Funções de impulso resposta (choque em $I g$ ) . . . 93

Figura 16 - Teste de Robustez 4: Funções de impulso resposta (choque em $I g$ ) . . . 94

Figura 17 - Variável de transição . . . . . . . . . . . . . . . . . . . . . . . 99

Figura 18 - Investimento da APU . . . . . . . . . . . . . . . . . . . . . . 99

Figura 19 - Análise de estabilidade do VAR linear . . . . . . . . . . . . . . . . . . 119

Figura 20 - Decomposição da variância . . . . . . . . . . . . . . . . . . 122 



\section{Lista de tabelas}

Tabela 1 - Desvios-padrão dos distúrbios . . . . . . . . . . . . . . 78

Tabela 2 - Efeitos sazonais . . . . . . . . . . . . . . . . . . . 79

Tabela 3 - Parâmetros dos ciclos . . . . . . . . . . . . . . . 79

Tabela 4 - Vetor de estado no período $12 / 2014 \ldots \ldots$. . . . . . . . 83

Tabela 5 - Estatísticas do modelo . . . . . . . . . . . . . 83

Tabela 6 - Testes de Normalidade . . . . . . . . . . . . . . . . . . 84

Tabela 7 - Teste de Correlação Serial . . . . . . . . . . . . . . . . 84

Tabela 8 - Ajuste do Modelo . . . . . . . . . . . . . . . 85

Tabela 9 - Propriedades . . . . . . . . . . . . . 85

Tabela 10 - Multiplicadores fiscais . . . . . . . . . . . . . . 95

Tabela 11 - Resumo dos testes de raiz unitária . . . . . . . . . . . . . . . 111

Tabela 12 - ADF Investimento público . . . . . . . . . . . . . . . . . 112

Tabela 13 - DF-GLS Investimento Público . . . . . . . . . . . . . . . 113

Tabela 14 - NG-Perron Investimento Público . . . . . . . . . . . . . . . 113

Tabela 15 - KPSS Investimento Público . . . . . . . . . . . . . . . . 113

Tabela 16 - ADF Investimento Privado . . . . . . . . . . . . . . . . . . 114

Tabela 17 - DF-GLS Investimento Privado . . . . . . . . . . . . . . . . 114

Tabela 18 - NG-Perron Investimento Privado . . . . . . . . . . . . . . . . . 115

Tabela 19 - KPSS Investimento Privado . . . . . . . . . . . . . . . . 115

Tabela 20 - ADF Produto Interno Bruto . . . . . . . . . . . . . . 116

Tabela 21 - DF-GLS Produto Interno Bruto . . . . . . . . . . . . . . 116

Tabela 22 - NG-Perron Produto Interno Bruto . . . . . . . . . . . . . . 117

Tabela 23 - KPSS Produto Interno Bruto . . . . . . . . . . . . . . . . 117

Tabela 24 - Critério do número de defasagens . . . . . . . . . . . . . . . . . 119

Tabela 25 - Teste de Autocorrelação Portmanteau . . . . . . . . . . . . . . . . 120

Tabela 26 - Teste de Autocorrelação LM . . . . . . . . . . . . . . . . . . . . . . 120

Tabela 27 - Teste de Normalidade . . . . . . . . . . . . . . . . . . . . 121

Tabela 28 - Critérios de Informação (Modelo não-linear) . . . . . . . . . . . . . . . 123

Tabela 29 - Covariância dos Resíduos . . . . . . . . . . . . . . . . . 123

Tabela 30 - Omega (pré-eleitoral) . . . . . . . . . . . . . . 123

Tabela 31 - Omega (pós-eleitoral) . . . . . . . . . . . . . . . . 123

Tabela 32 - Resumo do Modelo 1 . . . . . . . . . . . . . . . . . 124 



\section{Introdução}

Governos maximizam o bem-estar social? De acordo com a teoria econômica tradicional, governantes tentam maximizar crescimento econômico ou se esforçam em alcançar a fronteira de possibilidade de produção eficiente ao selecionar investimentos públicos.

Keynes defendia que os investimentos públicos seriam a ferramenta de política fiscal ideal reunindo duas virtudes: capacidade de estimular a demanda no curto prazo e gerar o aumento da capacidade produtiva no longo prazo.

Baseado nos pressupostos keynesianos, origina-se a Regra de Ouro, a qual se sustenta sob a hipótese de que os investimentos públicos se financiam através de efeitos virtuosos sobre o investimento privado e o Produto Interno Bruto (PIB), gerando os ganhos de receitas no futuro, que justificam o endividamento no presente. A partir dos anos 1990, certos estudos passaram a defender a chamada visão expectacional da política fiscal, na qual um aumento dos gastos ou redução dos impostos podem não ter efeitos expansionistas nem mesmo no curto prazo, pelo fato da sinalização que essa política fiscal gera junto aos agentes econômicos.

A percepção dos limites da atuação estatal em assuntos econômicos por parte da Academia, políticos e policy makers oscilou entre uma visão liberal e outra intervencionista durante o século passado e o começo deste. Neste sentido, o papel ativo da política fiscal é uma das questões que surgem quando se discute como deve ser o comportamento das autoridades governamentais.

A crise financeira de 2007 trouxe uma velha questão da macroeconomia de volta à pauta: qual o papel da política fiscal em uma recessão? Ela deve neutralizar movimentos da demanda privada, aceitar déficits orçamentários mais elevados, ou visar a sustentabilidade das finanças públicas? A resposta a estas questões depende, dentre outros fatores, da magnitude do multiplicador fiscal. Uma nova literatura surgiu a partir de então que se preocupa em estimar esses multiplicadores condicionando-os ao estado da economia (expansão ou recessão).

Os resultados sugerem que há uma grande diferença quando se considera a economia nesses dois estados de natureza. Ou seja, se constatou que os impactos da política fiscal são sensíveis ao ciclo econômico, o objetivo deste trabalho, contudo, é fazer o mesmo exercício com relação ao ciclo político.

Pode-se afirmar que princípios como eficiência e alocação ótima de recursos não devem ser pressupostos como verdades absolutas, uma vez que incentivos políticos podem distorcer os investimentos públicos, tanto na destinação da verba a determinados setores quanto no timing com que isso é feito. 
Neste contexto, o objetivo desta dissertação é contribuir com a literatura empírica em macroeconomia da política fiscal unindo elementos de ciclo político. Para tanto, o presente trabalho está dividido em mais quatro capítulos além desta introdução.

O propósito do capítulo de Revisão de Literatura é especificar as vertentes analisadas das duas escolas de pensamento que aqui se estudou: ciclos políticos e mensuração de impactos de política fiscal. Na seção de ciclo político, subdividiu-se a literatura em quatro frentes, as três primeiras contendo os principais modelos teóricos e a última reunindo os trabalhos empíricos relevantes para o desenvolvimento do presente estudo. A subdivisão da seção de política fiscal seguiu os mesmos critérios, sendo mais específica, contudo, no sentido de criar um aparte para considerações sobre multiplicadores fiscais e agrupar os modelos empíricos com relação à metodologia adotada. A contribuição da primeira parte ao presente trabalho se concentra na capacidade de explicar as causas de certas peculiaridades da execução do investimento público no Brasil. A segunda, por sua vez, auxilia na análise do impactos dessas peculiaridades na economia do país. Um enfoque maior de fato foi dado à segunda parte, uma vez que toda a etapa de estimação que será realizada toma esses trabalhos como modelo.

O capítulo 3 apresenta os dados, explica como que as séries de formação bruta de capital fixo foram obtidas, apresenta a técnica utilizada para a obtenção de séries mensais, fornece uma análise descritiva dos dados e expõe o modelo econométrico aqui adotado. No capítulo 4 estão os resultados do Modelo Estrutural e do Modelo STVAR, sendo que, com relação ao primeiro, se preocupou em incluir uma exposição teórica da abordagem de espaço de estados. O capítulo 5, por fim, expõe as conclusões do estudo. Entre elas, se destaca o fato de que as respostas do produto frente a choques nos investimentos público e privado são distintas perante o ciclo político, além de se ter constatado que prevalece no Brasil o fenômeno de crowding-out dos investimentos privados. Ademais, pode-se dizer que a execução dos investimentos públicos possui um comportamento cíclico de expansão nos anos pré-eleitorais e de contração nos anos pós-eleitorais, característica de ciclo político orçamentário. 


\section{Revisão de Literatura}

\subsection{Ciclo Político}

Existe viés eleitoral na manipulação da política econômica? Para muitos economistas, cientistas políticos e leigos, a resposta é obviamente sim. A ideia geral é que políticos no poder, com pretensões de reeleição, têm um incentivo para usar instrumentos de política fiscal ou monetária de tal forma que, durante anos de eleição, o gasto público ou agregados monetários aumentam de modo a satisfazer o eleitor mediano, apesar de isso implicar potenciais efeitos adversos sobre sustentabilidade fiscal e estabilidade macroeconômica. Os efeitos desse fenômeno, entretanto, não são tão claros, sendo necessários teoria econômica e métodos quantitativos para a formulação de argumentos razoáveis.

Apesar de certos economistas, como Kalecki e Robinson, terem escrito sobre o assunto na primeira metade do século passado, a literatura de ciclos políticos avançou a partir de meados da década de 70, com a publicação do artigo seminal de Nordhaus (1975). Neste trabalho, o autor formalizou e clarificou a ideia de ciclos políticos oportunistas. De acordo com esse modelo, políticos estimulam a demanda agregada antes das eleições de maneira a impulsionar crescimento e reduzir o desemprego. Passado o período eleitoral, os policymakers tomam medidas para reverter os efeitos adversos da política econômica implementada anteriormente. Desse modo, ao analisar a trajetória das variáveis macroeconômicas, deve-se observar a ocorrência de um ciclo econômico, no qual os pontos de inflexão coincidem com o calendário eleitoral.

Como os partidos representam a união de indivíduos que, teoricamente, compartilham de mesmos interesses e preferências, é de se esperar que a condução da política econômica seja influenciada pela ideologia partidária. Com base nessa premissa, foram desenvolvidos modelos que incorporaram o componente de ideologia partidária à teoria dos ciclos político-econômicos, denominados modelos partidários (HIBBS, 1977; HIBBS, 1986).

Com o surgimento da teoria das expectativas racionais, os modelos de ciclos políticoeconômicos tiveram que ser reformulados, isso pois a premissa de que os eleitores são ingênuos, incapazes de aprender e propensos a erros sistemáticos, torna-se insatisfatória. Passado um ciclo político, o eleitor consegue internalizar os fatos e entender a jogada política intertemporal, tendo a consciência de que um aumento da atividade econômica no período pré-eleitoral será seguido por uma elevação do nível de preços e recessão após as eleições. Rogoff e Sibert (1988) e Rogoff (1990) são trabalhos precursores dessa área.

Nessa seção uma revisão da literatura será feita focando, brevemente, nas três subdivisões mencionadas acima e, principalmente, nos trabalhos empíricos realizados até então. Sempre que conveniente, comentários serão feitos ao longo das seções de revisão de 
literatura de modo a salientar pontos relevantes para o presente estudo.

\subsubsection{Modelos Oportunistas}

Embora economistas, de tempo em tempo, tenham feito observações sobre as causas políticas dos ciclos econômicos, para Nordhaus (1975), a única teoria séria é de Kalecki (1943). Para este autor, uma situação prolongada de pleno emprego não é de bom grado aos líderes empresariais. Isso porque perderiam o controle dos trabalhadores e os "capitães da indústria" ficariam ansiosos para "ensinar-lhes uma lição". Como resultado, pressão política seria feita no sentido de promover o resurgimento de políticas ortodoxas, como o corte de déficit orçamentário. A economia passaria então para um estágio com maior desemprego e menor geração de renda como produto do ciclo político.

O modelo de Kalecki (1943) assume, implicitamente, que líderes econômicos têm um controle desproporcional dos mecanismos políticos. Para esse pensador, a causa dos ciclos políticos é a natureza não representativa do sistema político . A sugestão de Nordhaus (1975) é que o processo de formulação de decisões em um governo representativo levará a um fenômeno similar, embora as causas e o tempo de maturação sejam distintos. Cabe ressaltar que a teoria kaleckiana se funda na predominância de interesses capitalistas no mecanismo político, enquanto que o modelo de Nordhaus (1975) se aplicaria a qualquer sistema democrático envolvendo escolhas intertemporais.

Dito isso, pode-se afirmar que Nordhaus (1975) foi de fato o pioneiro na modelagem de ciclos políticos. Em seu modelo teórico, políticos em exercício tendem a explorar os tradeoffs da curva de Phillips antes das eleições de modo a lhes aferir reconhecimento líquido positivo e, portanto, certa vantagem nas urnas. Através de política fiscal e monetária, políticos seriam capazes de gerar o denominado ciclo político-econômico, que consiste em uma situação de gerar condições econômicas aparentemente favoráveis para a sociedade (ou para um grupo dela) de maneira a aumentar a probabilidade de reeleição.

Analisando a figura (1), pode-se notar a forma que o ciclo político-econômico proposto por Nordhaus (1975) se manifesta. A taxa de desemprego é declinante ao longo de todo o mandato, entretanto, imediatamente após as eleições, o vitorioso força a economia para a direita da curva de Phillips, aumentando a taxa de desemprego de maneira a combater a inflação e modificar as expectativas inflacionárias dos agentes. Note que mesmo que no instante da eleição a inflação seja bastante elevada, o governante conseguirá se reeleger, basta que a desutilidade marginal do desemprego para o eleitor representativo no modelo de Nordhaus (1975) seja maior que a desutilidade marginal da inflação. 
Figura 1 - Ciclo político-econômico de Nordhaus (1975)

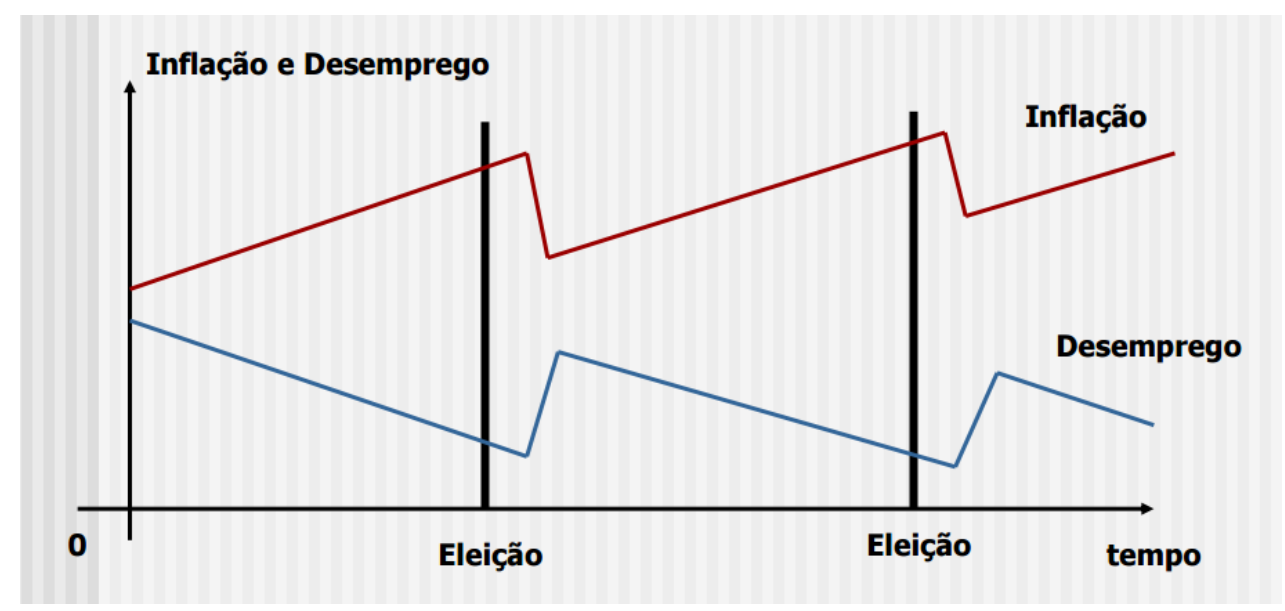

Esse modelo relativamente simples de indicação de política macroeconômica tem duas predições importantes: primeiramente, que políticas dotadas de viés eleitoreiro geram menos desemprego e mais inflação do que o ótimo social; e que a política partidária ideal induz a formação de ciclos político-econômicos, com desemprego e contenção da inflação nos primeiros anos de mandato, seguido de um surto inflacionário quando perto das eleições.

Ressaltam-se três premissas segundo as quais a última predição acima mencionada é observada no mundo real: que os governos sejam escolhidos através de eleições competitivas e periódicas; que o governo tenha sofisticação e controle econômico suficiente para mover a economia para a direção desejada; e que os eleitores sejam míopes, no sentido de que estes tomam a decisão de votação com base no conjunto de informação presente no período eleitoral, e somente neste.

As duas variáveis macroeconômicas modeladas por Nordhaus (1975) são inflação e emprego, entretanto, não se limitam a essas os efeitos adversos dos ciclos políticoeconômicos. Como será extensamente discutido na subseção de literatura empírica, inúmeras são as possibilidade de manipulação política, de tal forma que até a taxa de câmbio está sujeita a tal processo (ver Bonomo e Terra (1999)).

Para Nordhaus (1975), há uma possível implicação dos ciclos políticos sobre o investimento público. Na medida que investimento requer uma subtração do consumo presente através de taxação ou inflação de modo a aumentar o consumo depois das eleições, sua teoria indica que o nível de tal investimento será menor que o ótimo. Mais especificamente, em equilíbrio, a taxa social de retorno sobre investimento público será maior do que a de investimento privado devido à miopia democrática. Esse resultado sugere que a teoria dos desequilíbrios sociais de J. K. Galbraith ${ }^{1}$ é plausível nesses fundamentos

1 Para a teoria de Galbraith, há uma sub-alocação de recursos para bens públicos. A criação de demandas artificiais quer através da publicidade ou da propensão para a rivalidade desloca recursos para bens privados em detrimento de bens públicos que têm maior valor inerente. 
teóricos.

Ainda com relação ao investimento público, tornam-se relevantes as considerações existentes no trabalho de Nordhaus (1975) no que diz respeito ao fato de existir uma potencial relação positiva entre a necessidade de investimentos governamentais e a existência de interesses oportunistas da classe política. Isto é, pode-se considerar a hipótese de que a classe dos governantes pode extrair algum benefício político particular em função do atendimento das necessidades coletivas, influenciando assim, de maneira positiva, a probabilidade e a permanência dos ciclos eleitorais.

Como será argumentado na subseção de evidência empírica de ciclos políticos, o ciclo político pode ser considerado um fato estilizado em vários países e em diversas esferas de governo. Dada a recorrência e seu impacto negativo sobre o bem-estar social, quais as soluções para eliminar esse viés das políticas públicas? Nordhaus (1975) lista pelo menos quatro alternativas.

Uma solução óbvia seria melhorar o conjunto de informação disponível para eleitores, assim, eles conseguiriam julgar e penalizar aqueles que engajam em políticas econômicas míopes. Quando a transmissão e recepção de informação não são custosas, essa opção é vantajosa. Com informações verdadeiras sobre os trade-offs de longo prazo, os ciclos de curto prazo tenderiam a se extinguir; por outro lado, é impraticável exigir de cada cidadão elaborar um modelo econométrico na sua cabeça antes de tomar sua decisão.

Outra possibilidade é designar a condução da política econômica a pessoas sem vínculos políticos. Esse procedimento é típico de política monetária, a qual, por razões históricas, é conduzida por bancos centrais. Nessa mesma linha, pode-se argumentar que é válido entregar a política fiscal para o Tesouro Nacional, o qual é composto por servidores, técnicos no assunto. Pode-se contra-argumentar, entretanto, que delegar responsabilidade a uma agência que não é politicamente responsável por legitimar as necessidades reais é mais perigoso que evitar eventuais ciclos. Em suma, os custos e benefícios de uma política econômica independente são de difícil mensuração e requer uma análise cuidadosa.

Uma alternativa seria eliminar os trade-offs de curto prazo a partir de políticas eficazes, retirando dos políticos a oportunidade de levar vantagem em certas decisões. Há pouca dúvida de que se puder curar o paciente da doença, os sintomas desapareceriam. O problema é que, assim como pessoas sempre ficam doentes, sempre existirão trade-offs em economia, uma vez que os recursos são escassos.

Por último, Nordhaus (1975) sugere que aumente a base de participação na formulação de políticas. A estrutura de planejamento força o governo a abrir mão de sua visão e negociar o rumo de novas políticas com a oposição e outros grupos de interesse. Seria muito mais difícil convencer outros grupos a aceitarem um plano que deliberadamente projeta um ciclo político-econômico. Essa característica já está presente, em certo grau, 
no legislativo; no executivo, contudo, não há a mesma estrutura organizacional favorável para tal.

Além desses pontos, é conveniente ressaltar o papel das instituições para a criação de um ambiente pouco propício à propagação de ciclos políticos. Leis de responsabilidade fiscal, compromissos com o FMI, legislação que delimite o poder discricionário em anos eleitorais são exemplos de como um arcabouço institucional bem delineado pode ser preventivamente eficiente.

\subsubsection{Modelos Partidários}

No primeiro tipo de modelo, assume-se um comportamento essencialmente oportunista por parte dos políticos incumbentes, os quais utilizam instrumentos de política pública de modo a obter um bom e visível desempenho a curto prazo (antes das eleições), sem ponderar suas consequências a médio prazo. O próximo tipo de modelo que será tratado considera diferenças de preferências por políticas ou resultados econômicos entre partidos políticos, permitindo, assim, que os resultados variem de acordo com o partido no poder.

De maneira bem genérica, partidos de esquerda são mais propensos a intervenções na economia, tendem a escolher pontos para a esquerda da curva de Phillips, privilegiando níveis menores de desemprego e aceitando taxas maiores de inflação. Em contrapartida, partidos à direita do espectro ideológico preferem, em termos relativos, o controle dos preços e a estabilidade financeira à diminuição do desemprego (HIBBS, 1977).

$\mathrm{Na}$ opinião deste autor, isso ocorre porque os partidos de direita representam os interesses das classes mais abastadas, seus membros possuem a maior parte do capital financeiro e acumulam maiores perdas com a elevação da inflação, enquanto que os partidos de esquerda são formados por indivíduos das classes trabalhadoras, mais sensíveis ao aumento do desemprego.

Hibbs (1977) fez uma análise de séries de tempo trimestrais do período pós-guerra com relação à taxa de desemprego para os EUA e Grã-Bretanha. O estudo empírico sugere que a taxa de desemprego tem sido movida para baixo em administrações democráticas e pró-trabalhistas e para cima em governos republicanos e conservadores. A conclusão geral é que governos utilizam políticas macroeconômicas de acordo com seus interesses econômicos e preferências subjetivas de seus círculos eleitorais políticos.

De maneira a avaliar sua proposição, Hibbs (1977) formula um modelo capaz de estimar os efeitos hipotéticos de políticas macroeconômicas sobre a taxa de desemprego, livre de tendência, ciclos e flutuações estocásticas. A metodologia utilizada é Box-Jenkins, de tal forma que a variável endógena (taxa de desemprego) é uma realização de um processo 
estocástico linear autorregressivo e de médias móveis (ARMA).

$$
U_{t}=\frac{\beta}{1-\delta L} G_{t-1}+\frac{\theta_{0}+\theta_{q}(L)}{\phi_{p}(L)(1-L)^{d}} a_{t}
$$

onde $U_{t}$ é taxa de desemprego, $G_{t}$ é uma dummy diferenciando administrações pró-trabalho ou democráticas $(=1)$ de conservadoras ou republicanas $(=-1), \beta$ e $\delta$, por fim, são parâmetros descrevendo os efeitos de mudanças nas variáveis.

A equação acima foi estimada para os casos britânico e americano, separadamente. Para o primeiro cenário, os resultados indicam que a taxa de desemprego diminui durante governos pró-trabalhistas e aumenta no período de gestão conservadora. Para o caso americano, o modelo em questão é incapaz de prover uma boa estimativa para o efeito líquido das políticas macroeconômicas de Republicanos versus Democratas sobre a variável de emprego.

Nessa linha, conclui-se que resultados macroeconômicos não são completamente endógenos à economia, mas obviamente influenciados, em uma parcela significativa, por escolhas políticas de curto e longo prazo. Os verdadeiros ganhadores das eleições são talvez melhores determinados ao examinar as consequências em termos de políticas da mudança partidária ao invés de simplesmente contar votos.

Esse modelo assume em sua formulação que os eleitores têm expectativas adaptativas, isso implica que os cidadãos são sistematicamente enganados por políticos antes de irem às urnas, o que não parece ser razoável. Tendo isso em vista, surgiram os modelos de expectativas racionais. Os trabalhos pioneiros em ciclos políticos com agentes racionais foram Rogoff e Sibert (1988) e Rogoff (1990). A próxima seção irá descrever os pontos principais desse tipo de modelo destacando a sua importância para o presente estudo.

\subsubsection{Modelos de Expectativas Racionais}

Diferentemente de Persson e Tabellini (1990), que deram um tratamento keynesiano aos ciclos político-econômicos, baseando suas análises em curvas de Phillips de curto prazo e na eficácia de políticas monetárias expansionistas, Rogoff e Sibert (1988) elaboraram uma proposta alternativa, sugerindo que, sob expectativas racionais, os ciclos políticoeconômicos devem ser observados nos instrumentos de política fiscal. De acordo com os autores, em anos eleitorais, os políticos tendem a engajar em política fiscal expansionista, reduzindo os impostos ou elevando os gastos públicos, criando o que se denominou ciclos políticos orçamentários (political budget cycle).

A argumentação dos modelos partidários tradicionais de que o partido no poder escolhe a combinação de inflação e desemprego ao longo do mandato condizente com a sua ideologia não se sustenta numa economia cujos agentes possuem expectativas racionais. 
Sob essa hipótese, as políticas econômicas implementadas somente terão efeitos sobre as variáveis reais se os agentes econômicos forem surpreendidos. Como as pessoas têm conhecimento sobre o nível de inflação preferido pelos partidos, passadas as eleições, os agentes econômicos incorporam essa informação na formação de expectativas e neutralizam os efeitos das políticas econômicas adotadas.

Teorias de ciclo político-econômico em geral contam com rigidez nominal e miopia dos eleitores. Rogoff (1990) elabora um modelo que preserva algumas contribuições dos modelos anteriores, contudo com refinamentos significativos. O ciclo político orçamentário se dá na política fiscal ao invés de produto e inflação, bem como resulta de um processo de sinalização multidimensional.

Nesse modelo, tanto os eleitores quanto os políticos são agentes racionais maximizadores de utilidade. O ciclo político orçamentário surge das assimetrias de informação intertemporais sobre a competência do incumbente em administrar os bens públicos e o processo produtivo dos mesmos. O político no poder tem o incentivo de enviesar a política fiscal no período pré-eleitoral em direção a gastos de consumo visíveis em detrimento de investimento público.

O modelo de Rogoff (1990) sugere que a "visibilidade" dos gastos seria associada com as despesas correntes, ao invés daqueles referentes a bens de capital. Portanto, assumese que a manipulação política perto das eleições é realizada de maneira a prover benefícios imediatos para um número considerável de cidadãos.

Em seções futuras serão apresentados dados para a economia brasileira acerca do investimento público. Adiantando certas informações, o que se observa é um aumento do investimento público em um período imediatamente anterior às eleições e, subsequentemente, uma queda dessa variável no período pós-eleitoral. Em outras palavras, se realmente comprovado que a política fiscal é utilizada para fins eleitoreiros, pode-se dizer que o investimento público é uma variável pró-cíclica (na mesma direção do ciclo político) e não uma variável de ajuste como prega a teoria acima.

No equilíbrio do modelo de Rogoff (1990), eleitores podem deduzir a competência contemporânea do líder através do grau que ele distorce impostos e despesas governamentais. Talvez a mais importante razão para desenvolver esse tipo de modelo foi permitir analisar implicações de ganhos de bem-estar a partir de regimes eleitorais alternativos e de várias propostas para evitar distorções no orçamento em anos eleitorais.

A percepção popular é a de que ciclos políticos orçamentários são uma coisa ruim. Entretanto, uma conclusão central de Rogoff (1990) é que pode ser um mecanismo social eficiente para difundir informações atualizadas sobre a competência administrativa do incumbente. Esforços para encurtar esse tipo de ciclo podem reduzir o bem-estar, ou impedindo a transmissão de informação ou induzindo políticos a selecionar caminhos de 
sinalização socialmente mais custosos.

Claramente, se algum grupo fosse capaz de monitorar as ações do governo e transmitir informações de maneira crível para a população de uma maneira que não seja muito custoso para um cidadão mediano compreender, não haveria ciclo político orçamentário para Rogoff (1990).

Se a sinalização pré-eleitoral é de fato a causa de ciclos políticos orçamentários, existe alguma maneira de a sociedade mitigar esse problema? Rogoff (1990) lista duas possíveis soluções: a primeira é a apresentação de emendas à Constituição com vistas a restringir política fiscal discricionária em meses perto das eleições, como a adoção de planos orçamentários bienais. Para o autor, a redução da intensidade ou duração do ciclo político orçamentário a partir dessa alternativa gera um custo, que é a impossibilidade do eleitor distinguir políticos eficientes e ineficientes.

Para Rogoff (1990), a análise precedente exagera na eficácia de tentar extinguir o ciclo político com legislação. Na prática, um político incumbente tem uma longa lista de opções de política fiscal com as quais ele pode sinalizar, sendo irrealista, portanto, a ideia de restringi-lo em todas as dimensões. Desse modo, conclui que a tentativa de suprimir o ciclo político pode na verdade reduzir o bem-estar do cidadão representativo ao induzir políticos competentes a sinalizar de maneira ineficiente.

A segunda possibilidade é uma proposta mais complexa em termos jurídicos, em que o autor propõe que as eleições não sejam estabelecidas exogenamente, mas sim que haja um sistema no qual o governante possa convocar as eleições antes do final do mandato, a exemplo de países industrializados como Canadá, Reino Unido e Japão.

Resumindo, Rogoff e Sibert (1988) desenvolveram um modelo de modo a explicar a existência de ciclos políticos ao longo do tempo, incorporando no mesmo eleitores racionais que não possuem informação perfeita com relação às competências dos líderes políticos. Subsequentemente, Rogoff (1990) formula um modelo similar no qual políticos no poder manipulam a composição de gastos públicos totais antes das eleições na direção de despesas mais visíveis.

\subsubsection{Literatura Empírica}

A presente seção pretende relacionar, de maneira resumida, os resultados obtidos até então de estudos acerca dos mais variados tipos de ciclo político. Optou-se por organizá-los perante a classe de ciclo político estudada de acordo com a seguinte sequência: ciclos políticos oportunistas; partidários e político-orçamentários. Pretende-se também focar naqueles que, de alguma forma, contribuem para o desenvolvimento do presente trabalho.

Alesina e Roubini (1992) foi um dos primeiros a levar o debate de ciclo político para a esfera empírica; de acordo com seu estudo, pouca evidência foi encontrada de efeitos 
pré-eleitorais sobre variáveis macroeconômicas, em especial crescimento do PIB e taxa de desemprego, como sugerido pelo modelo teórico de Nordhaus (1975). Por outro lado, indícios foram encontrados no sentido de que há ciclos políticos monetários, isto é, política monetária expansionista em anos eleitorais. O estudo também encontrou indicações de ciclo político orçamentário ou política fiscal descontrolada anteriormente a eleições. A inflação exibe um salto no período pós-eleitoral, o que pode ser explicado ou por uma política monetária e fiscal desregrada no período pré-eleitoral ou por uma escolha de políticas ao longo do tempo de maneira, no mínimo, oportuna.

Testes de ciclos político-econômicos oportunistas podem ser divididos em duas categorias: testes sobre variáveis de resultado, tradicionalmente, produto, inflação, emprego e testes sobre instrumentos de política como agregados monetários, impostos, transferências e gastos governamentais. Para Alesina e Roubini (1992)), o primeiro conjunto de testes rejeita esmagadoramente a hipótese de ciclo político-econômico, enquanto que o segundo grupo de testes apresenta resultados mistos.

Os estudos empíricos da década de 1970 até o início de 1990 centraram, quase exclusivamente, em países industrializados e geralmente não encontraram efeitos estatisticamente significantes para a corroboração de hipótese de ciclos políticos orçamentários regulares (ver Alesina e Cohen (1997) e Drazen (2001)). Em contrapartida, outros estudos (Schuknecht (1996), Shi e Svensson (2002), Brender e Drazen (2005)) não apenas confirmaram a existência de ciclos políticos orçamentários para países em desenvolvimento, mas também têm demonstrado a grande magnitude destes ciclos.

Alguns modelos teóricos argumentam que os políticos podem combinar políticas fiscais e monetárias para a manipulação de variáveis econômicas. Entretanto, a maior parte da literatura defende que é na política fiscal que se observa os canais do ciclo político. Não apenas o canal de transmissão entra em discussão, mas a eficácia das políticas uma vez que são implementadas.

Para Drazen (2001), a principal conclusão é que modelos baseados na manipulação da economia através de política monetária não são convincentes tanto do ponto de vista teórico quanto empírico. Em contrapartida, explicações baseadas em política fiscal conformam melhor aos dados e apresentam argumentos mais fortes em termos teóricos. Drazen (2001) salienta ainda que políticas fiscais são relevantes neste contexto político dado que as mesmas sempre geram resultados econômicos de ordem real, ao contrário de políticas monetárias.

Grande parte dos trabalhos que testaram a hipótese da existência dos ciclos políticoeconômicos oportunistas nas variáveis macroeconômicas para dados dos Estados Unidos o rejeitaram, a exemplo de McCallum (1978) e Alesina e Cohen (1997). Em um trabalho englobando dezoito países desenvolvidos com regimes democráticos, entre 1960 e 1987, Alesina e Roubini (1992) testaram a teoria dos ciclos político-econômicos. 
Para proceder ao teste, utilizaram dados de painel para estimar modelos autorregressivos do crescimento do produto e das taxas de desemprego e inflação, incluindo, também, variáveis dummy nos períodos eleitorais. A partir dos resultados gerais, rejeitaram a hipótese de ciclos oportunistas, indo na direção contrária às predições do modelo de Nordhaus (1975). Em estimações distintas para cada país, Alesina e Roubini (1992)) detectaram ciclos eleitorais no crescimento do produto e na taxa de inflação para Nova Zelândia e Alemanha.

Schuknecht (1996) é um trabalho que contempla 35 países subdesenvolvidos entre os anos de 1970 e 1992. A conclusão geral é que há uma maior probabilidade de manipulação política nesses países, uma vez que os pesos e contrapesos são mais frágeis. O mesmo estudo sugere que políticas de gastos, como distribuição ou subsidiamento de bens, geração de emprego através de programas públicos são provavelmente mais eficazes do que desonerações no processo de influenciar a decisão de voto. Ohlsson e Vredin (1996) também rejeitaram a hipótese oportunista, ao testarem como a arrecadação e os gastos do governo foram influenciados pela atividade econômica, eleições e ideologia, na Suécia, no período de 1968 a 1993.

Preussler e Portugal (2003) testam a hipótese de oportunismo político nas variáveis macroeconômicas, nos instrumentos de política fiscal e nas taxas de juros para o Brasil no período de 1980 a 2000. O procedimento econométrico usado pelos autores foi modelos ARIMA de séries temporais com a inclusão de variáveis dummy de modo a inserir janelas de período eleitoral e captar o efeito ceteris paribus.

Os resultados confirmam a hipótese de oportunismo político com relação à taxa de inflação e gastos totais do governo federal, descartando a hipótese para a taxa de desemprego, crescimento do PIB e os demais instrumentos de política fiscal. Como os dados utilizados para estimação foram contabilizados pelo critério de caixa, há um efeito defasado que deve ser considerado, uma vez que há um intervalo considerável entre empenho, liquidação e pagamento, sendo que as eleições podem estar entre essas etapas. Ao constatarem que houve um aumento da despesa total nos 8 meses que sucedem as eleições, os autores concluíram que os governantes empenharam suas despesas antes da votação, postergando seu pagamento para o mandato seguinte. A Lei de Responsabilidade Fiscal, instituída para coibir esse tipo de comportamento, indica que essa prática era comum na administração pública, reforçando, assim, a conclusão do estudo empírico.

No presente estudo, esse tipo de problema foi razoavelmente contornado pelo processo de construção da série de investimento público. Idealmente, o critério mais apropriado para mensurar a Formação Bruta de Capital Fixo (FBCF) da Administração Pública é o valor de liquidação, entretanto, devido às peculiaridades do processo orçamentário brasileiro, a maneira mais recomendável, na verdade, é o que se denominou liquidação efetiva (GOBETTI, 2007). Na seção de metodologia e construção dos dados, uma explicação 
completa será feita sobre esse quesito.

Em seguida, dois trabalhos são listados (ambos para o caso brasileiro). Sakurai e Gremaud (2004) analisam o comportamento fiscal dos municípios paulistas perante dois fatores de ordem política: o calendário eleitoral e os diferentes partidos políticos dos prefeitos municipais, entre os anos de 1989 e 2001. São analisados componentes específicos do orçamento público por meio de Econometria de dados em painel, sendo encontradas evidências de impulsos positivos na despesa municipal nos anos eleitorais de 1992 e 1996, ao passo que, no tocante às agremiações partidárias, observa-se que PFL é o partido que mais investe, além de que PTB, PPB/PDS e PMDB são os partidos que mais despendem recursos em transferências correntes.

Sakurai e Menezes-Filho (2011) testam a hipótese de ciclo político oportunista e partidário através de uma base de dados de municípios brasileiros no período de 1989 a 2005. Os resultados apontam para um aumento em despesas correntes e totais, assim como para uma queda de investimentos municipais, receitas fiscais locais e superávit orçamentário em anos eleitorais. Há também evidências de que existe certo grau de ideologia partidária, uma vez que o partido que se encontra no poder exerce uma influência relativa na performance das contas públicas locais. Em outras palavras, há embasamento empírico para o argumento de que existe, no Brasil (pelo menos a nível municipal), comportamento oportunista dos políticos em poder assim como viés partidário na condução da política fiscal.

O maior interesse deste estudo recai sobre os ciclos de natureza político-orçamentária, desse modo, encerra-se esta seção com os trabalhos empíricos dessa vertente. Os resultados de Block (2002) são consistentes com o modelo de ciclo orçamentário de Rogoff (1990). Baseado em 69 países em desenvolvimento, esse estudo provê evidências de que os gastos de governos deslocam para despesas correntes e visíveis, ao passo que verbas para investimentos públicos são comprometidas.

Fatás e Mihov (2003) estudam os efeitos da política fiscal discricionária sobre a volatilidade e crescimento do produto. Usando dados de 29 países, os autores chegam a três conclusões principais: governos que usam a política fiscal agressivamente geram significativa instabilidade macroeconômica; a volatilidade do produto causada por política fiscal discricionária diminui a taxa de crescimento do PIB; para cada ponto percentual adicional de volatilidade, 0,8 ponto percentual é o decréscimo em termos de crescimento; o uso prudente da política fiscal é explicado, em grande parcela, pela presença de restrições políticas e outros tipos de arranjos institucionais. As conclusões desse trabalho sustentam argumentos que defendem a implementação de regras que limitem o poder discricionário dos formuladores de políticas, uma vez que se constatou sua eficácia na redução da volatilidade e contribuição ao crescimento econômico.

Aidt, Veiga e Veiga (2007) estimaram um painel composto por municípios portugueses para o intervalo de anos entre 1979 e 2001 e encontraram, em anos eleitorais, 
decréscimos nos saldos orçamentários e receitas locais, assim como aumento das despesas, especialmente em relação aos investimentos públicos.

Vários estudos encontram evidências de ciclos eleitorais para um amplo leque de países. No entanto, para Vergne (2009), esta constatação empírica parece refletir de maneira mais acentuada em um subconjunto de países que foram recentemente democratizados. Assim, os ciclos políticos orçamentários são um fenômeno das novas democracias, e tendem a diminuir com o tempo. Essa afirmação levanta a seguinte pergunta: distorções fiscais aparecem em diferentes formas? Vergne (2009) supera modelos tradicionais de ciclos políticos orçamentários, os quais são centrados exclusivamente sobre a dinâmica de déficits e gastos agregados do governo, a fim de lançar luz sobre mudanças na composição eleitoral de gastos públicos.

Usando dados de 42 países em desenvolvimento de 1975 a 2001, Vergne (2009) encontra evidências de impactos eleitorais sobre a alocação da despesa pública. Os resultados mostram que, em anos eleitorais, as despesas públicas se concentram em despesas correntes mais visíveis, em particular salários e subsídios, em detrimento das despesas de capital. Além disso, os resultados sugerem que impactos eleitorais sobre a alocação dos gastos públicos são propensos a durar, mesmo com países ganhando experiência em política eleitoral.

Para Vergne (2009), a literatura não se preocupou suficientemente em detalhar os instrumentos de política fiscal através dos quais o governo pode tentar influenciar sua popularidade perto das eleições. Análises que focam somente na dinâmica do déficit público geral correm o risco de interpretar de forma errônea as evidências, além de perder uma parte importante do processo. Isso pois os políticos podem mudar a composição de gastos em determinado ano sem incorrer em déficits.

Brender e Drazen (2005) encontram um ciclo político orçamentário a partir de um painel de países, mas argumentam que esse resultado é obtido principalmente pela experiência das novas democracias, onde a manipulação fiscal deve funcionar pelo fato dos eleitores ainda serem inexperientes com a política eleitoral ou simplesmente por não possuírem informação suficiente para avaliar a competência do político no poder. O ciclo fiscal forte nesses países em particular é o responsável pela constatação de um ciclo na amostra completa; uma vez que esse grupo de países é retirado da amostra, o ciclo político desaparece. Os resultados do estudo, por outro lado, apontam que o ciclo político existe tanto em países desenvolvidos quanto em países subdesenvolvidos.

Shi e Svensson (2002) consideram um painel de 91 países, incluindo tanto democracias quanto países não democráticos, no período de 1975 a 1995, e encontram que, em anos eleitorais, o superávit orçamentário cai significantemente, tanto em países desenvolvidos quanto subdesenvolvidos, embora o efeito seja consideravelmente mais forte nesses últimos. Shi e Svensson (2002) também encontram evidências de que ciclos fiscais tendem a ser 
mais prevalecentes em países onde os eleitores têm menos acesso à imprensa livre e a outros mecanismos de monitoramento das políticas governamentais.

Krueger e Turan (1993) argumentam que manipulação fiscal pré-eleitoral era comum na Turquia no período 1950-1980. Para os autores, política fiscal tem efeitos reais mesmo se for antecipada, além do fato de que ela pode influenciar a decisão do voto mesmo se não houver nenhum efeito agregado.

Focando em países de baixa renda, Ebeke e lcer (2013) investigam o comportamento de variáveis fiscais durante e após as eleições. Os resultados apontam que, durante anos eleitorais, o consumo governamental aumenta significantemente, gerando déficits fiscais maiores. Durante os dois anos subsequentes às eleições, o ajuste fiscal toma a forma de crescente mobilização de geração de receitas e corte em investimento público sem nenhum ajuste significante em despesas de consumo corrente.

Usando uma base de dados contendo regras fiscais nacionais e programas do FMI, Ebeke e lcer (2013) encontram evidências de que essas regras e os programas ajudam a amortecer a magnitude dos ciclos políticos orçamentários nos países investigados. A conclusão é que o processo eleitoral insere não apenas um custo macroeconômico, mas também gera um ajuste fiscal doloroso no qual investimento público é amplamente sacrificado.

A teoria que prega a existência de ciclos eleitorais na política fiscal indica que antes das eleições ocorre uma expansão do déficit público. Contudo, não sugerem, explicitamente, se este aumento reflete a redução de receita ou o aumento dos gastos do governo. Outra possibilidade é que, em anos eleitorais, ocorra uma transferência de recursos para projetos que tragam maiores benefícios políticos, não havendo necessariamente expansão do déficit público. Desta forma, os estudos empíricos usam diferentes variáveis para testar a presença de ciclos políticos oportunistas nos instrumentos de política fiscal (PREUSSLER; PORTUGAL, 2003).

Nessa linha de raciocínio, Vergne (2009) interpreta os ciclos em gastos de capital como um indicativo de tentativa de alcance de interesses especiais em um ano eleitoral, ao passo que despesas de consumo corrente são mais propensos a beneficiarem uma massa de eleitores. Rogoff (1990) defende em seu modelo teórico que o ciclo político orçamentário se dá pelo crescimento dos gastos correntes a custo de despesas de capital. Existem trabalhos, entretanto, que apresentam resultados que rejeitam essa premissa, apontando que o investimento público nem sempre é uma variável de ajuste no período pré-eleitoral.

Khemani (2004) investiga eleições para Assembleias Legislativas Estaduais nos 14 maiores estados da Índia e mostra que anos eleitorais têm um impacto positivo e significativo sobre investimentos públicos, particularmente sobre a construção de estradas, em detrimento de gastos de consumo corrente. 
Schuknecht (2000), por sua vez, com um estudo de 24 países em desenvolvimento no período de 1973 a 1992, conclui que o instrumento preferido para influenciar os resultados das eleições é a despesa de capital.

A partir de dados municipais da Colômbia, no período de 1987 a 2002 , Eslava (2006) também encontra mudanças pré-eleitorais no orçamento público, no sentido de aumentar os projetos relacionados à infraestrutura - particularmente em infraestrutura urbana, de saneamento básico e energia - e diminuir os gastos correntes.

O objetivo do presente trabalho não é analisar a mudança da composição dos gastos governamentais para o Brasil, mas compreender a dinâmica do investimento público em um contexto de ciclo político. Dessa forma, conclusões como as dos trabalhos recém citados não podem ser feitas; em contrapartida, um nível de detalhamento maior pode ser alcançado em alguns aspectos, como a caracterização e parametrização do ciclo a partir de Modelos Estruturais.

Unindo elementos de modelos de ciclo político-econômico e de modelos que analisam o comportamento e o impacto distributivo da regulação do governo em mercados específicos, Paiva (1994) estima o impacto das eleições em preços regulados. A partir de dados dos preços da gasolina no Brasil entre 1964 e 1984, o estudo mostra que o preço relativo da gasolina cai em anos eleitorais.

Sobre estudos que cobrem entidades da Federação brasileira, um trabalho importante a ser considerado é o realizado por Cossio (1998), no qual é estimado um painel com variáveis fiscais dos Estados brasileiros e uma variável dummy de ano eleitoral para o período de 1985 a 1997. De acordo com os resultados, são encontradas evidências estatisticamente significantes, sugerindo a existência de impulsos positivos de despesa em anos eleitorais. Dois outros pontos são relevantes. Com relação ao grau de participação do eleitorado, um maior grau de participação da sociedade no processo político (eleições) tende a gerar uma maior disciplina fiscal do governante. Concernente ao grau de fragmentação partidária, o estudo sugere que uma maior dificuldade em formar maiorias de governo estaria relacionada de forma positiva com um maior volume de gastos, isto é, uma maior dificuldade em realizar ajuste fiscal.

Bonomo e Terra (1999) fizeram um estudo captando a influência política na condução da política cambial brasileira entre os anos de 1964 e 1997. Utilizando modelos Markov-Switching, chegaram à conclusão de que a probabilidade da taxa de câmbio de mercado estar valorizada nos meses que precedem as eleições é maior do que em meses que não se enquadram nesse quesito. Além do mais, a probabilidade da taxa de câmbio se desvalorizar nos meses subsequentes às eleições também é maior que no caso contrafactual.

Os pontos abordados até aqui permitem inferir que houve comprovação e rejeição da presença de diversos tipos de ciclos políticos para uma grande lista de países, sendo que 
tanto os instrumentos de política fiscal quanto as variáveis macroeconômicas abordados nesses estudos são dos mais variados possíveis.

Observa-se que os trabalhos em ciclo político, de maneira geral, focam em analisar a existência do ciclo intrínseco às variáveis econômicas, sejam elas instrumentos ou de resultado, mas fazem isso de maneira separada. O foco deste trabalho é incluir na análise de ciclo político a interação dessas variáveis e colocar em discussão se essa interação também é afetada pelo próprio ciclo político. Até onde se sabe, nenhum outro trabalho se preocupou em testar a sensibilidade de multiplicadores fiscais ao longo do ciclo político, mas apenas frente ao ciclo econômico. E é nesse sentido que a literatura de ciclos políticos e a de mensuração de impactos de política fiscal chegam a um ponto de convergência. 


\subsection{Política fiscal}

\subsubsection{Multiplicadores fiscais}

Política fiscal, em uma visão geral, pode ser resumida no conjunto de medidas pelas quais o Governo extrai renda do setor produtivo e realiza despesas visando alcançar três objetivos: estabilização macroeconômica, alocação de recursos e redistribuição da renda.

A função estabilizadora se resume na sustentação da renda, com baixo desemprego e estabilidade de preços. Em outras palavras, é a tentativa de induzir a economia a um estado próximo do pleno emprego, com uma taxa de crescimento do Produto Interno Bruto (PIB) condizente com as condições macroeconômicas e com estabilidade de preços relativos, sendo que inflações são inibidas e deflações evitadas. A função alocativa consiste no fornecimento eficiente de bens e serviços públicos, compensando as falhas de mercado. Por fim, a função redistributiva visa assegurar a distribuição equitativa da renda.

A vertente da política fiscal aqui estudada, a política de execução de investimentos públicos, teria como canais de atuação principais as duas primeiras funções acima citadas.

A política fiscal tem sido objeto de estudos e controvérsias desde a década de 1930, tempo em que Keynes (1936) recomendou o aumento de gastos do governo como forma de impulsionar produção e emprego. A teoria keynesiana teve grande repercussão, sendo que pouco depois tornou-se hegemônica no meio acadêmico e na condução da política econômica.

A mensuração dos efeitos da política fiscal surgiu, entretanto, após a própria implementação de tais medidas. A partir de então, diversas técnicas foram criadas de modo a estimar melhor parâmetros, lidar de forma mais inteligente com problemas metodológicos e, cada vez mais, poder responder diferentes perguntas. Um conceito que ficou enraizado na teoria macroeconômica como medida de impacto dessas políticas é o de multiplicador fiscal. Na sua forma mais simples, é a mudança do produto causada por uma variação exógena do instrumento de política fiscal, $\frac{\Delta Y(t)}{\Delta G(t)}$, este é o multiplicador de impacto. Por ter efeitos defasados, outra forma de considerar essa variável é pela fórmula $\frac{\Delta Y(t+n)}{\Delta G(t)}$. Há também o multiplicador de pico, definido como o impacto máximo em um certo horizonte de tempo $n$ : $\max _{n} \frac{\Delta Y(t+n)}{\Delta G(t)}$. Por fim, o multiplicador cumulativo, definido como a mudança cumulativa do produto sobre a mudança cumulativa dos gastos em um período $n$ é $\frac{\sum_{i=1}^{n} \Delta Y(t+i)}{\sum_{i=1}^{n} \Delta G(t+i)}$. Grande parte dos estudos que estimam multiplicadores o fazem a partir das estimativas das elasticidades. Pela definição, a elasticidade do produto frente aos gastos é:

$$
\varepsilon_{Y, X}=\frac{\left(\frac{\Delta Y}{Y}\right)}{\left(\frac{\Delta X}{X}\right)}=\left(\frac{\Delta Y}{Y}\right)\left(\frac{X}{\Delta X}\right)=\left(\frac{\Delta Y}{\Delta X}\right)\left(\frac{X}{Y}\right)
$$

Manipulando algebricamente, a relação entre a elasticidade $\left(\varepsilon_{Y, X}\right)$ e o multiplicador $(\mu)$ é 
dada por:

$$
\mu=\left(\frac{Y}{X}\right) \varepsilon_{Y, X}
$$

A literatura de estimação de multiplicadores fiscais é relativamente recente, sendo que os primeiros trabalhos que serão aqui tratados datam do final da década de 90 . Os estudos podem ser divididos em três vertentes principais: abordagem narrativa, liderada por Ramey e Shapiro (1998); vetores autoregressivos, cujo expoente é Blanchard e Perotti (2002); e multiplicadores endógenos ao ciclo, representada por Auerbach e Gorodnichenko (2012).

Antes de expor a literatura de estimação dos efeitos de política fiscal, será feita uma breve revisão sobre os diferentes pensamentos das escolas de macroeconomia sobre a repercussão da política de gastos governamentais como embasamento teórico.

\subsubsection{Modelos Teóricos}

No debate entre macroeconomistas, não existe consenso acerca dos efeitos de política fiscal sobre a economia real. Enquanto uns pregam que o gasto tem um caráter keynesiano e serve como impulsionador do crescimento, no outro extremo, há aqueles que consideram a política fiscal inócua e defendem o menor intervencionismo possível. Essas pessoas pensam através de modelos, que diferem em suposições, metodologias e resultados. Abaixo seguem resumos sobre como cada escola do pensamento trata o assunto.

\subsubsection{Modelos keynesianos}

Keynes argumenta na sua Teoria Geral de 1936 que a política fiscal deveria ser uma ferramenta importante no controle do nível de demanda agregada. Isso implica que o governo deveria aumentar os gastos e/ou reduzir a tributação todas as vezes que o nível da demanda for insuficiente para gerar pleno-emprego, como nos casos de uma simples recessão ou mesmo uma Grande Depressão. Uma vez que o consumo das famílias era visto por Keynes como uma função direta da renda disponível, o impacto de um aumento do gasto público ou de uma diminuição dos impostos na atividade econômica era tido como sempre positivo (JESUS, 2011).

Seguindo o arcabouço teórico construído por Keynes, é possível mostrar que tanto o multiplicador dos gastos quanto o dos tributos são sempre maiores que a unidade e dependem, entre outros fatores, da magnitude da propensão marginal a consumir (JESUS, 2011).

Com relação à condução da política de estabilização, foi disseminada a ideia de que a política fiscal é geralmente preferível à política monetária, uma vez que os efeitos da primeira são considerados mais diretos, previsíveis e de rápida ação na demanda 
agregada. Dessa maneira, pode-se afirmar que a política fiscal ganhou status de política de estabilização por excelência no imediato Pós-Guerra e, por esse motivo, certos economistas keynesianos, como Modigliani, Tobin e Samuelson, ficaram conhecidos como "fiscalistas" e a própria política fiscal passou a ser sinônimo de "política keynesiana" (SNOWDOW; VANE, 2005).

Conhecido como síntese neoclássica, o modelo keynesiano ortodoxo de maior impacto no desenvolvimento da macroeconomia se originou do artigo seminal de Hicks (1937) Mr. Keynes and the "Classics": A Suggested Interpretation. Em seguida, o modelo foi elaborado por Modigliani (1944) e popularizado nos EUA por Hansen (1949), Hansen (1953). Conhecido também como IS-LM, essa compatibilização da revolução Keynesiana com a macroeconomia clássica se tornou o modelo estabelecido para teorização macroeconômica e teve uma grande influência sobre as políticas públicas até meados da década de 60 .

\subsubsection{Modelos neoclássicos}

Seguindo o raciocínio lógico da crítica de Lucas (1972) e a hipótese da renda permanente de Friedman (1957), Barro (1974) mostrou que a tributação e a emissão de dívida pública exercem basicamente efeitos equivalentes. Esse resultado passou a ser chamado de "teorema da equivalência ricardiana" e questionou, com grande intensidade, o ativismo fiscal keynesiano vigente no Pós-Guerra.

Para modelos neoclássicos de referência, como Barro (1981), Barro (1987) e Hall(1980), os aumentos de gastos do governo, sejam eles transitórios ou permanentes, devem impulsionar o produto e horas trabalhadas. Ademais, Hall (1980) argumenta que os efeitos sobre emprego e produto de aumentos persistentes dos gastos públicos são menores que aqueles provindos de choques transitórios. Por fim, de acordo com Barro (1987), a razão entre a variação do produto contemporâneo (e de estado estacionário) e a variação dos gastos públicos deve ser menor que a unidade.

Entretanto, outros modelos neoclássicos surgiram com resultados alternativos aos primeiros. Para Aiyagari, Christiano e Eichenbaum (1992), sobre certas hipóteses, os efeitos sobre produto e emprego a partir de choques na política fiscal são sempre maiores para as mudanças permanentes e não para as transitórias. Segundo, a resposta contemporânea do produto frente a uma variação unitária do gasto pode sim exceder a unidade. Portanto, pode existir um análogo ao multiplicador fiscal keynesiano em modelos neoclássicos.

Em linhas gerais, o resultado característico de modelos neoclássicos (vide Baxter e King (1993)) é o reportado a seguir. Considere um aumento permanente dos gastos do governo, financiado por meios não-distorcivos de tal maneira que não altere a utilidade marginal do consumo privado nem o estoque de capital produtivo. O aumento dos gastos do governo cria um efeito renda negativo para o consumidor representativo, assim, se tanto lazer quanto consumo forem bens normais, esse responde diminuindo consumo e 
aumentando a oferta de trabalho. A expansão da oferta fará com que o salário real diminua, aumentando o produto marginal do capital e, portanto, o investimento. Contudo, se o aumento permanente dos gastos públicos é financiado com impostos distorcivos, o produto cai em proporção maior do que o aumento dos gastos públicos.

Nesse contexto, a forma de financiamento da política fiscal não faz muita diferença, pois se trata de modelos ricardianos. Ao incorporar a questão de financiamento tributário distorcivo, os modelos predizem uma queda substancial no multiplicador. Em certos casos, o multiplicador fiscal poderia até ser negativo (BAXTER; KING, 1993).

Em suma, com o renascimento da nova economia clássica na década de 1970 e 80, o papel da política fiscal ficou subestimado . De acordo com essa teoria, expansões fiscais esperadas seriam ineficazes porque as pessoas esperariam aumentos de impostos futuros, ajustando suas ações no presente e anulando, assim, o esforço fiscal (BARRO, 1989). Sob essa ótica (e em contraste com a teoria keynesiana), a política fiscal teria efeitos contracionistas e não expansionistas. Com Giavazzi e Pagano (1990), o argumento neoclássico também se move para o terreno empírico e se cria um novo termo poderoso: contrações fiscais expansionistas.

\subsubsection{Modelos novo-keynesianos}

A resposta novo-keynesiana a essa teoria seria que uma parte da população sofre restrição de crédito e reage à renda corrente ao invés da renda permanente (MANKIW, 2000). Ademais, certas propriedades como falhas de mercado, rigidez de preços e salários, custos de transações, poder de mercado ou assimetria de informação são hipóteses consideradas nesses novos modelos, permitindo então pareceres favoráveis à eficácia da política fiscal.

Nesses novos modelos, aumentos de gastos governamentais estimulam a renda interna, assim como o consumo e, por conseguinte, o produto. Portanto, os modelos novokeynesianos restabeleceram o potencial da política fiscal (QAZIZADA; STOCKHAMMER, 2015).

Galí, López-Salido e Valls (2007) preveem aumento do produto no longo prazo em resposta a choques nos gastos públicos, quando esses são financiados com aumento de impostos do tipo lump-sum.

A diferença com relação aos modelos neoclássicos é que os resultados são nãoricardianos, uma vez que o consumo privado se expande no longo prazo. Esse resultado pode ser mostrado pela interação entre a regra de bolso para o comportamento dos consumidores (no qual consumo se iguala a renda do trabalho) e preços rígidos, como bem faz Galí, López-Salido e Valls (2007). Ademais, se a premissa de que os trabalhadores sempre possam ofertar a quantidade de horas demandada pelas firmas, os multiplicadores 
se tornam consideravelmente maiores que a unidade.

Existem certas condições econômicas que alimentam o debate sobre a magnitude dos multiplicadores fiscais. São questões ateóricas e não se encaixam em uma categoria específica de modelos discutidos anteriormente.

O primeiro caso se refere à ideia de que quanto maior a persistência do gasto, maior é o efeito multiplicador. Um dos argumentos utilizados é que quando a política fiscal expansionista tem duração mais prolongada, os trabalhadores devem trabalhar mais horas para compensar o efeito riqueza negativo gerado pela tributação maior (PIRES, 2014). Hall (2009) conclui que esse efeito não é compatível com o conceito de equivalência ricardiana, concluindo que o mesmo não se mostra relevante nesse debate.

O segundo caso considera como a política monetária pode afetar os multiplicadores fiscais. Modelos novo-keynesianos mostram que, em situações de juros nominais próximos de zero, multiplicadores tendem a ser maiores que na situação contrafactual (CHRISTIANO; EICHENBAUM; REBELO, 2011; COENEN; STRAUB; TRABANDT, 2012).

O terceiro caso está associado ao fato de que o desempenho das políticas fiscais pode diferir de acordo com estado subjacente da economia. Esses efeitos são de difícil caracterização em modelos econômicos teóricos, mas sua aplicação em modelos econométricos é relativamente fácil. Novos estudos empíricos têm encontrado diferentes multiplicadores para períodos de contração e expansão econômica: em geral, eles são maiores em tempos de recessão, indicando que políticas contracíclicas têm embasamento empírico (BAUM; POPLAWSKI-RIBEIRO; WEBER, 2012; AUERBACH; GORODNICHENKO, 2012; QAZIZADA; STOCKHAMMER, 2015).

Outras considerações importantes interferem no tamanho dos multiplicadores fiscais, como o tamanho da dívida pública (FAVERO; GIAVAZZI, 2010; EGGERTSSON; KRUGMAN, 2012) e a composição da expansão fiscal entre investimentos, consumo do governo e os programas de transferências direta de renda (HALL, 2009).

Até onde se sabe, nenhum trabalho diferencia multiplicadores fiscais ao longo do ciclo político. Nesse sentido, os resultados encontrados nesta dissertação podem contribuir para a disseminação da discussão sobre impactos de política fiscal em outras searas.

\subsubsection{Modelos Empíricos}

Os exercícios econométricos têm se utilizado de três técnicas principais para a mensuração de impactos de política fiscal. O primeiro grupo de estudos utiliza vetores autorregressivos (alguns trabalham com modelos univariados), salientando que há uma divisão em três grandes subgrupos com base na técnica de identificação dos choques: identificação a partir de VAR estrutural/recursivo, abordagem narrativa e restrição de sinais. O segundo grupo utiliza modelos com dependência de regime, de maneira a obter 
diferentes multiplicadores para distintos estados de natureza da economia. Enquanto os dois primeiros estudam séries temporais, o terceiro grupo trabalha com microdados e obtém resultados a partir de técnicas microeconométricas.

\subsubsection{VAR/SVAR}

Nem sempre é conhecido se a trajetória temporal de uma série temporal designada a ser a variável independente não é afetada pela trajetória temporal da chamada variável dependente. A forma mais básica de um VAR trata todas as variáveis simetricamente sem fazer referência a questões de independência versus dependência (ENDERS, 2010). Matematicamente, esse trecho apresenta-se pelo seguinte sistema de equações :

$$
\begin{gathered}
\mathbf{x}_{\mathbf{t}}=\boldsymbol{\Gamma}_{\mathbf{0}}+\mathbf{\Psi}_{\mathbf{t}}+\boldsymbol{\Gamma}_{\mathbf{1}} \mathbf{x}_{\mathbf{t}-\mathbf{1}}+\epsilon_{\mathbf{t}} \\
\mathbf{x}_{\mathbf{t}}=\left(\begin{array}{c}
x_{1 t} \\
x_{2 t} \\
x_{3 t}
\end{array}\right) \\
\mathbf{x}_{\mathbf{t}-\mathbf{1}}=\left(\begin{array}{c}
x_{1 t-1} \\
x_{2 t-1} \\
x_{3 t-1}
\end{array}\right) \quad \epsilon_{\mathbf{t}}=\left(\begin{array}{c}
\epsilon_{1 t} \\
\epsilon_{2 t} \\
\epsilon_{3 t}
\end{array}\right) \\
\boldsymbol{\Gamma}_{\mathbf{0}}=\left(\begin{array}{c}
k_{1} \\
k_{2} \\
k_{3}
\end{array}\right) \\
\boldsymbol{\Gamma}_{\mathbf{1}}=\left(\begin{array}{lll}
b_{11} & b_{12} & b_{13} \\
b_{21} & b_{22} & b_{23} \\
b_{31} & b_{32} & b_{33}
\end{array}\right) \quad \boldsymbol{\Psi}=\left(\begin{array}{ccc}
0 & -a_{12} & -a_{13} \\
-a_{21} & 0 & -a_{23} \\
-a_{31} & -a_{32} & 0
\end{array}\right)
\end{gathered}
$$

Essa é a chamada forma estrutural do VAR (por simplicidade na notação, considerase um VAR de três variáveis), em que as variáveis dependem tanto dos valores correntes quanto dos valores defasados de todas elas. O VAR estrutural faz uso da teoria para classificar as relações contemporâneas entres as variáveis endógenas do modelo, procedimento necessário para inferir causalidade nos resultados. Essa metodologia é útil para a caracterização e descrição de dados macroeconômicos, previsão e inferência sobre as relações estruturais entre as variáveis (PERES, 2007).

Diversos trabalhos utilizam VAR estrutural como modelo principal, entre eles, Blanchard e Perotti (2002), Perotti (2004), Monacelli, Perotti e Trigari (2010), Ravnik e Zilic (2011), Burriel et al. (2010), Galí, López-Salido e Valls (2007), Peres (2007), Peres (2012), Unal (2011). Estes realizam a classificação da relação contemporânea entre as variáveis do VAR impondo restrições sobre os elementos da matriz $\Psi$. O trabalho pioneiro nesse quesito foi Blanchard e Perotti (2002), que utilizou informações institucionais sobre as elasticidades das variáveis fiscais frente à atividade econômica.

Cabe ressaltar que $\epsilon$ é o vetor de inovações, que são erros ortogonais entre si, ou seja, o choque em cada variável é perfeitamente diferenciável do choque das demais, diferentemente de quando se analisa os resíduos da forma reduzida. Essa diferenciação é importante quando forem traçadas funções de impulso resposta. 
É possível transformar o sistema de equações em uma forma mais maleável. Usando álgebra matricial, pode-se colocar o sistema na seguinte forma compacta:

$$
\begin{gathered}
\mathbf{A x}_{\mathbf{t}}=\boldsymbol{\Gamma}_{\mathbf{0}}+\boldsymbol{\Gamma}_{\mathbf{1}} \mathbf{x}_{\mathbf{t}-\mathbf{1}}+\epsilon_{\mathbf{t}} \\
\mathbf{A}=\mathbf{I}-\boldsymbol{\Psi}=\left(\begin{array}{ccc}
1 & a_{12} & a_{13} \\
a_{21} & 1 & a_{23} \\
a_{31} & a_{32} & 1
\end{array}\right)
\end{gathered}
$$

Pré-multiplicando os termos de (2.5) por $A^{-1}$, obtém-se a forma reduzida do VAR (2.6). Essa representação é uma função linear dos valores defasados de todas as variáveis do sistema, além de um termo erro. Caso haja correlação entre as variáveis, o que é bastante provável um modelo macroeconômico, os erros devem ser correlacionados entre si.

$$
\begin{gathered}
\mathbf{x}_{\mathbf{t}}=\mathbf{B}_{\mathbf{0}}+\mathbf{B}_{\mathbf{1}} \mathbf{x}_{\mathbf{t}-\mathbf{1}}+\mathbf{e}_{\mathbf{t}} \\
\mathbf{B}_{\mathbf{0}}=\mathbf{A}^{-\mathbf{1}} \boldsymbol{\Gamma}_{\mathbf{0}}=\left(\begin{array}{c}
d_{1} \\
d_{2} \\
d_{3}
\end{array}\right) \\
\mathbf{B}_{\mathbf{1}}=\mathbf{A}^{-\mathbf{1}} \boldsymbol{\Gamma}_{\mathbf{1}}=\left(\begin{array}{lll}
c_{11} & c_{12} & c_{13} \\
c_{21} & c_{22} & c_{23} \\
c_{31} & c_{32} & c_{33}
\end{array}\right)
\end{gathered}
$$

Esse resíduos são interpretados como surpresas, ou movimentos não esperados, e serão chamados de erros de previsão. Eles são uma combinação linear das inovações do VAR estrutural, isto é,

$$
\mathbf{e}_{\mathbf{t}}=\left(\begin{array}{c}
e_{1 t} \\
e_{2 t} \\
e_{3 t}
\end{array}\right)=\mathbf{A}^{-1} \epsilon_{\mathbf{t}}
$$

Nesse caso, a maneira pela qual a identificação é feita se baseia na decomposição de Cholesky. Em uma linguagem não muito técnica, ela ordena as variáveis da mais exógena para a mais endógena de modo que a condição de identificação seja satisfeita . Dito de outro modo, 3 coeficientes da matriz $A$ serão igualados a zero ex-ante a partir de algum juízo de valor acerca das inter-relações das variáveis do modelo. Por exemplo, pode ser razoável supor que tanto $x_{2 t}$ quanto $x_{3 t}$ não impactam contemporaneamente $x_{1 t}$, dessa forma, considera-se que $a_{12}=a_{13}=0$, a identificação requereria apenas uma restrição 
adicional, por exemplo, $a_{23}=0$. Esse exemplo específico foi feito propositalmente, pois a decomposição de Cholesky transforma $A$ em uma matriz triangular inferior, que é o caso quando se olha (2.4) com as restrições mencionadas. Caso a última restrição fosse de que $x_{3 t}$ não é afetada contemporaneamente por $x_{2 t}$, a matriz resultante de (2.4) não seria triangular inferior. Logo, se presume que o ordenamento das variáveis importa quando se analisa funções de impulso resposta pela decomposição de Cholesky.

Entre os estudos que estimam o VAR pela forma reduzida e identificam os choques por Cholesky se destacam Almunia et al. (2009), Gordon e Krenn (2010), Galí, López-Salido e Valls (2007), Fatás e Mihov (2001b) e Cavalcanti e Silva (2010). Vetores autoregressivos são uma abordagem poderosa para calcular multiplicadores, a princípio. O VAR pode absorver grande parte do ruído, associando-o com outros fatores causais. Assim, a precisão das estimativas pode ser mais elevada em um VAR do que em uma simples regressão. Além disso, um VAR pode levar em conta os efeitos que estão correlacionados com as mudanças na compras governamentais que resultem em vieses nas regressões simples (HALL, 2009).

Entretanto, como em toda metodologia, existem limitações. Peres (2007) salienta a instabilidade dos parâmetros ligada ao uso do VAR para estimar efeitos na mudança de política. Ademais, as funções de reação podem mudar com o tempo e as estimativas desses efeitos são sensíveis a alterações.

Outros ponto a ser considerado é o fato de que os desvios-padrão estimados para as funções de impulso-resposta podem apresentar viés caso as variáveis em questão apresentem forte tendência e a incapacidade de lidar bem com heterocedasticidade condicional. Por fim, surge o critério da parcimônia, sobre o qual se lança a preocupação com a manutenção dos graus de liberdade, isso pois o total de parâmetros a ser estimado aumenta consideravelmente com a inclusão de variáveis e defasagens. O número exato é $k(1+q+k p)$, tal que $k$ representa o número de variáveis endógenas, $q$ o número de variáveis exógenas e $p$ o número de lags incluídos no VAR.

Uma breve revisão de alguns trabalhos que adotam o VAR como técnica de estimação será feita a seguir, destacando os pontos principais e suas contribuições para o presente estudo.

O artigo seminal é Blanchard e Perotti (2002), cujo diferencial se encontra na identificação: ela é alcançada explorando a lentidão nas decisões de política fiscal e a informação institucional sobre a elasticidade das variáveis fiscais em relação à atividade econômica.

Blanchard e Perotti (2002) caracterizam os efeitos dinâmicos de choques nos gastos e receitas de governo sobre a atividade econômica dos Estados Unidos no período pósguerra. Os resultados apontam que choques positivos na despesa de consumo do governo têm um impacto positivo sobre produto, tendo um multiplicador associado próximo à 
unidade, ao passo que um aumento das receitas líquidas de impostos causa efeito contrário.

Em conformidade com o pensamento keynesiano, o modelo indica um efeito positivo de gastos governamentais em consumo privado, resultado difícil de conciliar com o arcabouço teórico neoclássico, exceto se certas suposições contrafactuais forem feitas a respeito da trajetória de taxação no tempo. Por outro lado, choques positivos em gastos do governo e impostos levam a contrações do investimento privado, resultado condizente com a teoria neoclássica e inconsistente com a keynesiana.

Fatás e Mihov (2001b) comparam o impacto dinâmico da política fiscal sobre variáveis macroeconômicas a partir de uma gama de modelos de equilíbrio geral com os resultados obtidos de um VAR identificado. As conclusões são: choques positivos de gastos governamentais levam a um aumento permanente dessa variável; o multiplicador fiscal dos gastos com relação ao produto é maior que a unidade; a expansão fiscal leva a um aumento significante e de grande magnitude; por fim, a resposta do investimento privado frente ao choque de gastos não é significante.

Dois quesitos devem ser exaltados a partir da sua leitura: primeiro, ao fato de que ambas as receitas e gastos são geralmente pré-anunciados; segundo, ao fato estilizado de que os efeitos de um aumento de gastos e de um corte de gastos são distintos.

Enquanto variáveis de previsão são fundamentais para estudar política monetária, a mesma lógica não se aplica para política fiscal. Em termos práticos, o primeiro quesito é difícil de controlar por duas razões principais. A primeira é que não existem previsões em nível mensal para investimento público. Segundo, e mais importante, as peculiaridades do processo orçamentário brasileiro enviesam as estimativas anuais dos investimentos públicos divulgadas nas estatísticas oficiais do Tesouro Nacional.

O segundo quesito foi extensivamente tratado na literatura, inserindo no modelo tanto receita quanto despesa e construindo diferentes funções impulso resposta, cenários, multiplicadores que permitam caracterizar os efeitos expansionistas ou contracionistas da política fiscal.

Outra contribuição dos autores se refere à análise dos estabilizadores automáticos e aos efeitos dinâmicos provindos da política fiscal discricionária para países da OCDE. Fatás e Mihov (2001a) concluem que há uma correlação negativa entre tamanho do governo com a volatilidade do PIB privado e que os efeitos estabilizadores são transferidos para o setor privado; construindo uma medida de política discricionária a partir da decomposição de Cholesky em um VAR, encontram um impacto positivo, forte e persistente de expansões fiscais sobre a atividade econômica; e, desagregando a política fiscal em diferentes componentes, acham indícios de que mudanças nos impostos, transferências e empregos públicos são os instrumentos mais efetivos de política fiscal.

Galí, López-Salido e Valls (2007) proveem evidências complementares usando uma 
estratégia de identificação similar aos trabalhos acima citados. Por meio de dados trimestrais para os Estados Unidos, estimam as respostas de certas variáveis macroeconômicas a um choque de gastos governamentais. O último é identificado assumindo que compras do governo não são afetadas contemporaneamente (dentro de um trimestre) por inovações de outras variáveis do VAR. Encontram um efeito positivo sobre o produto a partir dos choques de política fiscal, mas com um multiplicador associado consideravelmente inferior à unidade.

Perotti (2004) estima um VAR contendo PIB, gastos governamentais, carga tributária, inflação e taxa de juros para Australia, Canadá, Alemanha, Reino Unido e EUA, encontrando os seguintes resultados: os efeitos da política fiscal sobre o PIB e seus componentes se tornaram substancialmente mais fracos a partir de meados da década de 80; os efeitos estimados da política fiscal sobre o PIB tendem a ser pequenos (no período pós 1980, multiplicadores dos gastos do governo positivos e maiores que a unidade tendem a ser a exceção); choques dos gastos do governo têm efeitos significativos sobre a taxa de juros real, porém de sinal incerto.

Ravnik e Zilic (2011) utilizam a metodologia multivariada SVAR de Blanchard e Perotti (2002) para analisar efeitos desagregados de curto prazo da política fiscal sobre a atividade econômica, inflação e taxas de juros de curto prazo. Os resultados sugerem que os efeitos de choques de despesas e receitas do governo são relativamente maiores sobre as taxas de juros e menores sobre a inflação. Um choque em arrecadação no curto prazo aumenta a taxa de inflação e também diminui a taxa de juros de curto prazo.

Também apoiando na especificação de Blanchard e Perotti (2002) para caracterizar as respostas do produto a choques nos gastos e nos impostos do governo central, Peres (2007) realiza um estudo para o Brasil no período 1994.I - 2005.II. Os resultados desse trabalho se aproximam daqueles encontrados para os EUA e membros da OCDE, de que a resposta do produto a choques fiscais é pequena e tem características tipicamente keynesianas. O orçamento público foi desagregado em investimento e consumo, o que permitiu estimar de maneira mais precisa os efeitos da política fiscal sobre a atividade econômica: os efeitos de choques nos investimentos são mais persistentes e eficientes para gerar crescimento.

Avançando a pesquisa, Peres (2012) investigou os efeitos dinâmicos dos choques fiscais sobre os componentes do produto, dando atenção para o consumo e investimento privado, realizando uma análise sob a ótica de modelos neoclássico e keynesiano. Os resultados desse trabalho ratificam o de Peres (2007), sem grandes alterações, as repostas das variáveis indicam uma dinâmica com características keynesianas. Em especial, tanto consumo das famílias quanto investimento privado respondem positivamente a aumento de gastos e negativamente a choques na tributação.

Em um VAR estrutural padrão, Burriel et al. (2010) analisam o tamanho e sinal 
dos multiplicadores fiscais na zona do Euro, usando uma base de dados em frequência trimestral para o período de 1981 a 2007. Em linha com evidência prévia, os resultados indicam respostas positivas do PIB e inflação a choques nos gastos do governo, muito embora os multiplicadores encontrados situem abaixo da unidade. Entretanto, evidências são providas de que os multiplicadores do produto aumentaram de forma constante depois de 2000 na União Econômica e Monetária (UEM). Também em consonância com estudos anteriores, os autores concluem que os multiplicadores de curto prazo associados a gastos são maiores que aqueles relacionados a impostos.

Unal (2011) caracteriza os efeitos dinâmicos de choques em impostos líquidos e gastos do governo sobre preços, taxa de juros, PIB e seus componentes particulares para quatro países da OCDE, utilizando para tal uma abordagem de VAR estrutural. De maneira inédita na literatura, foi feita uma decomposição estrutural do total dos impostos líquidos em quatro componentes: imposto de renda corporativo, imposto de renda, imposto indireto e imposto de previdência social.

O artigo fornece estimativas das respostas de agregados macroeconômicos a inovações nesses componentes da tributação. As principais conclusões podem ser resumidos da seguinte forma: decomposições de inovações dos impostos líquidos mostram que esses componentes têm diferentes impactos sobre variáveis econômicas; o tamanho e a persistência desses efeitos variam de país para país; enquanto se constatou crowding-out do investimento privado causado tanto pela taxação quanto pelos gastos do governo para EUA e Reino Unido (visão compatível com o modelo neoclássico); para França e Canadá, observou-se crowding-in, alinhando à teoria keynesiana; para todos os países, há crowdingin em consumo privado a partir de aumento dos gastos públicos (exceto reino Unido) e crowding-out da mesma variável frente a tributação (exceto França). Enquanto o primeiro resultado é consistente com um modelo keynesiano, este último está em consonância com a teoria neoclássica.

Gordon e Krenn (2010) avançam na compreensão dos multiplicadores e do papel da política fiscal em dar fim à Grande Depressão. Um novo conjunto de dados em base trimestral foi desenvolvido datando desde 1919 e um VAR foi estimado para o período de 1920 a 1941. Esse trabalho contradiz as visões de Romer (1992) e Long e Summers (1991), que acreditam que a política fiscal não contribuiu significantemente ao crescimento até 1942, e conclui que tanto a política fiscal quanto a monetária foram importantes para a recuperação, a primeira tendo papel papel dominante.

Este artigo contribui à literatura recente utilizando o modelo VAR para calcular multiplicadores fiscais. Em vez de calcular multiplicadores simplesmente como a mudança no PIB dividido pela mudança nos gastos do governo ao longo de um determinado intervalo, ele subtrai do numerador e denominador a previsão do modelo VAR quando todas as inovações são suprimidas. O paper calcula dois multiplicadores levando em consideração 
restrições de capacidade: 1,8 para períodos de baixa utilização da capacidade produtiva e 0,88 para tempos de restrição de oferta.

De maneira a contribuir para o melhor entendimento dos efeitos da política fiscal na economia brasileira no período 1995 a 2008, Cavalcanti e Silva (2010) realizaram uma análise VAR que leva explicitamente em consideração o papel da dívida pública na determinação da política fiscal. De acordo com os resultados obtidos, a consideração explícita do papel da dívida pública na evolução das variáveis fiscais parece realmente fazer diferença na estimação dos efeitos de choques fiscais sobre o nível de atividade; em particular, é provável que os efeitos dos choques fiscais estimados a partir de modelos que omitem a dívida pública estejam superestimados.

Monacelli, Perotti e Trigari (2010) estimam os efeitos da política fiscal sobre o mercado de trabalho americano. Um acréscimo dos gastos do governo da ordem de $1 \%$ do PIB gera multiplicadores do produto e emprego de, respectivamente, 1,2 (em um ano) e 0,6 (no pico). Horas trabalhadas, total de empregados e probabilidade de encontrar um emprego aumentam frente a política fiscal expansionista.

Depois de exposta a literatura, cabe ressaltar que há três problemas característicos na tentativa de identificação de choques de política fiscal em vetores autorregressivos. Primeiramente, o que caracteriza um choque de política fiscal. Enquanto que em política monetária não se discorda, em geral, de que os choques surgem em virtude de mudanças inesperadas da taxa de juros, essa definição é mais complexa do lado fiscal (MOUNTFORD; UHLIG, 2009).

Em segundo lugar, tem-se dificuldade em separar variáveis exógenas de endógenas. Ou seja, o que se pretende é distinguir choques exógenos de política fiscal de movimentos de variáveis fiscais causados por outros fatores.

O terceiro se refere ao fato de que há uma defasagem entre o anúncio e a implementação da política fiscal. Felizmente, neste estudo, esse obstáculo é contornado pela própria característica dos dados utilizados de ter frequência mensal. Blanchard e Perotti (2002) afirmam que as defasagens entre decisão e implementação em política fiscal implica que, em uma frequência suficientemente alta - dentro de um trimestre, por exemplo - há pouco ou quase nenhuma resposta discricionária da política fiscal em resposta a movimentos contemporâneos na atividade econômica. Como será mostrado adiante, essa estratégia foi adotada na identificação, onde o investimento público foi considerado como o mais inelástico a curto prazo.

Com relação aos resultados obtidos pelos trabalhos em questão, as críticas surgiram quanto à verdadeira exogeneidade dos gastos do governo. Argumenta-se, alternativamente na literatura, que restringir os gastos de governos às despesas militares é suficiente para corrigir essa fragilidade, uma vez que esse tipo de gasto poderia ser considerado exógeno 
na medida em que a decisão de elevá-los teria pouca relação com o ciclo econômico (PIRES, 2014). Esse tipo de técnica foi utilizada principalmente por aqueles que seguiram a abordagem narrativa, como será discutido adiante.

Entretanto, mesmo que o problema da exogeneidade seja melhor controlado através da identificação dos choques a partir dos gastos militares, deve-se salientar que esse experimento tem pouca aplicabilidade. Isso pois não se observa esse tipo de gasto para efeito de suavização de ciclo econômico, e é exatamente isso que se pretende mensurar: o impacto da política fiscal convencional em variáveis chave da economia.

\subsubsection{Abordagem Narrativa}

Certos episódios (períodos eleitorais caracterizam um bom exemplo) são marcados por mudanças de certas variáveis econômicas demasiadamente grandes para serem tratadas como provenientes do mesmo processo estocástico subjacente ao período contrafactual (BLANCHARD; PEROTTI, 2002).

A estratégia de incorporar na metodologia a técnica de estudo de evento, feita por Edelberg, Eichenbaum e Fisher (1999), Ramey e Shapiro (1998), Burnside, Eichenbaum e Fisher (2004), entre outros, permitiu controlar esses episódios, adequando os procedimentos empíricos aos dados.

Todos os três estudos adotam a abordagem narrativa explorando a exogeneidade dos armamentos militares. Fazem isso definindo uma variável dummy para aqueles trimestres nos quais esses gastos foram concentrados e traçam os efeitos para variáveis macroeconômicas relevantes. Todos eles encontram um impacto positivo sobre gastos com defesa e produto (horas trabalhadas para Edelberg, Eichenbaum e Fisher (1999)).

Ramey e Shapiro (1998) analisam os efeitos de mudanças setoriais específicas de gastos governamentais em um modelo de equilíbrio geral de dois setores no qual a realocação de capital entre setores é custosa. Os autores dão ênfase ao fato de que a composição dos gastos do governo é importante para entender os efeitos agregados dos choques.

Eles estudam os efeitos de armamentos militares pós II Guerra Mundial sobre variáveis macroeconômicas, uma vez que aqueles acontecem de maneira rápida e inesperada, sendo então naturalmente modelados como choques. Para isolar os eventos políticos, usaram uma abordagem narrativa similar à usada por Hamilton (1985) para choques do petróleo e Romer e Romer (1990) para choques monetários.

Os resultados empíricos reproduzem os fatos estilizados da resposta da economia frente a grandes armamentos militares e demonstram a compatibilidade do comportamento das séries com o modelo neoclássico de dois setores apresentados. Outra contribuição relevante é a de que mudanças setoriais pode levar a mudanças no emprego e variações 
nos salários pagos entre os setores.

Edelberg, Eichenbaum e Fisher (1999) utilizam na especificação do VAR variáveis dummy a la Ramey e Shapiro (1998), reportando como que diferentes setores da economia respondem ao início de episódios "Ramey-Shapiro". Em linhas curtas, os resultados são os seguintes: depois de um aumento das compras governamentais, há uma considerável expansão, através de uma curva côncava, de despesas com defesa, produto agregado e emprego.

Ademais, o modelo deles prevê que a taxa de juros real não é afetada por choques de política fiscal. De acordo com os autores, isso ocorre pela fragilidade do modelo em lidar com um consumidor representativo que leve em consideração o comportamento de séries históricas de retornos de ativos.

Para Edelberg, Eichenbaum e Fisher (1999), a forma e o tamanho das respostas de todas as variáveis ao choque são as mesmas em cada episódio Ramey-Shapiro . Uma versão menos rigorosa desta abordagem (introduzida por Burnside, Eichenbaum e Fisher (2004)) consiste em permitir que cada episódio tenha uma intensidade diferente, embora o formato das respostas ainda seja suposto como sendo o mesmo.

Burnside, Eichenbaum e Fisher (2004) investigam a resposta de horas trabalhadas e salários reais frente a choques de políticas fiscais, incorporando no VAR episódios "RameyShapiro". Assim como em Ramey e Shapiro (1998), identificam os choques como mudanças exógenas nas despesas de consumo militar e argumentam que eles levam a um declínio nos salários reais e a um aumento permanente nos gastos de governo, nas horas trabalhadas e nas taxas de imposto sobre capital e trabalho.

Os autores se atentam à aplicabilidade de modelos neoclássicos para explicar respostas do mercado de trabalho a choques de política fiscal. Se os impostos forem lump sum por natureza, esses modelos são convenientes. Caso sejam distorcivos (o que é mais provável, no mundo real), os resultados podem ser enganadores. Ao incorporar formação de hábito no consumo e custo de ajustamento de investimento, o modelo neoclássico modificado se torna razoavelmente adequado para explicar efeitos qualitativos e quantitativos de choques de política fiscal a variáveis macroeconômicas.

Outro trabalho seminal é o de Romer e Romer (2010), que estudam o impacto de mudanças na taxação sobre a atividade econômica. Com o propósito de identificar o tamanho, tempo e motivação principal de todas as principais ações de política fiscal do pós-guerra, constroem uma base de dados alternativa, caracterizada como ficha narrativa, consistindo de discursos presidenciais, documentos executivos e relatórios do Congresso. Essa análise narrativa permite separar variações de receita decorrentes da legislação de mudanças ocorrendo por outras razões, permite ainda separar mudanças legisladas daquelas tomadas por razões relacionadas com condições econômicas, tais como ações anticíclicas e 
alterações fiscais vinculados a mudanças nos gastos do governo, e as tomadas por razões mais exógenas, tais como reduzir um déficit orçamentário ou para promover o crescimento de longo prazo.

Romer e Romer (2010) examinam o comportamento do produto a partir dessas mudanças mais exógenas. As estimativas resultantes indicam que os aumentos de impostos são altamente contracionistas. Os efeitos são fortemente significativos, robustos, e muito maior do que os obtidos usando medidas mais amplas de mudanças tributárias. O grande efeito resulta em parte considerável de um poderoso efeito negativo do aumento dos impostos sobre o investimento.

Cloyne (2011) estima os efeitos das alterações fiscais sobre a economia do Reino Unido através da identificação por isolamento dos choques de política fiscal "exógenos"segundo a estratégia narrativa de Romer e Romer (2010). Os resultados mostram que um corte de um ponto percentual nos impostos estimula o PIB em 0,6 ponto percentual no momento do impacto e em 2,5 ao longo de três anos. Os resultados reforçam a visão de que as alterações fiscais têm de fato efeitos poderosos, persistentes e significativas sobre a economia.

Choques fiscais são normalmente utilizados na abordagem moderna para a análise de políticas porque permitem selecionar, a partir da evidência empírica, fatos que podem ser adaptados a modelos DSGE. Pelo fato de que a solução de um modelo DSGE pode ser bem aproximada por um modelo VAR, os modelos empíricos tornaram-se a ferramenta natural para selecionar entre diferentes modelos. Esses modelos, no entanto, devem ser produzidos no contexto de experimentos válidos, que significa: identificar ações de política exógenas que podem ser simuladas mantendo os parâmetros do modelo empírico estimado constante; simular experiências que não alteram a correlação dos dados utilizados para estimar os parâmetros do modelo empírico.

Choques ortogonalizados obtidos pela imposição de restrições sobre um VAR satisfazem estas duas condições e sua simulação é comumente considerada o experimento correto; entretanto, Alesina, Favero e Giavazzi (2012) argumentam que este não é o caso quando se analisa a política fiscal. Para os autores, a maneira correta pela qual os efeitos de uma consolidação fiscal devem ser analisados consiste em simular planos, e não choques fiscais individuais.

O problema que se coloca quando se analisa os planos orçamentários é que a "previsão fiscal" - o fato de que os agentes estão cientes de futuros ajustes fiscais ainda não realizados - provoca um desalinhamento entre o conjunto de informações utilizadas pelo econometrista em um VAR e aquele disponível para os agentes econômicos (LIPPI; REICHLIN, 1994).

A consequência é que a combinação exógena de correções fiscais imprevistas e anun- 
ciadas que caracterizam um plano não podem ser unicamente recuperadas por inovações de um VAR. A solução é adotar a abordagem narrativa de Romer e Romer (2010), que não sofre desse problema porque mudanças exógenas na política fiscal não são reconstruídas através da inversão da representação de uma média móvel do VAR, mas observadas diretamente utilizando documentos oficiais para identificar o tamanho, tempo e motivação para as ações fiscais tomadas ou anunciadas pelo governo.

A evidência empírica de Alesina, Favero e Giavazzi (2012) sugere que os efeitos das consolidações fiscais dependem de seu esboço e de duas características em particular: sua composição (aumentos de impostos contra cortes de gastos) e sua consistência ao longo do tempo (ou seja, se cortes de gastos são permanentes ou transitórios). Ajustes com base em gastos foram associados, em média, com recessões leves e de curta duração. Por outro lado, os ajustes baseados em aumentos de impostos foram seguidos por recessões prolongadas e profundas.

Também usando a abordagem narrativa, Leigh, Pescatori e Guajardo (2011) estimam que o efeito de curto prazo da consolidação fiscal sobre a atividade econômica é contracionista, as estimativas implicam que um ajuste fiscal de um por cento do PIB reduz o consumo privado real ao longo dos próximos dois anos por 0,75 por cento, enquanto o efeito sobre o produto é de 0,62 por cento. Assim como diversos outros estudos, os autores encontram que os ajustes fiscais concentrados na receita em detrimento da despesa trazem efeitos nocivos à demanda privada relativamente maiores.

Hayo e Uhl (2014) estudam os efeitos macroeconômicos de curto prazo de mudanças tributárias na Alemanha usando um VAR de cinco variáveis, sendo que a identificação do choque fiscal segue uma abordagem narrativa recentemente proposta. Com base em um relato histórico da legislação fiscal alemã, o calendário , o tamanho e a motivação das mudanças tributárias legisladas são avaliados e uma série temporal de choques fiscais exógenos é construída. Os resultados indicam uma reação substancial e estatisticamente significativa do produto frente a implementação de uma mudança fiscal. Em resposta a um aumento de um ponto percentual na razão imposto/PIB , observa-se uma redução de potência máxima de 2,4\%. Estes resultados sugerem que as estimativas anteriores sobre os efeitos das mudanças de imposto sobre a produção realizada na Alemanha estão subestimadas.

Usando medidas narrativas como proxies para choques estruturais para as receitas fiscais totais em um SVAR, Mertens e Ravn (2014) estimam multiplicadores fiscais relativamente altos para a economia norte-americana: em torno de dois no momento do impacto e até três após 6 trimestres. Mostram também que as conclusões anteriores de multiplicadores menores podem ser explicadas por uma hipótese de elasticidade do produto frente as receitas de impostos distinta da evidência empírica ou por falha em contabilizar os erros de medição na série narrativa de choques fiscais. 
Ramey (2011) explorou possíveis explicações sobre os resultados dramaticamente diferentes entre os métodos VAR padrão e a abordagem narrativa para a identificação de choques de gastos do governo. A principal diferença é que os choques da abordagem narrativa parecem capturar muito melhor o momento das notícias sobre futuros aumentos nos gastos do governo. Na verdade, esses choques Granger-causam os choques do VAR. Os resultados teóricos mostram como o timing pode representar toda a diferença nos resultados entre os dois métodos. Pelo fato do VAR captar os choques tarde demais, ele perde o declínio inicial no consumo e nos salários reais que ocorrem assim que a notícia é assimilada. Por fim, Ramey (2011) mostra que atrasar os episódios de Ramey-Shapiro replica os resultados VAR.

\subsubsection{Restrição de Sinais}

Outra alternativa comum na literatura para resolver o problema de efeito do anúncio é utilizar restrições de sinais das funções de impulso resposta como meio de identificação, assim como fez pioneiramente Uhlig (2005) para política monetária.

Mountford e Uhlig (2009) propõem essa abordagem para analisar os efeitos de política fiscal usando vetores autorregressivos. Fazem isso usando restrições de sinais para identificar choques tanto das receitas quanto dos gastos do governo, enquanto controlam para choques de ciclos econômicos e de política monetária. Cabe ressaltar que é explicitamente levado em consideração no modelo o efeito anúncio, o fato de choques contemporâneos da política fiscal mudar variáveis de política fiscal no futuro, e não no presente.

Eles analisam a economia americana da segunda metade do século XX construindo funções de impulso-resposta para três cenários distintos de política fiscal: gastos financiados por déficits; corte de receitas financiado por déficits e gastos sob orçamento equilibrado. Dentre os cenários analisados, constatou-se que o segundo é o melhor ambiente para incentivar crescimento.

Como ficou claro nas subseções anteriores, ainda coexiste uma ampla gama de visões acerca da robustez dos impactos macroeconômicos de políticas fiscais, dos canais pelos quais esses efeitos são transmitidos e das variações desses impactos e canais com respeito a condições econômicas.

Tão importante quanto conhecer o valor do multiplicador é saber se ele é estável ao longo do tempo ou possui uma variância não desprezível. Existe uma literatura nova que trata de mudanças do multiplicador fiscal em função do estado da natureza da economia, e essa se baseia em argumentos keynesianos de que é mais provável que gastos do governo gerem efeitos expansionistas em tempos de recessão. Intuitivamente, quando a economia tem capacidade ociosa, choques de política fiscal tendem a não criar efeitos crowding out sobre consumo e investimento. 
Em suma, deseja-se saber como que os efeitos de choques de política fiscal variam ao longo do ciclo econômico. O objetivo do presente trabalho, entretanto, é determinar como que os multiplicadores fiscais variam ao longo do ciclo político. Para tanto, se baseará na metodologia adotada pelos modelos da próxima subseção.

\subsubsection{Regime-Switching VAR}

A crise financeira de 2007 em especial reergueu o debate acerca da importância da política fiscal contracíclica e quais políticas macroeconômicas a serem adotadas pelas autoridades competentes. A ideia de inspiração keynesiana de que multiplicadores fiscais em crises tendem a ser maiores em comparação a tempos normais gerou um ramo de pesquisa que distingue multiplicadores fiscais em expansões e recessões, sendo que os estudos podem ser classificados com relação à técnica econométrica utilizada: (i) modelos VAR de parâmetros variáveis no tempo com volatilidade estocástica (KIRCHNER; CIMADOMO; HAUPTMEIER, 2010); (ii) threshold VAR (TVAR) (BAUM; POPLAWSKI-RIBEIRO; WEBER, 2012); (iii) regressões em painéis e técnicas VAR (CORSETTI; MEIER; MLLER, 2012; ILZETZKI; MENDOZA; VGH, 2013; AUERBACH; GORODNICHENKO, 2011); (iv) Markov switching (smooth transition) VAR (AUERBACH; GORODNICHENKO, 2012; COS; MORAL-BENITO, 2013).

Warmedinger, Westphal e Cos (2015) argumentam que a maioria desses estudos encontram multiplicadores de gastos significantemente maiores em recessões quando comparados a períodos de expansão econômica. Entretanto, existe uma grande variabilidade entre esses estudos com relação à diferença da resposta nos dois regimes. O presente trabalho adota a metodologia do último grupo de estudos mencionado, assim sendo, uma maior atenção será dada aos modelos STVAR.

De modo a permitir respostas diferenciadas entre recessões e expansões, (AUERBACH; GORODNICHENKO, 2012) empregam um Regime Switching VAR em que as transições entre os estados são suaves. A técnica de estimação, que eles denominaram STVAR, é similar ao Smooth Transition Autoregressive (STAR) de Granger, Terasvirta e Anderson (1993). Uma importante diferença entre STAR e STVAR, entretanto, é que, no último, são permitidas não apenas respostas dinâmicas diferenciais mas também respostas dinâmicas contemporâneas diferenciais a choques estruturais.

Controlar para expectativas, permitir respostas variarem em expansões ou recessões e deixar que os multiplicadores tenham diferentes valores para componentes distintos dos gastos governamentais são quesitos importantes para a obtenção de melhores resultados qualitativos por parte de Auerbach e Gorodnichenko (2012). Os autores constataram que políticas que aumentam gastos têm um impacto consideravelmente maior em recessões comparativamente a expansões, ainda mais quando se inclui o controle para expectativas. Os multiplicadores estimados para expansões variam de 0 a 0,5 enquanto que aqueles para 
recessões vão de 1 a 1,5 .

Assim como proposto por Auerbach e Gorodnichenko (2012), Cos e Moral-Benito (2013) estimam um STVAR de maneira a permitir que os multiplicadores fiscais variem com relação a três dimensões da economia espanhola: recessão, finanças públicas frágeis e estresse financeiro.

Os resultados do estudo mostram que o multiplicador da despesa Espanhola pode ser maior durante recessões (entre 1, 26 e 1,75 durante o primeiro ano) do que em expansões (entre 0,17 e 0,65). Por outro lado, a situação precária das finanças públicas na Espanha pode fazer com que o multiplicador do gasto fique próximo de zero ou mesmo negativo. Ademais, a amplificação do canal de restrição de liquidez também pode aumentar o tamanho do multiplicador durante a crise financeira. Combinando estas três dimensões em um único indicador através da análise de componentes principais (PCA), os multiplicadores estimados estão entre 1,4 e 0,6 em períodos de perturbação e de tranquilidade, respectivamente.

Monokroussos e Thomakos (2012) analisam a política fiscal para a Grécia perante os modelos SVAR e STVAR. Para o primeiro caso, os resultados estão em conformidade com outros estudos já realizados para o país, apresentando multiplicadores em torno de 0,4 e 0,5. Com relação ao segundo método, as estimativas indicam multiplicadores fiscais altos e estatisticamente significantes $(1,32)$ nos períodos de recessão econômica, em paralelo com multiplicadores negativos e não significantes em tempos de expansões.

Auerbach e Gorodnichenko (2011) estimam multiplicadores fiscais para um grupo de países da OCDE, permitindo que esses variem suavemente de acordo com o estado da economia. Eles adaptam a metodologia precedente (Auerbach e Gorodnichenko (2012)) para usar projeções diretas em detrimento de SVAR para estimar multiplicadores, de modo a economizar graus de liberdade e relaxar hipóteses impostas sobre as funções impulso resposta do SVAR.

Os resultados desse trabalho, assim como de Auerbach e Gorodnichenko (2012), sugerem que uma política fiscal ativa pode de fato ser efetiva no objetivo de estimular o produto durante uma recessão. Ademais, as potenciais consequências do estímulo fiscal, como pressão inflacionária, são menos prováveis nessas circunstâncias.

Em geral, modelos neoclássicos e novo-keynesianos são tipicamente incapazes de gerar acréscimos em consumo privado depois de um choque de gasto de governo. Em contraste, modelos keynesianos antigos enfatizam que mercados não se equilibram a todo tempo, especialmente em recessões, de tal modo que o crowding-out de consumo ou investimento privado pode ser mínimo. Os autores encontram que há crowding-out de consumo privado em expansões e crowding-in em recessões, em resposta a um choque nos gastos governamentais.

É importante salientar que, como Bachmann e Sims (2012) defendem, um ingre- 
diente importante para estimular consumo em recessões é a resposta da confiança do consumidor frente ao choque de política fiscal.

Enquanto no modelo linear investimento privado não responde a choques de política fiscal, no modelo em que se permite dinâmicas particulares para cada estado da economia, se observa dois efeitos distintos. Em um período de três anos, um aumento de um dólar em gastos do governo leva também a um aumento de 1,5 dólares no investimento privado, em tempo de recessão. Em contrapartida, esse mesmo gasto adicional causa uma redução de 1,4 dólares nessa variável quando a economia se encontra em expansão. Com base na mesma metodologia de Auerbach e Gorodnichenko (2011), Auerbach e Gorodnichenko (2014) analisam a política fiscal japonesa no período entre 1960 e 2012. As estimativas para o Japão são bastante consistentes com as estimadas anteriormente para a OCDE, bem como com aquelas estimadas utilizando uma metodologia um pouco diferente para os Estados Unidos (AUERBACH; GORODNICHENKO, 2012). Os resultados indicam que a política fiscal tem a capacidade de estimular a economia, particularmente em tempos de recessão. Entretanto, as conclusões são menos claras para períodos mais recentes e há evidência de instabilidade do multiplicador.

Também utilizando a metodologia de transições suaves de multiplicadores entre regimes com a técnica de projeção local de Jorda, Ramey e Zubairy (2014) não encontram evidências de que os multiplicadores fiscais sejam maiores em períodos com capacidade produtiva ociosa para os EUA entre 1890 e 2010. Esses resultados não prevalecem para os dados canadenses; nesse caso, os multiplicadores seguem o padrão encontrado na literatura, de que eles são maiores nas recessões e menores nas expansões.

Pires (2014) estimou multiplicadores fiscais para a economia brasileira, concluindo que esses dependem do ciclo econômico e diferenciando o impacto entre consumo do governo, investimentos públicos e carga tributária líquida. A metodologia empregada segue um modelo Markov Switching de regressão dinâmica, em que uma matriz de probabilidade de transição descreve a variável dependente como seguindo dois regimes que diferem entre si pela média e volatilidade.

As evidências empíricas indicam que o ciclo econômico no Brasil é caracterizado por períodos de baixa ou elevada volatilidade. Com efeito, os multiplicadores mostraram significância estatística em períodos de baixa volatilidade. A carga tributária líquida apresentou multiplicador fiscal robusto da ordem de 0,2 a 0,3 enquanto o investimento público apresentou multiplicador maior que a unidade, entre 1,4 e 1,7. O multiplicador fiscal do consumo do governo não apresentou significância estatística. 



\section{Metodologia e Dados}

\subsection{Construção da série de investimento público}

Compreender os conceitos macroeconômicos ao maior nível de detalhamento possível é uma importante ferramenta tanto para aqueles que procuram traçar perspectivas para o futuro da economia quanto para os que desejam entender acontecimentos do passado.

Melhor ainda é possuir as informações dessas variáveis por um longo intervalo de tempo, pois isso permite a utilização de técnicas que atuam no sentido de verificar teorias, corroborar hipóteses e assimilar fatos estilizados, contribuindo cada vez mais para os conhecimentos em assuntos macroeconômicos.

Em suma, a existência de dados de qualidade é fundamental para que a pesquisa possa ser feita com confiabilidade. No caso brasileiro, os dados representam uma das principais restrições à pesquisa aplicada. Um dos objetivos desse trabalho é contornar essa restrição a partir da construção de séries de alta frequência.

A metodologia que este trabalho emprega requer dados de contas nacionais, isto é, séries longas o suficiente para a realização do procedimento econométrico. A principal variável em questão é a Formação Bruta de Capital Fixo, divulgada em base trimestral a partir de 1995; logo, são quase 20 anos, menos de 80 trimestres, pouca informação para os propósitos do trabalho.

Ademais, como foi discutido em seções anteriores, deseja-se aqui analisar a dinâmica de curto prazo entre investimento e desempenho econômico, portanto, isso constitui mais um fator que justifique o esforço em trabalhar com séries mensais.

As séries de desempenho econômico (PIB, emprego, juros) são divulgadas em frequência mensal por órgãos confiáveis, sendo que apenas a série de investimento se encontra em frequência trimestral (IBGE, Contas Nacionais Trimestrais). O Ipea construiu uma série de investimento público mensal, publicando-a através do Texto para Discussão do Ipea 1660. Dessa maneira, a estratégia será obter a série de FBCF através de métodos de desagregação temporal e, em seguida, obter a série de investimento privado por resíduo. Essa subseção irá detalhar os procedimentos utilizados para a construção da série de investimento público e a próxima os métodos de construção de séries de alta frequência.

Santos et al. (2011) apresentam estimativas inéditas de séries mensais da formação bruta de capital fixo das administrações públicas (APUs) para o Brasil. Realizaram uma análise criteriosa dos conceitos de contabilidade pública e da contabilidade nacional, desenvolveram procedimentos para compatibilizar ambos os conceitos e contornaram a escassez de informações dos governos subnacionais solicitando informações adicionais de centenas de contadores públicos, técnicos ou secretários de Fazenda/Planejamento de todos 
os estados da Federação, do Distrito Federal (DF) e dos maiores municípios.

De acordo com esse estudo, não se pode negligenciar o fato de que os conceitos de despesas de investimentos da contabilidade pública são distintos dos conceitos de FBCF das contas nacionais. A compatibilização desses conceitos requer algumas considerações: modalidade de aplicação, a informação de qual esfera do governo é responsável pela execução; classificação dos itens contabilizados, o que ficou mais fácil com a atualização do conceito de investimento na Portaria da STN/SOF de 2001; elementos de despesa, os quais identificam com mais precisão o objeto do gasto; subelemento da despesa, que, para determinados tipos de despesas, como equipamentos e material permanente, distinções a esse nível de detalhamento são necessárias para a contabilização mais precisa da FBCF; por fim, os próprios conceitos de Governo Federal, Estadual e Municipal nas Contas Nacionais são diferentes da contabilidade pública .

Santos et al. (2011) argumentam que as diferenças conceituais entre a contabilidade pública e a contabilidade nacional além da limitação de acesso a informações, tendo um grau de detalhamento inferior aos dados utilizados pelo IBGE, não são grandes problemas. Entretanto, as despesas na contabilidade pública são contabilizadas em valores empenhados, o que pode ser um problema conceitual e empiricamente sério. No quadro abaixo, as definições perante as duas vertentes são especificadas. 


\begin{tabular}{|c|c|}
\hline \multicolumn{2}{|r|}{ Despesas de investimentos da contabilidade pública } \\
\hline $\begin{array}{l}\text { Lei de Finanças Públicas } \\
\text { que regulamenta o processo } \\
\text { orçamentário brasileiro, Lei } \\
\text { no } 4.320 \text {, de } 17 \text { de março } \\
\text { de } 1964\end{array}$ & $\begin{array}{l}\text { "(...) classificam-se como investimentos as dotações para o planejamento e a } \\
\text { execução de obras, inclusive as destinadas à aquisição de imóveis considerados } \\
\text { necessários à realização destas últimas, bem como para os programas especiais } \\
\text { de trabalho, aquisição de instalações, equipamentos e material permanente } \\
\text { e constituição ou aumento do capital de empresas que não sejam de caráter } \\
\text { comercial ou financeiro." }\end{array}$ \\
\hline $\begin{array}{l}\text { Portaria Interministerial } \\
\text { no } 163 \text {, de } 4 \text { de maio de } \\
2001 \text {, que dispõe sobre } \\
\text { normas gerais de } \\
\text { consolidação das } \\
\text { contas públicas }\end{array}$ & $\begin{array}{l}\text { Despesas orçamentárias com softwares e com o planejamento e a execução de } \\
\text { obras inclusive com a aquisição de imóveis considerados necessários à realização } \\
\text { destas últimas, e com a aquisição de instalações, equipamentos e material } \\
\text { permanente. }\end{array}$ \\
\hline
\end{tabular}

FBCF da contabilidade nacional

\begin{tabular}{|c|c|}
\hline $\begin{array}{l}\text { Sistema de Contas } \\
\text { Nacionais (SCN) da } \\
\text { Organização das Nações } \\
\text { Unidas(ONU, 1993) }\end{array}$ & $\begin{array}{l}\text { A FBCF de um determinado setor institucional é "medida pelo valor total (...) } \\
\text { da aquisição, menos o valor total das vendas, de ativos fixos [pelo referido } \\
\text { setor institucional] durante o período contábil, mais certas adições ao valor dos } \\
\text { produtos não produzidos feitas por meio da atividade produtiva (...). Ativos } \\
\text { fixos são ativos tangíveis ou intangíveis resultantes de processos de produção } \\
\text { e que são utilizados repetida e continuamente em outros processos de produção } \\
\text { por mais de um ano" (tradução dos autores). }\end{array}$ \\
\hline IBGE (2008a, p. 35-36) & $\begin{array}{l}\text { A FBCF “inclui o valor da aquisição de bens de capital novos, da importação } \\
\text { de bens de capital usados e as aquisições, líquidas de cessões, de bens de } \\
\text { capital já existentes na economia nacional. Quanto às categorias de ativos } \\
\text { considerados, destacam-se os bens imóveis (construções residenciais, comerciais, } \\
\text { industriais, obras de infraestrutura etc.) e móveis (meios de transporte, máquinas, } \\
\text { equipamentos e outros bens de capital). A FBCF inclui, ainda, o valor dos serviços } \\
\text { ligados à instalação dos bens de capital, dos bens e serviços incorporados aos } \\
\text { terrenos, das melhorias que elevam a vida útil dos ativos existentes, assim } \\
\text { como o valor dos gastos inerentes à transmissão de propriedades de terrenos, } \\
\text { edifícios e outros bens de capital existentes. Ficam excluídos da FBCF o valor da } \\
\text { aquisição de pequenos equipamentos, como as máquinas-ferramentas, o gasto } \\
\text { com manutenções e reparações ordinárias em ativos tangíveis, bens de consumo } \\
\text { duráveis adquiridos pelas famílias e despesas com pesquisas e desenvolvimento". }\end{array}$ \\
\hline
\end{tabular}

Fonte: Quadro 1 de Santos et al. (2011).

A despesa pública é passível de ser mensurada nas diversas fases de execução, que inclui os atos de empenho, liquidação e pagamento, explicitamente previstos na Lei das Finanças Públicas de 1964. De maneira resumida, pode-se afirmar que o empenho corresponde à reserva de dotação orçamentária para a execução da despesa e provê garantias ao fornecedor de que existe crédito orçamentário para atendê-la. A liquidação ocorre imediatamente após a entrega da mercadoria ou a conclusão do serviço, momento no qual o governo verifica os documentos que comprovam que o fornecedor cumpriu devidamente suas obrigações. O governo assume a existência do direito adquirido pelo credor por receber o pagamento, correspondendo aos lançamentos na sua contabilidade de um passivo financeiro e, no caso dos investimentos, um ativo permanente. É nesta ocasião que há a transferência (formal) da propriedade do ativo fixo para a APU. O pagamento, por sua vez, é a última etapa, quando ocorre a emissão da ordem bancária de pagamento ou desembolso efetivo de recursos por parte da APU para saldar o compromisso com o 
credor (SANTOS et al., 2011).

Surge então a questão de qual o critério mais apropriado para a mensuração do investimento público: empenho, liquidação ou pagamento. Pelo manual da ONU (1993), em casos gerais, a resposta caminharia em direção à segunda opção; entretanto, para o caso brasileiro, a existência de algo chamado restos a pagar não processados (RAPsNPs) impede que a resposta seja tão direta.

Os RAPsNPs correspondem a despesas que são empenhadas em um determinado ano e chegam ao final do exercício (31 de dezembro) sem terem sido sequer liquidadas, isto é, a mercadoria não foi entregue ou o serviço não foi concluído (ou ao menos não houve tempo hábil de comprová-los). Note-se que a despesa, além de não ter sido paga, também não foi liquidada e por isso recebe a denominação "não processado" (SANTOS et al, 2011).

Acontece no Brasil um fenômeno que Gobetti (2007) chamou de liquidação forçada a generalização da execução por inscrição em RAPsNPs- ou seja, uma liquidação meramente contábil de uma despesa para a qual não houve efetivamente o reconhecimento do direito do credor. Melhor dizendo, no mês de dezembro, os valores liquidados são intencionalmente inflados e igualados aos valores empenhados.

Cabe ressaltar que a parcela de gastos com investimento nos restos a pagar é considerável. Desde 2005, essa conta é responsável por aproximadamente a metade da expansão do estoque de RAPsNPs do GF. O que não é de surpreender, pelo fato de gastos como obras e instalações levarem muito tempo para serem realizadas e tendo grande parte de recursos orçamentários discricionários.

Há uma distorção institucionalizada que enviesa as estatísticas oficiais de empenho e também de liquidação, uma vez que ambos são muitas vezes igualados artificialmente na presença da liquidação forçada e ainda é difícil discriminar a parcela referente à execução por inscrição em RAPsNPs.

Santos et al. (2011) conclui que o mais importante é perceber que o critério de competência utilizado nos relatórios contábeis - e que serve de insumo para os cálculos do IBGE - tem se tornado cada vez mais inadequado para mensuração da FBCF, notavelmente quando se objetiva construir séries temporais de alta frequência com o objetivo de empregálas na pesquisa macroeconômica.

Para tanto, qual a alternativa para mensurar o investimento público? A conclusão de Santos et al. (2011) é que o critério de liquidação efetiva, que corresponde à soma das liquidações do exercício e das liquidações dos RAPs é o conceito mais recomendável, pois o mesmo não gera distorções da FBCF da economia, somente altera sua repartição entre os setores institucionais.

Os dados para o investimento público na frequência mensal são listados na figura (2). A próxima subseção se concentra em especificar como a série mensal de investimento 
privado foi obtida, detalhando o procedimento econométrico e justificando o uso das variáveis auxiliares.

Figura 2 - Série Nominal do Investimento Público

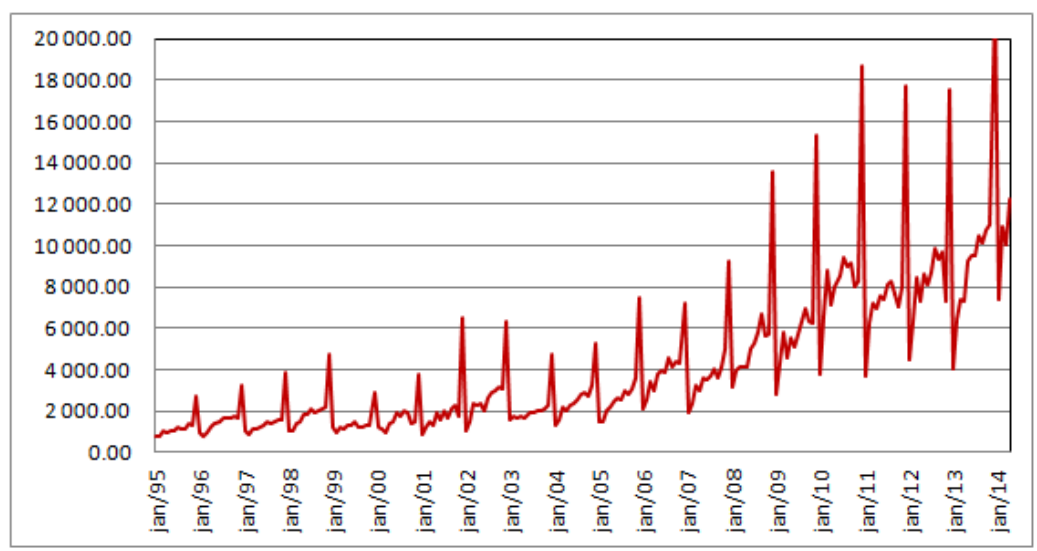

Fonte: Dimac/Ipea. Escala: $(R \$ 1.000 .000)$. 


\subsection{Desagregação temporal}

Não existe uma estimativa para o investimento privado em frequência mensal. A maneira pela qual essa série foi obtida segue os seguintes passos: (i) decomposição da Formação Bruta de Capital Fixo em duas séries de referência; (ii) desagregação temporal de cada série decomposta; (iii) obtenção da série de interesse por resíduo.

Há duas fontes principais para a decomposição da Formação de Capital Fixo no Brasil, ambas do IBGE. A primeira é a Tabela de Recursos e Usos, que discrimina a formação de capital fixo para uma extensa lista de produtos. A segunda são as tabelas sinóticas, que dividem a FBCF em três elementos principais de forma agregada: máquinas e equipamentos; construção e outros. Ambos os bancos de dados estão disponíveis somente em bases anuais; logo, se supõe que a divisão da FBCF entre esses componentes não varia ao longo do ano.

A base de dados usada nesse trabalho são as tabelas sinóticas, aqui, se considera que a FBCF pode ser dividida em dois componentes: construção civil (C) e máquinas e equipamentos (ME) (desconsidera a subconta outros $\left.(\mathrm{O})^{1}\right)$. Isso pois existem séries de alta frequência com relação a esses critérios a partir das quais se permite caracterizar a dinâmica de curto prazo da FBCF da economia.

Resumindo, a série trimestral de FBCF das Contas Nacionais Trimestrais será dividida em duas séries trimestrais com base na ponderação acima descrita, ressaltando para o fato que os pesos variam apenas no ano e não nos trimestres do ano, por restrições de dados compatíveis. A fórmula abaixo resume essas informações.

$$
\begin{aligned}
& F B C F_{a, t}^{C}=\left(\frac{C}{C+M E}\right)_{a} F B C F_{a, t} \\
& F B C F_{a, t}^{M E}=\left(\frac{M E}{C+M E}\right)_{a} F B C F_{a, t} \\
& \forall a, \quad F B C F_{a}=C_{a}+M E_{a}+O_{a}
\end{aligned}
$$

Como obter séries mensais a partir de séries trimestrais? Tipicamente, se pretende realizar um ajuste que distorça o mínimo possível os movimentos de mês a mês ou de trimestre a trimestre das séries. Um procedimento simples seria distribuir a discrepância de um dado ano entre os períodos daquele ano, de maneira homogênea ou pro rata; entretanto, as discrepâncias não são uniformes ao longo ano, de modo que esse método introduziria uma descontinuidade entre o último período de um ano e o primeiro do subsequente (DENTON, 1971). Assim sendo, adota-se aqui a técnica de desagregação temporal de Denton (1971), a qual constrói séries de alta frequência supondo que existe uma série que dita os movimentos de curto prazo da série de baixa frequência de referência.

1 A subconta "outros" foi desconsiderada por conter diversos produtos de distintos setores, impossibilitando a compatibilização com uma série de alta frequência para a realização da desagregação temporal. 
O método de desagregação temporal utilizado foi de acordo com Denton (1971), com modificações nas condições iniciais seguindo as contribuições de Cholette (1984). O método utilizado - que se baseia na minimização de uma soma quadrática e no princípio da preservação de movimentos - decompõe as séries de uma frequência trimestral para mensal.

Para isso, tem-se duas séries de baixa frequência (FBCF de insumos típicos da construção civil (FBCFc) e FBCF de máquinas e equipamentos ( FBCFme)) e duas séries de alta frequência (índices de produção física de insumos típicos da construção civil (Ic) e outro de máquinas e equipamentos (Ime)). Duas desagregações temporais distintas serão realizadas: FBCFc a partir de Ic; e FBCFme de Ime, obtendo, logo em seguida, duas séries da FBCF em base mensal.

Como a restrição da estimação é que a soma dos valores referentes aos meses de um trimestre seja exatamente igual ao dado original do trimestre, não há erros sistemáticos. Pode-se obter, portanto, a estimativa da FBCF em base mensal apenas somando as duas séries desagregadas. Como já possuo a série mensal de investimento público, a série de investimento privado é obtida subtraindo da FBCF os investimentos da APU. Abaixo segue o gráfico das séries mencionadas já em termos reais (a próxima subseção expõe a escolha do índice de preço utilizado para deflacionar as séries).

Figura 3 - Séries reais mensais de investimento público e privado

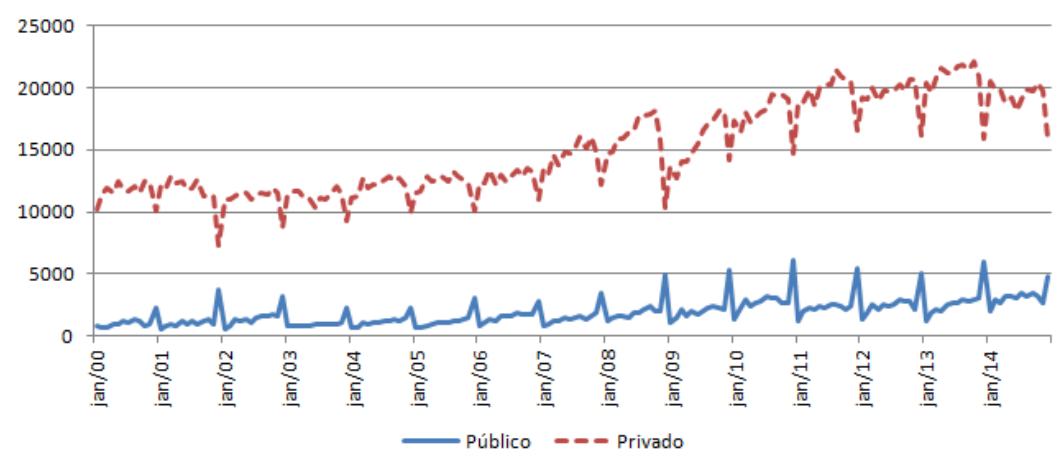

Fonte: IBGE, Contas Nacionais Trimestrais; Dimac/Ipea. Escala: $(R \$ 1.000 .000)$. 


\subsection{Análise Descritiva}

Antes de apresentar um modelo econométrico complexo que dê instrumentos para construir argumentos convincentes a favor ou contra determinada hipótese, é importante se dirigir aos dados com um olhar crítico e fazer uma análise descritiva da economia no período em questão.

Pode-se perceber que a série real mensal de investimento público apresenta um claro padrão de sazonalidade: ao longo do ano os valores são quase sempre crescentes, atingindo um pico no mês de dezembro. Logo em janeiro, há uma queda média de $73 \%$ com relação ao mês anterior, sendo que essa volatilidade na virada do ano se manteve aproximadamente da mesma magnitude ao longo de toda a amostra.

Além da prática recorrente de aguardar até o final do ano para equilibrar valores liquidados a valores empenhados, o fato das despesas inscritas em RAPsNPs no final do ano não serem executadas no início (ou ao longo) do ano subsequente contribui para que a série tenha esse formato.

O crescimento médio de mês a mês ao longo da amostra foi de $8,9 \%$, sendo que para a subamostra atingindo até o final de 2002 esse crescimento foi de $7,6 \%$ e de $9,7 \%$ de 2003 até 2014.

Os dados foram deflacionados pelo Índice Nacional de Preços para o Consumidor Amplo (IPCA), a Figura (4) justifica essa escolha em detrimento do Índice Nacional de Custo da Construção (INCC). A consideração deste último índice surgiu pelo fato de que cerca de $91 \%$ dos investimentos estão enquadrados nos elementos típicos da FBCF, como obras e instalações, equipamento e material permanente e aquisição de imóveis ligados a uma obra.

Para isso, duas séries mensais foram construídas a partir da série nominal de investimento público, uma utilizando o IPCA como deflator, e a outra, o INCC. Em seguida, essas duas séries foram trimestralizadas e comparadas com a série nominal de investimento público trimestralizada e, em seguida, corrigida pelo deflator da FBCF total das Contas Nacionais Trimestrais.

Como se pode ver na Figura (4), a diferença entre as duas alternativas não era relevante até meados de 2005, ao passo que após esse período, houve um descolamento da série derivada do INCC e uma quase perfeita relação entre a série derivada do IPCA e a série de referência. Desse modo, o deflator mensal utilizado será o IPCA, tanto para a série de investimento público quanto para o privado, uma vez que este será obtido por resíduo. 
Figura 4 - Comparação de Índices

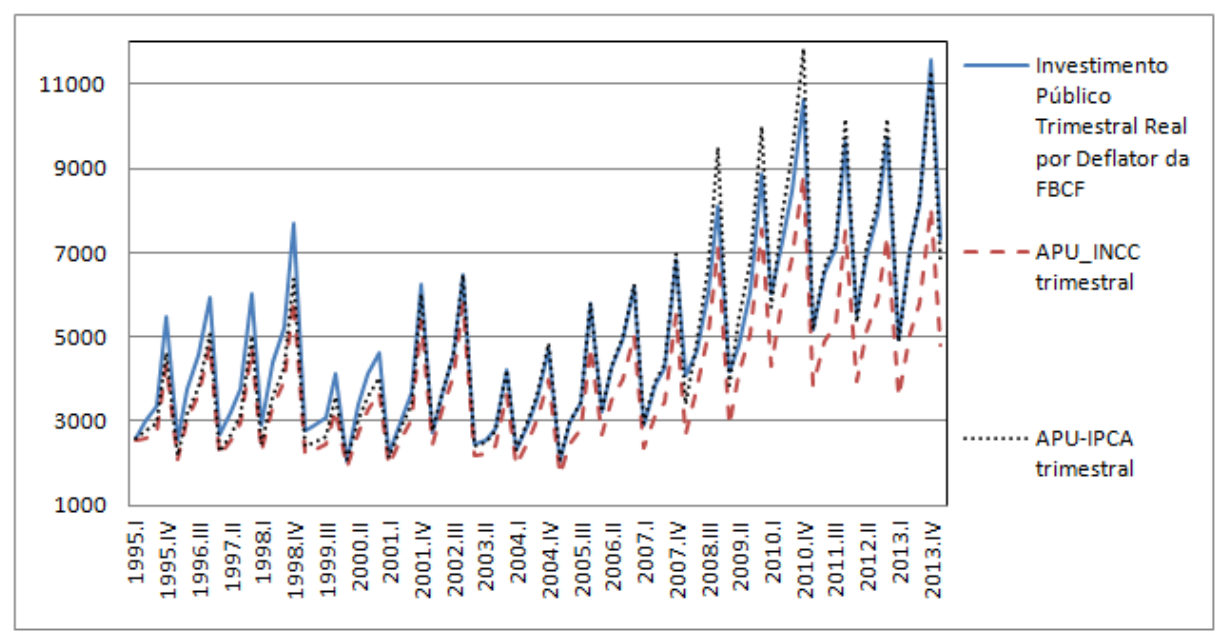

Fonte: IBGE; Dimac/Ipea. Escala: $(R \$ 1.000 .000)$.

Como foi discutido nos capítulos de revisão literária, há teorias que defendem que o investimento público é uma variável de ajuste na direção inversa do ciclo político, e outras que dizem que o investimento é inflado em anos eleitorais por motivos políticos. O exame da Figura (5) não tem a pretensão de corroborar ou rejeitar determinado argumento, mas apenas entender como que a série se comporta em tais anos.

Separando a amostra em anos pares (nos quais há eleições) e em anos ímpares e desconsiderando o mês de dezembro devido à sazonalidade, percebe-se que, na primeira subamostra, a série de investimento público apresenta um crescimento médio intra-anual de cerca de $8,1 \%$, ao passo que esse valor é de $7,3 \%$ na outra situação. Ou seja, em anos eleitorais, o investimento público cresce mais rápido. Assim como a tendência, o nível da série em anos pares é $17 \%$ superior à média de anos ímpares.

Figura 5 - Anos pares e ímpares

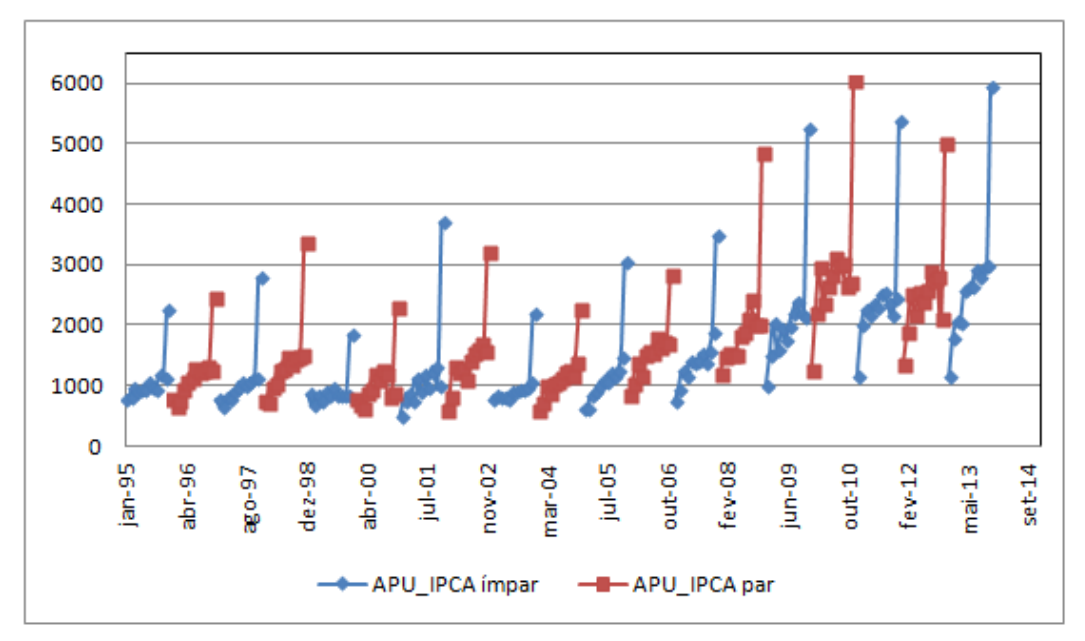

Fonte: IBGE; Dimac/Ipea.

A série mensal de investimento público foi trimestralizada e comparada com a FBCF da economia. A partir de então, pode-se decompor o investimento em público e privado, 
este último sendo obtido por resíduo. Percebe-se que, em média, os investimentos públicos compõem 11,6 \% dos investimentos totais da economia, de forma que essa participação é relativamente constante ao longo do tempo, como mostra a Figura (6).

Figura 6 - Composição do Investimento Trimestral

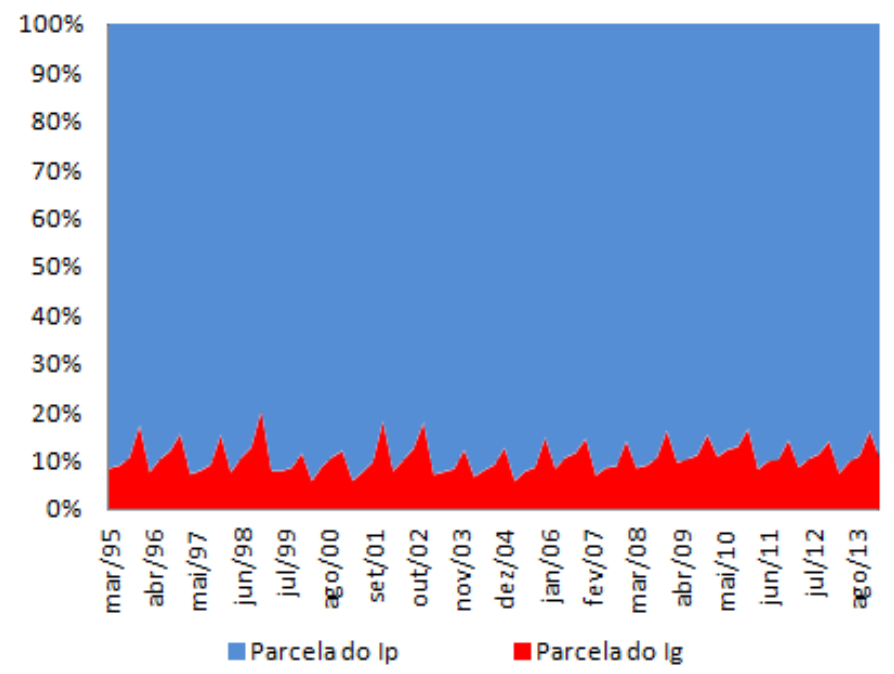

Fonte: IBGE, Contas Nacionais Trimestrais; Dimac/Ipea.

Ter uma série trimestral dos investimentos público e privado não é suficiente, dada a pequena extensão da amostra. Desse modo, métodos de desagregação temporal serão utilizados de maneira a conseguir séries de alta frequência para as duas variáveis chave do modelo. Antes disso, convém analisar também a série de investimento privado trimestral. Para essa frequência, os dados estão disponíveis desde 1995, sendo que a partir desse ano até meados de 2003, o investimento privado real praticamente ficou estagnado, tendo uma média de crescimento de trimestre para trimestre de cerca de 0,06\%. Após esse período até o final da amostra, a média passou para $6,5 \%$ (Figura (7)).

Figura 7 - Investimento privado trimestral

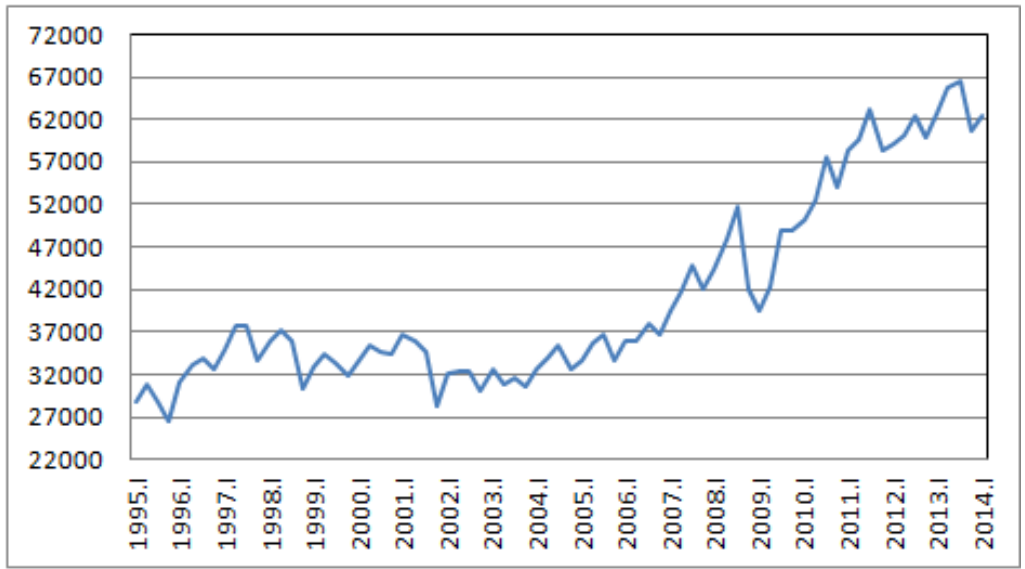

Fonte: IBGE, Contas Nacionais Trimestrais; Dimac/Ipea. 


\subsection{Modelo econométrico}

O modelo econométrico de referência para este trabalho é Auerbach e Gorodnichenko (2012), cuja metodologia consiste em vetores autoregressivos não lineares em que a economia transita suavemente entre dois regimes. Nessa abordagem, dois grupos de parâmetros são construídos, um para cada regime, de maneira que tanto a relação contemporânea quanto o comportamento dinâmico das variáveis são distintos.

A especificação básica do modelo se encontra resumida nas equações de (3.2) a (3.6). A equação (3.2) descreve o VAR, cujos coeficientes são diferenciados para cada regime, sendo que essa ramificação é definida pela função descrita em (3.5). A equação (3.4), por sua vez, descreve como a matriz de variância e covariância se comporta.

$$
\begin{gathered}
X_{t}=\left(1-F\left(z_{t-1}\right)\right) \Pi_{E}(L) X_{t-1}+F\left(z_{t-1}\right) \Pi_{R}(L) X_{t-1}+u_{t} \\
u_{t} \sim N\left(0, \Omega_{t}\right) \\
\Omega_{t}=\Omega_{E}\left(1-F\left(z_{t-1}\right)\right)+\Omega_{R} F\left(z_{t-1}\right) \\
F\left(z_{t}\right)=\frac{\exp \left(-\gamma z_{t}\right)}{1+\exp -\gamma z_{t}}, \quad \gamma>0 \\
\operatorname{var}\left(z_{t}\right)=1, E\left(z_{t}\right)=0
\end{gathered}
$$

O modelo permite duas maneiras para diferenciar a propagação de choques estruturais: de maneira contemporânea através da diferença das matrizes de variância e covariância $\Omega_{E}$ e $\Omega_{R}$; e de maneira dinâmica pela diferenciação das defasagens polinomiais $\Pi_{E}$ e $\Pi_{R}$.

Diferentemente da maioria dos trabalhos anteriormente mencionados, aqui não se utiliza de variáveis dummy para diferenciar períodos com processos de geração de dados distintos. É criada uma variável índice $z$ (normalizada para apresentar variância unitária de tal forma que gama não tenha escala) cujo objetivo é ser representativa das dinâmicas de curto prazo do ciclo em questão. Como o propósito foi observar a variação dos multiplicadores fiscais ao longo do ciclo econômico, Auerbach e Gorodnichenko (2012) escolheram a taxa de crescimento do produto (média móvel de 7 trimestres) como $z$.

Aqui, se pretende estudar o ciclo político e argumentos serão tecidos de que o investimento público é uma variável sensível a esse fenômeno; nesse sentido, a variável 
índice desse trabalho será derivada a partir de um modelo estrutural. ${ }^{2}$

Adotando a convenção de que $\gamma$ é positivo, interpreta-se $\Omega_{E}$ e $\Pi_{E}$ como parâmetros de um sistema em que incentivos políticos pré-eleitorais são levados à máxima $\left(1-F\left(z_{t}\right) \sim\right.$ 1 ), esse regime será denominado de janela eleitoral. Analogamente, $\Omega_{R}$ e $\Pi_{R}$ descrevem o comportamento da economia em períodos livres de mudanças no poder político $F\left(z_{t}\right) \sim 1$ ).

Assim como em Auerbach e Gorodnichenko (2012), os resultados serão avaliados a partir das funções de impulso resposta (FIR). Cabe salientar que a construção de funções de impulso resposta dinâmicas que incluem mudanças de regime internamente consistentes não é trivial, uma vez que deve-se computar o índice $z$ e avaliar a função $F(z)$ para cada período de tempo. Também pelo fato de que as FIRs são não-lineares, elas dependerão do valor inicial de $z$ e do tamanho do choque de política fiscal.

Uma diferença importante entre STAR e STVAR é que, neste último, é permitido não apenas repostas dinâmicas diferenciais mas também respostas contemporâneas diferenciais com relação a choques estruturais.

Cabe ressaltar que, como certas propriedades de um regime são estimadas a partir da dinâmica do sistema do outro regime, as estimativas são, em tese, enviesadas no sentido de não encontrar diferenças nos multiplicadores fiscais.

Dada a natureza não-linear do sistema descrito, os métodos de Monte Carlo Markov Chains (MCMC) utilizados por Chernozhukov e Hong (2003) foram incorporados tanto para estimação quanto para inferência, da mesma maneira como fizeram Auerbach e Gorodnichenko (2012). Segundo estes, a vantagem é que, uma vez que o regime for fixado, o modelo se comporta como linear e, portanto, as funções de impulso resposta não são funções da história.

A estimação de fato se dá por métodos de máxima verossimilhança. A logverossimilhança do modelo é dada por:

$$
\log L=\text { constante }-\frac{1}{2} \sum_{t=1}^{T} \log \left|\Omega_{t}\right|-\frac{1}{2} \sum_{t=1}^{T} u_{t}^{\prime} \Omega_{t}^{-1} u_{t}
$$

Onde $u_{t}=X_{t}-\left(1-F\left(z_{t}\right)\right) \Pi_{E}(L) X_{t-1}-F\left(z_{t}\right) \Pi_{R}(L) X_{t-1}$. Uma vez que o modelo é não-linear e tem diversos parâmetros $\Psi=\left\{\gamma, \Omega_{R}, \Omega_{E}, \Pi_{R}(L), \Pi_{E}(L)\right\}$, Auerbach e Gorodnichenko (2012) argumentam que rotinas de otimização padrão são problemáticas. Assim sendo, o método aqui utilizado (abaixo reportado) será exatamente igual ao proposto pelos últimos.

Condicionando sobre $\left\{\gamma, \Omega_{R}, \Omega_{E}\right\}$ o modelo se torna linear nas defasagens polinomiais $\left\{\Pi_{R}(L), \Pi_{E}(L)\right\}$. Desse modo, com um chute inicial para $\left\{\gamma, \Omega_{R}, \Omega_{E}\right\}$, pode-se estimar $\left\{\Pi_{R}(L), \Pi_{E}(L)\right\}$ por mínimos quadrados ponderados, em que a ponderação é dada por

$\overline{2}$ A próxima seção trará os detalhes concernindo a variável $z$. 
$\Omega_{t}^{-1}$ e as estimativas $\left\{\Pi_{R}(L), \Pi_{E}(L)\right\}$ devem minimizar $\frac{1}{2} \sum_{t=1}^{T} u_{t}^{\prime} \Omega_{t}^{-1} u_{t}$. Outra maneira de representar (3.2) é por $u_{t}=X_{t}-\Pi W_{t}^{\prime}$, tal que $\Pi=\left[\Pi_{R} \Pi_{E}\right]$ e

$$
\begin{aligned}
& W_{t}=\left[\begin{array}{lllll}
\left(1-F\left(z_{t}\right)\right) X_{t-1} & F\left(z_{t}\right) X_{t-1} & \ldots & \left(1-F\left(z_{t}\right)\right) X_{t-p} & F\left(z_{t}\right) X_{t-p}
\end{array}\right] \\
& \frac{1}{2} \sum_{t=1}^{T}\left(X_{t}-\Pi W_{t}^{\prime}\right)^{\prime} \Omega_{t}^{-1}\left(X_{t}-\Pi W_{t}^{\prime}\right)
\end{aligned}
$$

A função objetivo então é dada pela fórmula acima, a qual pode ser reescrita conforme o desenvolvimento abaixo:

$$
\begin{aligned}
\frac{1}{2} \sum_{t=1}^{T}\left(X_{t}-\Pi W_{t}^{\prime}\right)^{\prime} \Omega_{t}^{-1}\left(X_{t}-\Pi W_{t}^{\prime}\right)= & \\
& =\operatorname{trace}\left[\frac{1}{2} \sum_{t=1}^{T}\left(X_{t}-\Pi W_{t}^{\prime}\right)^{\prime} \Omega_{t}^{-1}\left(X_{t}-\Pi W_{t}^{\prime}\right)\right] \\
& =\frac{1}{2} \operatorname{trace}\left[\sum_{t=1}^{T}\left(X_{t}-\Pi W_{t}^{\prime}\right)^{\prime} \Omega_{t}^{-1}\left(X_{t}-\Pi W_{t}^{\prime}\right)\right]
\end{aligned}
$$

A condição de primeira ordem dessa função objetivo com relação ao vetor estendido de regressores $\Pi$ é $\sum_{t=1}^{T}\left(W_{t}^{\prime} X_{t} \Omega_{t}^{-1}-W_{t}^{\prime} W_{t} \Pi_{t}^{\prime} \Omega_{t}^{-1}\right)=0$. Usando o operador vec, obtém-se

$$
\begin{aligned}
& \operatorname{vec}\left(\sum_{t=1}^{T} W_{t}^{\prime} X_{t} \Omega_{t}^{-1}\right) \quad=\operatorname{vec}\left[\sum_{t=1}^{T} W_{t}^{\prime} W_{t} \Pi^{\prime} \Omega_{t}^{-1}\right] \quad=\sum_{t=1}^{T} \operatorname{vec}\left[W_{t}^{\prime} W_{t} \Pi^{\prime} \Omega_{t}^{-1}\right] \\
& =\sum_{t=1}^{T}\left[\operatorname{vec} \Pi^{\prime}\right]\left[\Omega_{t}^{-1} \otimes W_{t}^{\prime} W_{t}\right]=\operatorname{vec} \Pi^{\prime} \sum_{t=1}^{T}\left[\Omega_{t}^{-1} \otimes W_{t}^{\prime} W_{t}\right],
\end{aligned}
$$

gerando a fórmula final:

$$
\operatorname{vec} \Pi^{\prime}=\left(\sum_{t=1}^{T}\left[\Omega_{t}^{-1} \otimes W_{t}^{\prime} W_{t}\right]\right)^{-1} \operatorname{vec}\left(\sum_{t=1}^{T} W_{t}^{\prime} X_{t} \Omega_{t}^{-1}\right)
$$

Esse procedimento interage sobre $\left\{\gamma, \Omega_{R}, \Omega_{E}\right\}$ e gera $\Pi$ até que o ponto ótimo seja alcançado. Cabe ressaltar que, como o modelo é não-linear, é possível ter vários pontos de ótimo local, a depender dos valores iniciais imputados de $\left\{\gamma, \Omega_{R}, \Omega_{E}\right\}$ (AUERBACH; GORODNICHENKO, 2012).

Os valores iniciais em $\Psi^{(0)}$ são obtidos segundo os seguintes passos. O modelo ditado de (3.2) a (3.6) é aproximado pela regressão de $X_{t}$ sobre as defasagens de $X_{t}, X_{t} z_{t}, X_{t} z_{t}^{2}$, a partir de onde se retira os resíduos e constrói a matriz de variância e covariância $\Omega_{t}$ de (3.4), estimando então os parâmetros dessa equação $\left(\Omega_{R}, \Omega_{E}\right)$ por máxima verossimilhança.

Tendo $\Omega_{R}$ e $\Omega_{E}$, aliado ao fato de que, condicional a $\Omega_{R}$ e $\Omega_{E}$, o modelo é linear, os valores iniciais para as defasagens polinomiais $\left\{\Pi_{R}(L), \Pi_{E}(L)\right\}$ podem ser obtidas por (3.11). 



\section{Resultados}

\subsection{Modelo Estrutural}

A partir da revisão de literatura feita, percebe-se que a maioria dos estudos em ciclo político utiliza na sua modelagem variáveis binárias pré-determinadas de maneira a captar a existência de ciclo. Em suma, constroem-se variáveis dummy definindo, de maneira exógena, os períodos nos quais se julga haver uma grande influência das decisões políticas dotadas de viés eleitoral sobre variáveis econômicas . Esse tipo de técnica permite analisar a significância estatística e econômica do fenômeno, porém, tem recursos limitados concernentes à caracterização do ciclo em si.

Métodos alternativos, como modelos de espaço de estados, tratam as séries temporais como o resultado de componentes não-observáveis (tendência, sazonalidade, ciclo, irregular, etc.), sendo estes endogenamente estimados. Na econometria clássica, esses componentes (com a a exceção do erro) são especificados como determinísticos, na abordagem estrutural - na qual esse trabalho se delineará- eles adquirem uma natureza estocástica.

Este trabalho tem dois objetivos principais: explorar evidências de ciclo eleitoral na condução da política fiscal frente a investimentos públicos e avaliar os impactos desses possíveis ciclos sobre variáveis macroeconômicas. Essa seção se direciona a responder o primeiro ponto, desse modo, primeiramente será apresentado o modelo econométrico e, posteriormente, as estimações realizadas.

$\mathrm{Na}$ abordagem de espaço de estados, o desenvolvimento do sistema em estudo ao longo do tempo é determinado por uma série de vetores não observáveis $\alpha_{1}, \ldots, \alpha_{n}$, os quais são associados com uma série de observações $y_{1}, \ldots, y_{n}$. A relação entre $\alpha_{t}$, denominado vetor de estado, e o vetor de valores observados $y_{t}$, de ordem $p \times 1$, é determinada pela Equação de Medida abaixo descrita. (Durbin e Koopman, 2001)12.

$$
\begin{array}{ccc}
y_{t}=Z_{t} \alpha_{t}+\varepsilon_{t} & \varepsilon_{t} \sim N\left(0, H_{t}\right) \\
\alpha_{t+1}=T_{t} \alpha_{t}+R_{t} \eta_{t} & \eta_{t} \sim N\left(0, Q_{t}\right)
\end{array}
$$

A segunda equação, por sua vez, é chamada de Equação de Transição. Nesta, é modelado que o vetor de estado, cuja ordem é mx1, segue um processo autoregressivo de primeira ordem. Supõe-se inicialmente que as matrizes $Z, T, R, H$ e $Q$ são conhecidas e que os erros $\varepsilon$ e $\eta$ são serialmente independentes e independentes um do outro em todos os pontos do tempo.

As matrizes $Z$ e $T$ são as matrizes de observação e de transição, respectivamente, 
tendo dimensão $p \times m$ e $m \times m$, nessa ordem. $\mathrm{O}$ vetor $\varepsilon$ de ordem $p \times 1$ contém os $p$ resíduos da equação de medida - que seguem os pressupostos usuais e têm sua estrutura de variância-covariância representada na matriz $H$ de ordem $p \times p$ e forma o componente irregular dos MEEs (ORAIR; GOUVÊA; LEAL, 2014).

Note que a equação (4.1) tem a estrutura de uma regressão linear onde o coeficiente $\alpha_{t}$ varia no tempo. A segunda equação representa um modelo de vetor autoregressivo, sendo que a natureza Markoviana será responsável pela sofisticação das propriedades do modelo de espaço de estados.

Um modelo estrutural de séries temporais é aquele em que tendência $(\mu)$, sazonalidade $(\gamma)$, ciclo $(\psi)$ e erro $(\varepsilon)$ são explicitamente modelados, de tal forma que assume a seguinte estrutura:

$$
y_{t}=\mu_{t}+\gamma_{t}+\psi_{t}+\varepsilon_{t}
$$

A tendência é o componente que indica o caminho de longo prazo da série e é representada da seguinte forma:

$$
\begin{array}{ll}
\mu_{t}=\mu_{t-1}+\nu_{t-1}+\xi_{t} & \xi_{t} \sim N\left(0, \sigma_{\xi}^{2}\right) \\
\nu_{t}=\nu_{t-1}+\zeta_{t} & \zeta_{t} \sim N\left(0, \sigma_{\zeta}^{2}\right)
\end{array}
$$

$\mu$ é o nível da tendência, enquanto que $\nu$ é sua declividade. $\xi$ e $\zeta$ são ruídos brancos não correlacionados entre si. Note que $\xi$ permite que o nível da tendência seja variável, ao passo que $\zeta$ exerce o análogo para a declividade. Quanto maiores as variâncias desses termos de erro, mais estocásticos tendem a ser os movimentos, isto é, se $\sigma_{\xi}=0$, a tendência é determinística; caso contrário, já se configura como estocástica. Cabe ressaltar que a tendência será estimada diretamente, logo, aqui não se realiza testes de raiz unitária.

$$
\left(\begin{array}{l}
\mu_{t} \\
\nu_{t}
\end{array}\right)=\left(\begin{array}{ll}
1 & 1 \\
0 & 1
\end{array}\right)\left(\begin{array}{c}
\mu_{t-1} \\
\nu_{t-1}
\end{array}\right)+\left(\begin{array}{l}
\xi_{t} \\
\zeta_{t}
\end{array}\right)
$$

De maneira a modelar a sazonalidade em (4.3), consideram-se os subperíodos no período de um ano, no caso de dados mensais, $s=12$. Se o padrão sazonal é constante no tempo, os valores para os meses de 1 a $s$ podem ser modelados como constantes, respeitando a seguinte igualdade: $\sum_{j=1}^{s} \gamma_{j}^{\star}=0$. Na prática, é desejável que se permita que esse processo também seja estocástico; desse modo, o componente para a sazonalidade 
assume a seguinte forma:

$$
\gamma_{t}=\sum_{j=1}^{s-1} \gamma_{t-j}+\varpi_{t}
$$

O componente cíclico, por sua vez, é modelado como ondas geradas por funções trigonométricas do tipo $\psi_{t}=\rho(\alpha \cos \lambda t+\beta \operatorname{sen} \lambda t)+\kappa_{t}$ em que $\lambda$ é a frequência do ciclo medida em radianos, correspondente ao período do ciclo $(2 \pi / \lambda)$ e $\rho$ é denominado fator de amortecimento. Se $\alpha$ e $\beta$ evoluem aleatoriamente, assim como a variância do termo erro associado for não nula, então o ciclo tem natureza estocástica.

A grande vantagem dessa forma de especificação para os propósitos desse trabalho é que a frequência é tratada como um parâmetro desconhecido, o qual deve ser estimado de maneira endógena.

O problema pode ser escrito na forma recursiva segundo a fórmula abaixo, sendo que $\psi$ é o valor corrente do ciclo; e $\psi^{\star}$ aparece por construção para formar $\psi$. (Aqui, adota-se a mesma especificação de Orair (2014)).

$$
\left(\begin{array}{c}
\psi_{t} \\
\psi_{t}^{\star}
\end{array}\right)=\rho\left(\begin{array}{cc}
\cos \lambda & \operatorname{sen} \lambda \\
-\operatorname{sen} \lambda & \cos \lambda
\end{array}\right)\left(\begin{array}{c}
\psi_{t-1} \\
\psi_{t-1}^{\star}
\end{array}\right)+\left(\begin{array}{c}
\kappa_{t} \\
\kappa_{t}^{\star}
\end{array}\right)
$$

Para a estimação, que consiste na aplicação do Filtro de Kalman, é necessário que o modelo esteja na forma de espaço de estado. Desse modo, o que foi exposto até então 
será representado em notação matricial própria para fins práticos.

$$
\begin{aligned}
\alpha_{t} & =\left(\begin{array}{llllll}
\mu_{t} & \nu_{t} & \gamma_{t} & \gamma_{t-1} & \psi_{t} & \psi_{t}^{\star}
\end{array}\right)^{\prime} \\
Z_{t} & =\left(\begin{array}{ccccccc}
1 & 0 & 1 & 0 & 1 & 0
\end{array}\right) \\
T_{t} & =\left(\begin{array}{cccccc}
1 & 1 & 0 & 0 & 0 & 0 \\
0 & 1 & 0 & 0 & 0 & 0 \\
0 & 0 & -1 & -1 & 0 & 0 \\
0 & 0 & 1 & 0 & 0 & 0 \\
0 & 0 & 0 & 0 & \rho \cos \lambda & \rho \operatorname{sen} \lambda \\
0 & 0 & 0 & 0 & -\rho \operatorname{sen} \lambda & \rho \cos \lambda
\end{array}\right) \\
\eta_{t} & =\left(\begin{array}{ccccc}
\xi_{t} & \zeta_{t} & \varpi_{t} & \kappa_{t} & \left.\kappa_{t}^{\star}\right)^{\prime} \\
1 & 0 & 0 & 0 & 0 \\
0 & 1 & 0 & 0 & 0 \\
0 & 0 & 1 & 0 & 0 \\
0 & 0 & 0 & 0 & 0 \\
0 & 0 & 0 & 1 & 0 \\
0 & 0 & 0 & 0 & 1
\end{array}\right) \\
R_{t} & =\left(\begin{array}{ccccc}
\sigma_{\xi}^{2} & 0 & 0 & 0 & 0 \\
0 & \sigma_{\zeta}^{2} & 0 & 0 \\
0 & 0 & \sigma_{\varpi}^{2} & 0 \\
0 & 0 & 0 & \sigma_{\kappa}^{2} & 0 \\
0 & 0 & 0 & 0 & 0 \\
Q_{t} & =
\end{array}\right)
\end{aligned}
$$

\section{Filtro de Kalman}

O filtro de Kalman é o principal método para estimar sistemas dinâmicos representados na forma de espaço de estados: é um procedimento recursivo que gera uma estimativa ótima, no sentido de minimizar o Erro Quadrático Médio (EQM), do vetor de estado não observado em $t$, baseado na informação disponível em $t$. Em outras palavras, o objetivo do filtro é atualizar o estoque de informações do sistema a cada momento que uma nova observação de $y_{t}$ é lançada (DURBIN; KOOPMAN, 2001).

Para a estimação, algumas hipóteses adicionais são necessárias: o vetor de estado inicial $\alpha_{o}$ tem média $a_{o}$ e covariância $P_{0}\left(E\left(\alpha_{o}\right)=a_{o}, \operatorname{Var}\left(\alpha_{o}\right)=P_{o}\right) ; \eta$ e $\varepsilon$ são não correlacionados em todos os períodos e não correlacionados com o vetor de estado inicial, tal que

$$
\begin{array}{lcc}
E\left(\varepsilon_{t} \eta_{t}^{\prime}\right)=0 & \forall s, t=1, \ldots, T \\
E\left(\varepsilon_{t} \alpha_{o}^{\prime}\right)=0 & E\left(\eta_{t} \alpha_{o}^{\prime}\right)=0 \quad t=1, \ldots, T
\end{array}
$$

Ademais, supõe-se que $Z, H, Q$ e $T, \alpha_{o}$ e $P_{o}$ são conhecidos. Seja $a_{t-1}$ o estimador 
ótimo de $\alpha_{t-1}$, dadas as informações até e inclusive $y_{t-1}$ e $P_{t-1}$, a matriz de covariância do erro de estimação. As equações de predição (4.10) e atualização (4.11) abaixo descritas constituem o filtro de Kalman.

$$
\begin{aligned}
& \left.a_{t}\right|_{t-1}=T_{t} a_{t-1} \\
& \left.P_{t}\right|_{t-1}=E\left[\left(\alpha_{t}-\left.a_{t}\right|_{t-1}\right)\left(\alpha_{t}-\left.a_{t}\right|_{t-1}\right)^{\prime}\right] \\
& \left.P_{t}\right|_{t-1}=E\left[\left(T_{t} \alpha_{t-1}+R_{t} \eta_{t}-T_{t} a_{t-1}\right)\left(T_{t} \alpha_{t-1}+R_{t} \eta_{t}-T_{t} a_{t-1}\right)^{\prime}\right] \\
& \left.P_{t}\right|_{t-1}=E\left[T_{t}\left(\alpha_{t-1}-a_{t-1}\right)\left(\alpha_{t-1}-a_{t-1}\right)^{\prime} T_{t}^{\prime}+\eta_{t} \eta_{t}^{\prime}\right] \\
& \left.P_{t}\right|_{t-1}=T_{t} P_{t-1} T_{t}^{\prime}+R_{t} Q_{t} R_{t}^{\prime}
\end{aligned}
$$

As equações de atualização são construídas a partir da incorporação do erro de estimação de $y_{t}$ (o segundo termo do lado direito da igualdade), adquirindo a seguinte forma:

$$
a_{t}=\left.a_{t}\right|_{t-1}+\left.P_{t}\right|_{t-1} Z_{t}^{\prime} f_{t}^{-1}\left(y_{t}-\tilde{y}_{t \mid t-1}\right)
$$

Note que o problema é recursivo, a partir de condições iniciais $a_{o}$ e $P_{o}$ e interações entre (4.10) e (4.11), é possível obter o vetor de estado final $a_{t}$, este sendo o único vetor que incorpora toda a informação disponível da amostra.

Os parâmetros são estimados por máxima verossimilhança com restrição, supondo normalidade dos termos $\alpha_{o}$, $\varepsilon$ e $h_{t}$ para a determinação da variância condicional inerente à função a ser otimizada:

$$
\begin{aligned}
& L(Y, \Psi)=\prod_{t=1}^{T} P\left(y_{t} \mid y_{t-1}\right) \\
& \alpha_{t} \sim N\left(a_{t}, P_{t}\right) \\
& \varepsilon_{t} \sim N\left(0, h_{t}\right) \\
& \eta_{t} \sim N\left(0, Q_{t}\right)
\end{aligned}
$$

O modelo está adequadamente especificado se a convergência for forte ou muito forte. Além desse fator, é desejável que os resíduos não apresentem autocorrelação nem heterocedasticidade, mas possuam traços de normalidade. Após a estimação, esses diagnósticos devem ser feitos a fim de se obter uma boa especificação do modelo.

\section{Modelo estimado}


Figura 8 - Output do Modelo Estrutural
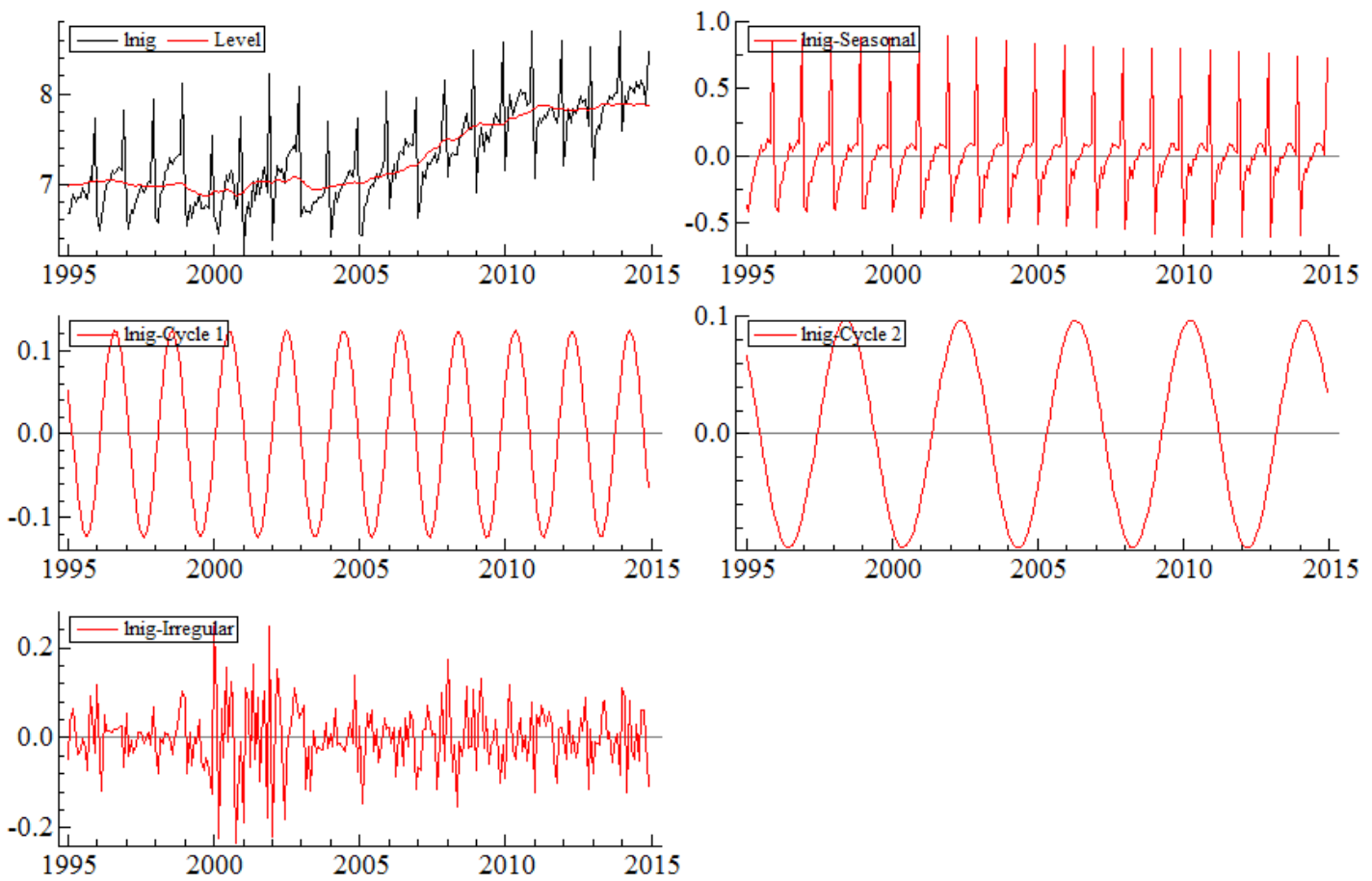

Fonte: Elaboração própria.

A Figura (8) traz os componentes estimados para a série mensal de investimento público real. O primeiro quadrante diz respeito à tendência, onde percebe-se que a mesma permanece por volta de 7 até meados de 2004, tendo uma expansão quase que linear chegando em 8 no final de 2014. O q-ratio (variância da disturbação sobre a maior delas), que é uma medida do grau estocástico indica que a tendência, com a exceção do termo irregular, é o componente com o maior teor de estocasticidade.

Tabela 1 - Desvios-padrão dos distúrbios

\begin{tabular}{|c|c|c|}
\hline \multicolumn{3}{|c|}{ Standard deviations of disturbances } \\
\hline & Value & \\
\hline Level & & \\
\hline Slope & 0 & \\
\hline Seasonal & 0.003 & \\
\hline Cycle & 0.000124713 & $(0.001400)$ \\
\hline Cycle2 & 0.000101998 & $(0.001145)$ \\
\hline Irregular & 0.0891084 & $(1.000)$ \\
\hline
\end{tabular}

O primeiro modelo estimado (diferente daquele aqui reportado) considera todos os componentes do modelo estrutural como estocásticos. Nesse caso, a variância da declividade $\left(v_{t}\right)$ (segundo termo da diagonal de $Q$ ) se aproxima de zero, dando indícios de que esse 
termo seja determinístico. Ao fixá-lo como tal, a convergência muda de fraca para forte, uma significativa melhora do ajuste do modelo.

O componente da sazonalidade evidencia que a execução dos investimentos se concentra nos últimos meses do ano, adotando um comportamento quase que idêntico ao longo dos anos: valores crescentes dentro do ano fiscal, pico no mês de dezembro e grande ajuste em janeiro.

Tabela 2 - Efeitos sazonais

\begin{tabular}{cccc}
\hline \multicolumn{4}{c}{ Seasonal effects } \\
\hline Period & Value & Prob & \%Effect \\
1 & 0.55442 & $(0.00000)$ & -44.5583 \\
2 & 0.80971 & $(0.00012)$ & -19.0287 \\
3 & 0.90889 & $(0.07422)$ & -9.11111 \\
4 & 0.89036 & $(0.02841)$ & -10.9639 \\
5 & 0.98892 & $(0.83050)$ & -1.10841 \\
6 & 0.97786 & $(0.66362)$ & -2.21388 \\
7 & 1.05277 & $(0.31211)$ & 5.27663 \\
8 & 1.09185 & $(0.08145)$ & 9.18492 \\
9 & 1.09987 & $(0.05618)$ & 9.98672 \\
10 & 1.07283 & $(0.15415)$ & 7.28316 \\
11 & 1.00932 & $(0.84897)$ & 0.93235 \\
12 & 2.07932 & $(0.00000)$ & 107.9322 \\
\hline
\end{tabular}

Muito embora na apresentação do modelo teórico, a série temporal tenha sido decomposta em apenas um ciclo, é possível distinguir dois ciclos no modelo estrutural, um de curto e outro de médio prazo. O terceiro gráfico se refere ao ciclo de menor extensão e o quarto, ao de maior, sendo que os parâmetros da equação (4.7) estão sumariados na tabela a seguir.

Tabela 3 - Parâmetros dos ciclos

\begin{tabular}{lll}
\hline & Cycle 1 & Cycle 2 \\
\hline Variance & 0.00778 & 0.0052 \\
Period & 23.53392 & 47.23211 \\
Period in years & 1.96116 & 3.93601 \\
Frequency & 0.26698 & 0.13303 \\
Damping factor & 1 & 1 \\
Order & 1 & 1 \\
\hline
\end{tabular}

O período do ciclo de médio prazo foi de 23, 72379 meses, quase dois anos exatos, enquanto que o período do ciclo de longo prazo teve valor de 47,71285, aproximadamente quatro anos. Não apenas as durações dos ciclos são interessantes, mas também os momentos em que há expansão e recessão. 
Figura 9 - Componentes cíclicos do Modelo Estrutural

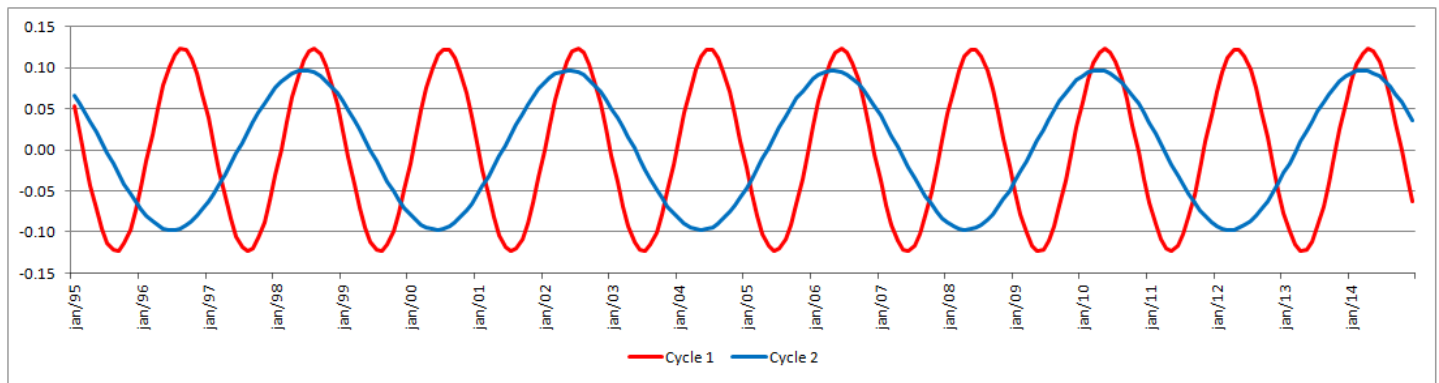

Fonte: Elaboração própria.

Observe que, com relação ao primeiro ciclo, o valor máximo acontece em anos de eleições e os vales sempre em anos ímpares. Como a duração do ciclo é de dois anos, esse ciclo capta o efeito das eleições municipais, estaduais e federais sobre o investimento público. Note que o valor máximo se dá poucos meses antes das eleições: de 1996 até 2000 no mês de agosto, de 2002 a 2006 no mês de julho e a partir de 2008 no mês de junho. Ou seja, o ápice do ciclo de médio prazo foi decrescente no tempo, a cada três eleições se reduziu em um mês o valor máximo de incidência da série.

O ciclo de longo prazo tem vale em anos de eleições regionais e pico em anos de eleições presidenciais, sendo o mês de maio o recorrente na quase totalidade da amostra. Conclui-se então que há uma clara coincidência dos ciclos estimados com o calendário eleitoral, constituindo evidências que há de fato um processo inerente à execução dos investimentos públicos envolvendo questões eleitoreiras.

Qual o efeito agregado desses ciclos? O primeiro passo para responder a essa perguntar é somar as séries mês a mês, duas séries foram calculadas: $c 1+c 2$ e $(1+c 1)(1+$ $c 2)-1$. Como os valores percentuais são próximas de zero, a diferença entre as mesmas é insignificante, obtendo a Figura $(10)^{1}$.

Figura 10 - Agregação dos componentes cíclicos

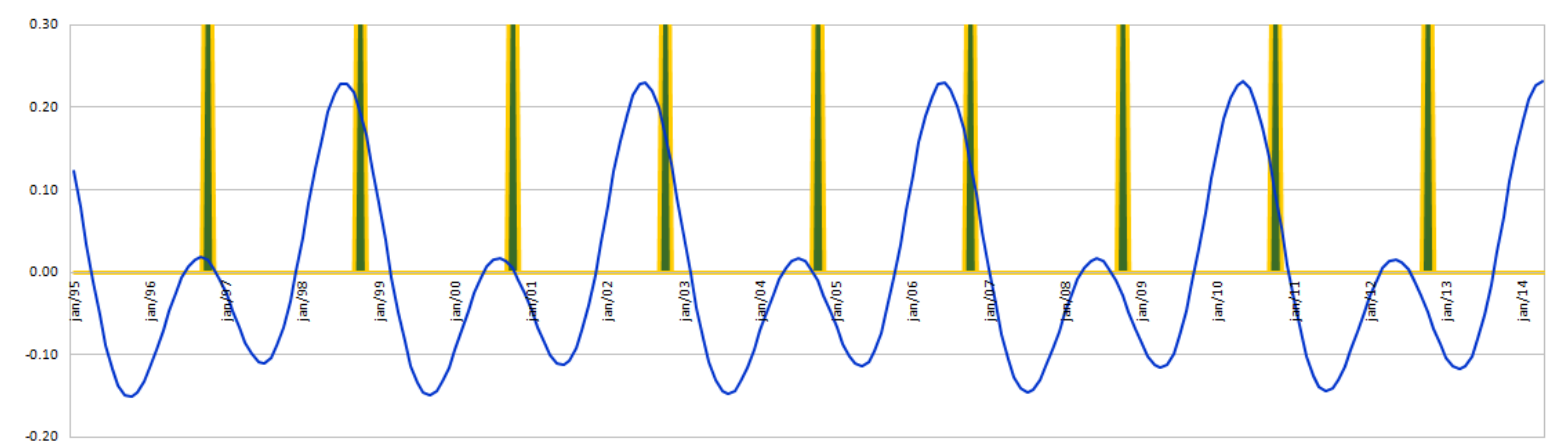

Fonte: Elaboração própria.

1 Adotou-se a segunda fórmula. 
Neste, o valor máximo do ciclo é poucos meses antes das eleições, que acontecem de dois em dois anos. Cabe ressaltar que a magnitude do ciclo é maior em anos com eleições para presidente, exemplificada pelos máximos locais em maiores níveis desde 1998, e desde então, de quatro em quatro anos. A alta do ciclo se encerra nos mês de setembro para 1996, agosto para 1998 e 2000, julho de 2002 a 2008 e junho para os dois demais. Ou seja, o pico da expansão fiscal tem ficado mais distante das eleições ao longo dos anos. ${ }^{2}$

O gráfico anterior comparou a soma dos ciclos com o período de três meses anteriores às eleições, que acontecem historicamente no começo de outubro. Percebe-se claramente que o ciclo tem seu efeito maximizado um pouco antes das eleições, alimentando o argumento de que os investimentos públicos são pró-ciclicos, não no sentido macroeconômico usual, mas sim no sentido de ciclo político.

A peculiaridade de que gastos públicos são pró-cíclicos, ou seja, há uma tendência de crescimento da despesa pública nos períodos em que a economia e a arrecadação estão crescendo, aliado ao fato de que os investimentos públicos representam a parte mais vulnerável (ou discricionária) do gasto público dá origem a uma correlação positiva entre a taxa de investimento público e os ciclos econômicos: os períodos de aceleração econômica e crescimento mais que proporcional das receitas públicas abrem espaço orçamentário para a expansão dos investimentos, enquanto a maior rigidez orçamentária durante as desacelerações provoca restrições e contingenciamentos nos investimentos públicos (SQUEFF, 2015).

A sobreposição do ciclo de negócios com o ciclo político incita dois argumentos centrais: primeiro, que os resultados desse trabalho não captam o impacto de ciclos políticos sobre multiplicadores fiscais, mas sim o efeito do ciclo de negócios, assim como o faz Auerbach e Gorodnichenko (2012). A discussão da ordem de causalidade entre ciclo político e ciclo de negócios é irrelevante para os propósitos do trabalho, mas sua alta correlação cria precedentes para esse primeiro argumento. Em segundo lugar, uma vez que o que se deseja mensurar é o impacto macroeconômico da política fiscal nas suas fases de expansão e contração, não importa se o efeito surge de um ciclo ou de outro, mas sim a constatação de que a economia tem respostas distintas nos dois períodos em consideração.

Resumindo, o modelo estrutural indicou um ciclo de dois anos e outro de quatro, que no agregado significa que se observa um comportamento cíclico da política fiscal de dois em dois anos, sendo que as fases de expansão (tanto dos investimentos quanto da atividade econômica) coincidem com o período pré-eleitoral e as de contração com o período pós-eleitoral.

Existem algumas maneiras de interpretar esses resultados. O viés pró-cíclico da política fiscal com relação aos investimentos públicos está mais propenso de ser observado

$\overline{2}$ Outro modelo estrutural foi ajustado, considerando os dados apenas a partir de 2000. Os resultados não se alteram. 
em países que adotam regimes rígidos de metas fiscais, como o que está em vigor no Brasil desde 1999 (SCHETTINI et al., 2011).

A "coincidência" de que todas as acelerações do ciclo acontecem no período préeleitoral (e as desacelerações no período pós-eleitoral) provê fundamentos para alguns dos argumentos da teoria econômica. Um deles é que há necessidade de promover um ajuste fiscal em resposta à maior pressão do mercado às políticas de pleno emprego. Outro é que esse fenômeno é fruto de políticas públicas cujo objetivo é influenciar os resultados das eleições com obras de maior visibilidade e que sinalizam competência administrativa.

Os componentes do ciclo extraídos do modelo estrutural não têm sua importância limitada à análise feita nessa seção. No modelo econométrico de referência - Auerbach e Gorodnichenko (2012) - o VAR a ser estimado exige uma variável auxiliar para a construção dos diferentes regimes, sendo a média móvel da taxa de crescimento do PIB a sua escolha, uma vez que se pretendeu estudar o ciclo de negócios.

Como o objetivo aqui é estudar o ciclo político, aquele presente em um ramo da política fiscal em particular, as séries dos ciclos de médio e longo prazo do investimento da Administração Pública são os melhores candidatos disponíveis para atacar o problema proposto. Na próxima subseção, um maior detalhamento será feito sobre como que essas variáveis foram tratadas para a inclusão no modelo empírico.

O vetor de estado final $a_{t}$, assim como suas estatísticas básicas, são reportados abaixo. Tomando como referência um nível de confiança de $6 \%$, todos os coeficientes são estatisticamente significantes, com a exceção do $\psi_{t}^{\star}$ para o ciclo de longo prazo. Outras propriedades do modelo são reportadas subsequentemente na Tabela 5.

A Tabela 6 traz os testes de normalidade dos resíduos, de uma maneira geral, percebe-se que o problema de ausência de normalidade está presente em todos os resíduos dos componentes. Ainda com relação aos resíduos, os testes de Durbin-Watson e Ljung-Box, reportados na Tabela 7, indicam que não há problemas de autocorrelação dos resíduos. Com relação ao erro de predição $\left(u_{t}=y_{t}-\tilde{y}_{t \mid t-1}=y_{t}-Z_{t} a_{t \mid t-1}\right)$, os testes presentes na tabela 8 indicam uma boa especificação do modelo estimado.

Outras propriedades, como a convergência e o valor da máxima verossimilhança, gradiente de convergência e número de más interações são incluídas na Tabela 9. Por fim, o modelo apresentou convergência muito forte; dessa forma, conclui-se que há uma especificação boa o suficiente para aceitar o modelo estrutural estimado. 
Tabela 4 - Vetor de estado no período 12/2014

\begin{tabular}{lllll}
\hline & Coefficient & RMSE & t-value & Prob \\
\hline Level & 7.86633 & 0.05584 & 140.8638 & $(0.00000)$ \\
Slope & 0.00371 & 0.00201 & 1.84695 & $(0.06606)$ \\
Seasonal & 0.02675 & 0.02238 & 1.19523 & $(0.23324)$ \\
Seasonal 2 & -0.15699 & 0.02306 & -6.80625 & $(0.00000)$ \\
Seasonal 3 & 0.0874 & 0.02115 & 4.13237 & $(0.00005)$ \\
Seasonal 4 & -0.08861 & 0.02146 & -4.1296 & $(0.00005)$ \\
Seasonal 5 & 0.14449 & 0.02117 & 6.82593 & $(0.00000)$ \\
Seasonal 6 & -0.07849 & 0.02108 & -3.72447 & $(0.00025)$ \\
Seasonal 7 & 0.17733 & 0.02138 & 8.29279 & $(0.00000)$ \\
Seasonal 8 & -0.06628 & 0.02091 & -3.16924 & $(0.00174)$ \\
Seasonal 9 & 0.20597 & 0.02158 & 9.54419 & $(0.00000)$ \\
Seasonal 10 & -0.01687 & 0.02085 & -0.80894 & $(0.41940)$ \\
Seasonal 11 & 0.0901 & 0.01802 & 5.00101 & $(0.00000)$ \\
Cycle 1 & -0.06284 & 0.01334 & -4.71124 & $(0.00000)$ \\
Cycle 1 2 & -0.10609 & 0.01339 & -7.92358 & $(0.00000)$ \\
Cycle 2 & 0.0359 & 0.02173 & 1.65237 & $(0.09984)$ \\
Cycle 2 2 & -0.09036 & 0.02193 & -4.12131 & $(0.00005)$ \\
\hline
\end{tabular}

Tabela 5 - Estatísticas do modelo

\begin{tabular}{|c|c|}
\hline \multicolumn{2}{|c|}{ Summary statistics } \\
\hline $\mathrm{T}$ & 240 \\
\hline $\mathrm{p}$ & 7 \\
\hline std.error & 0.11876 \\
\hline Normality & 5.752 \\
\hline $\mathrm{H}(75)$ & 0.5325 \\
\hline DW & 1.9716 \\
\hline $\mathrm{r}(1)$ & -0.00167 \\
\hline q & 24 \\
\hline$r(q)$ & -0.07337 \\
\hline $\mathrm{Q}(\mathrm{q}, \mathrm{q}-\mathrm{p})$ & 34.77 \\
\hline $\mathrm{Rs}^{2}$ & 0.53574 \\
\hline
\end{tabular}


Tabela 6 - Testes de Normalidade

\begin{tabular}{lllllll}
\hline Normality tests for & (a) & (b) & (c) & (d) & (e) & (f) \\
\hline Samplesize & 227 & 240 & 239 & 239 & 240 & 239 \\
Mean & 0.079883 & -0.00022 & -0.00424 & 0.53481 & -0.00022 & -0.00424 \\
St.Dev & 0.9968 & 0.99611 & 0.99748 & 0.9483 & 0.99611 & 0.99748 \\
Skewness & -0.021217 & -0.09282 & -0.06829 & -0.23837 & -0.09282 & -0.06829 \\
Excesskurtosis & 0.6831 & 1.1354 & 0.42568 & -1.2911 & 1.1354 & 0.42568 \\
Minimum & -3.271 & -3.1683 & -3.1655 & -1.708 & -3.1683 & -3.1655 \\
Maximum & 3.0891 & 3.3449 & 2.9941 & 1.8538 & 3.3449 & 2.9941 \\
\hline
\end{tabular}

(a): Residuals lnig
(b): Irregular Residual
(c): Level Residual
(d): Slope Residual
(e): lnig-Irregular Residual
(f): lnig-Level Residual

\begin{tabular}{lcccccc}
\hline Chi $^{2}$ prob & \multicolumn{2}{c}{$(\mathrm{a})$} & \multicolumn{2}{c}{ (b) } & \multicolumn{2}{c}{$(\mathrm{c})$} \\
\hline \multirow{2}{*}{ Skewness } & Value & Prob. & Value & Prob. & Value & Prob. \\
Kurtosis & 0.017032 & $(0.8962)$ & 0.34464 & $(0.5572)$ & 0.18579 & $(0.6664)$ \\
Bowman-Shenton & 4.4135 & $(0.0357)$ & 12.891 & $(0.0003)$ & 1.8044 & $(0.1792)$ \\
& 4.4305 & $(0.1091)$ & 13.236 & $(0.0013)$ & 1.9902 & $(0.3697)$ \\
\hline \multicolumn{2}{c}{$(\mathrm{d})$} & \multicolumn{2}{c}{$(\mathrm{e})$} & \multicolumn{2}{c}{$(\mathrm{f})$} \\
Skewness & Value & Prob. & Value & Prob. & Value & Prob. \\
Kurtosis & 2.2633 & $(0.1325)$ & 0.34464 & $(0.5572)$ & 0.18579 & $(0.6664)$ \\
Bowman-Shenton & 16.601 & $(0.0000)$ & 12.891 & $(0.0003)$ & 1.8044 & $(0.1792)$ \\
& 18.864 & $(0.0001)$ & 13.236 & $(0.0013)$ & 1.9902 & $(0.3697)$ \\
\hline
\end{tabular}

Tabela 7 - Teste de Correlação Serial

\begin{tabular}{lllll}
\hline \multicolumn{5}{c}{ Serial correlation statistics for Residuals lnig } \\
\multicolumn{5}{c}{ Durbin-Watson test is 1.97162} \\
Lag & df & Ser.Corr & BoxLjung & prob \\
6 & 1 & -0.06394 & 15.078 & $(0.0001)$ \\
7 & 2 & 0.093695 & 17.152 & $(0.0002)$ \\
8 & 3 & -0.00253 & 17.154 & $(0.0007)$ \\
9 & 4 & -0.04936 & 17.735 & $(0.0014)$ \\
10 & 5 & 0.007904 & 17.75 & $(0.0033)$ \\
12 & 7 & 0.042324 & 20.848 & $(0.0040)$ \\
24 & 19 & -0.07337 & 34.77 & $(0.0149)$ \\
36 & 31 & 0.021172 & 41.301 & $(0.1022)$ \\
\hline
\end{tabular}


Tabela 8 - Ajuste do Modelo

\begin{tabular}{|c|c|}
\hline \multicolumn{2}{|l|}{ Goodness-of-fit based on Residuals lnig } \\
\hline & Value \\
\hline Prediction error variance [p.e.v] & 0.014103 \\
\hline Prediction error mean deviation [m.d] & 0.010779 \\
\hline Ratio p.e.v. / m.d in squares & 1.0897 \\
\hline Coefficient of determination $\mathrm{R} \hat{2}$ & 0.95015 \\
\hline ... based on differences $\operatorname{Rd} \hat{2}$ & 0.93951 \\
\hline ... based on diff around seas mean Rs $\hat{2}$ & 0.53574 \\
\hline Information criterion Akaike [AIC] & -4.1447 \\
\hline ... Bayesian Schwartz $[\mathrm{BIC}]$ & -3.9417 \\
\hline
\end{tabular}

Tabela 9 - Propriedades

\begin{tabular}{ll}
\hline Strong convergence relative to & $1.00 \mathrm{E}-07$ \\
\hline likelihood cvg & 0 \\
gradient cvg & $1.45 \mathrm{E}-06$ \\
parameter cvg & 0 \\
number of bad iterations & $5.00 \mathrm{E}+00$ \\
\hline
\end{tabular}

\subsection{Modelo STVAR}

A escolha do modelo a ser estimado levou em consideração a parcimônia entre manter graus de liberdade e não incorrer em viés de variável omitida. Optou-se por um modelo de três variáveis, assim como o fez Auerbach e Gorodnichenko (2012), de modo que as variáveis do VAR são investimento público, investimento privado e PIB.

Os testes de raiz unitária para as três variáveis em questão indicam não estacionariedade das mesmas ${ }^{3}$, portanto, essas não podem ser incluídas em um VAR considerando-as em nível. Abaixo segue o resumo das estatísticas dos testes, todas significantes a um nível de confiança de 1\%, ou seja, para ADF (Augmented Dickey-Fuller), DF-GLS (Generalized Dickey-Fuller)e NG-Perron, não se rejeita a hipótese nula de existência de raiz unitária. Enquanto para o teste Kwiatkowski-Phillips-Schmidt-Shin (KPSS), que tem hipótese nula de estacionariedade,rejeita-se $H_{0} \cdot{ }^{4}$ Análise de cointegração não foi feita pelo fato de que o objetivo do trabalho é a estimação do VAR não linear, dando enfoque para uma possível diferença de impactos econômicos nos diferentes regimes, que é a pergunta que se pretende responder.

Assim sendo, as variáveis do VAR estão em primeira diferença. Pela característica dos dados mensais, aplicou-se a primeira diferença relativa ao mesmo mês do ano anterior

3 Realizou-se o teste Dickey-Pantula para verificação de duas raízes unitárias, estes indicaram a presença de uma raiz unitária, apenas. Optou-se por não reportar os resultados.

4 Os outputs dos testes de raiz unitária estão nos Apêndices. 
$\left(x_{a, m}-x_{(a-1), m}\right)$. Além das variáveis endógenas, outra variável exógena foi adicionada: dummy para o período da crise (=1 de 10/2008 a 01/2010).

A identificação seguiu a estratégia de Auerbach e Gorodnichenko (2012): adoção da decomposição de Cholesky considerando gasto público como a primeira variável do VAR, de tal forma que choques das demais variáveis não lhe causam impacto contemporaneamente. De fato, o processo orçamentário é lento e não acompanha as mudanças de mercado prontamente (pelo menos no que se refere à execução do investimento público). Segundo Blanchard e Perotti (2002), demora mais que um período para que os políticos e policy makers internalizem determinado choque e respondem via política fiscal.

Com relação à identificação dos choques do investimento privado e produto, considerou-se que os choques do primeiro afetam o segundo contemporaneamente, não valendo o argumento recíproco. Como o PIB é composto pelo próprio investimento privado, não faz sentido em dizer que choques no investimento privado não impactam o PIB, por uma simples definição de contas nacionais.

Os modelos foram estimados em três frentes ${ }^{5}$ : modelo linear, modelo não-linear e testes de robustez. As propriedades do modelo estimado foram analisadas para o caso linear, para a versão não-linear, contudo, o diagnóstico se concentra na análise das funções de impulso resposta e seus respectivos intervalos de confiança. Os parâmetros estimados de ambos modelos, por sua vez, são reportados nos Apêndices.

Os testes de robustez foram realizados em quatro variações. Embora a literatura não se preocupe com esse primeiro ponto, subtraiu-se do produto interno bruto os investimentos público e privado, com a intenção de minar possíveis problemas de multicolinearidade. Portanto, nessa nova especificação, analisa-se os efeitos de choques de investimento sobre os demais componentes do PIB sobre a ótica da demanda.

A segunda classe de testes de robustez concerne à alteração do parâmetro $\gamma$ de modo a checar a sensibilidade do modelo. Espera-se que os resultados não sofrerão grandes alterações, isso pois a variável índice $z$ foi obtida a partir da primeira diferença do componente cíclico do investimento. Ou seja, os pontos de inflexão não sofrem modificações com mudanças do parâmetro, apenas a amplitude de $F(z)$.

Em terceiro lugar, uma nova estimação será feita para um período truncado, de modo a comparar os impactos com relação aos distintos mandatos presidenciais. Por questão de limitação de dados, não se pode fazer uma análise separada de cada mandato. Assim sendo, a estratégia é estimar um modelo truncado até 12/2009 e comparar os resultados com o modelo da amostra completa. A partir daí, pode-se verificar qual o impacto marginal do último mandato presidencial completo que se teve no Brasil.

Por fim, o último teste tem como objeto uma reconsideração sobre o conceito

\footnotetext{
5 Os modelos foram estimados no MatLab.
} 
de investimento público. Em suma ,os modelos estimados até aqui utilizam dados de investimentos das administrações públicas (em nível federal, estadual e municipal), desconsiderando os montantes provindos de empresas estatais. A diferença dessa categoria de teste é considerar estes últimos como parte da formação bruta de capital fixo do setor público e reestimar os modelos linear e não-linear para esse caso. ${ }^{6}$

\section{Modelo 1}

A primeira coluna da tabela (10) traz o impacto máximo sobre o produto (seus respectivos erros-padrão na segunda coluna), o qual é amplamente adotado por Blanchard e Perotti (2002). A terceira coluna, por sua vez, reporta a razão entre a resposta do produto (frente ao choque em Ig) e a resposta do investimento público (frente ao choque em Ig), a qual é utilizada por Woodford (2011), uma vez que se argumenta que o tamanho do multiplicador fiscal depende da persistência dos choques fiscais.

Pela Figura (11), percebe-se que o choque no investimento público gera uma resposta negativa em formato de $\mathrm{U}$ do investimento privado, quando se considera o modelo linear. A resposta decresce do segundo até o nono período, depois converge para um valor ligeiramente superior a zero. Do terceiro mês em diante, a resposta é estatisticamente significante, sendo negativa na quase totalidade do intervalo considerado. A interpretação é de que há crowding-out do investimento privado, isto é, o efeito que se prevalece é o de que investimento do setor público compete por recursos físicos e financeiros com o setor privado, gerando uma relação de substituição entre as duas variáveis.

Com relação ao modelo não-linear, percebe-se que as respostas de fato variam com o ciclo: as linhas vermelhas são as respostas no período pré-eleitoral, que corresponde à fase de expansão do ciclo político; ao passo que as linhas azuis correspondem aos impactos estimados da retração do ciclo, a qual coincide com o período pós-eleitoral, também conhecido como ajuste fiscal.

A função de impulso resposta para o período pré-eleitoral deste modelo indica que o efeito crowding-out sobre investimento privado também persiste. Possíveis explicações para esse fenômeno se respaldam no próprio ciclo político: quando o investimento público está crescendo, empresários antecipam que haverá um ajuste fiscal e não investem como gostariam. Outro argumento é o de que, no período pré-eleitoral, as incertezas sobre o cenário político do próximo ano afetam as decisões de investimento, sendo que os investimentos públicos não conseguem alavancar os do setor privado, mas atuam na verdade na direção contrária.

O momento pós-eleitoral deve ser analisado com cuidado, uma vez que o que a função de impulso resposta retrata é o impacto do choque de uma unidade monetária (positivo) da variável impulso sobre a variável resposta. Como no período pós-eleitoral

6 Cabe ressaltar que o investimento privado também se altera, pelo fato do mesmo ser estimado por resíduo. 
sempre há ajuste sobre o investimento público, os choques provindo do setor público, na prática, são negativos. Trabalhando com choques negativos do investimento público no período pós-eleitoral, a interpretação é a seguinte: nos quatro primeiros meses seguidos do choque ainda prevalece o efeito negativo sobre o investimento privado, pode-se ver isso como a existência de um tempo mínimo para a retomada de expectativas, o mercado ainda está em fase de apreciação do novo governo, incertezas quanto ao cenário político ainda existem e isso repercute na formação de capital do setor privado. Passado um trimestre, a relação se inverte, a resposta de um choque positivo em $I g$ passa a ser negativa. Como esse choque é negativo, a trajetória de Ip é, na verdade, ascendente, alcançando 0,8 e estabilizando em torno de 0,6. É um argumento que deve ser melhor fundamentado ${ }^{7}$, mas, nessa perspectiva levantada, a primeira conclusão é que o ajuste fiscal é expansionista e a expansão fiscal é contracionista, quando se considera apenas os efeitos sobre o investimento do setor privado.

Cabe ressaltar que os resultados aqui obtidos indicam que, em ambos os períodos pré e pós eleitorais, prevalece o fenômeno de crowding-out sobre o investimento privado. Mesmo que a função de impulso resposta para o período pós-eleitoral no primeiro momento indique uma relação positiva entre o choque e a resposta, o efeito predominante é o de uma relação inversa.

No VAR linear, a resposta do Produto Interno Bruto frente a um choque no investimento público é positivo (Figura (11)) e tem a forma hump-shaped a partir do segundo mês. O ponto de maior impacto acontece depois de quatro meses do momento do choque - sendo estatisticamente significante até o oitavo período - e converge suavemente para zero.

Com relação ao modelo não-linear, as respostas são distintas. Na fase de expansão do ciclo, o multiplicador fiscal é positivo e com efeitos duradouros, alcançando valores maiores que a unidade, inclusive. Na fase de ajuste fiscal, a trajetória da resposta caminha na direção contrária, obtendo multiplicadores com magnitude também maiores que a unidade.

O diagnóstico é análogo ao feito para a resposta do investimento privado: no período pós-eleitoral, o choque em $I_{g}$ é negativo, assim, interpreta-se que o PIB, nos 5 primeiros meses decresce, mas depois atinge níveis positivos. Note que os multiplicadores fiscais no modelo não-linear alcançam valores maiores que a unidade e a função de impulso resposta não converge para zero dentro de vinte meses.

A partir desses resultados, pode-se concluir que a política fiscal no que concerne à condução dos investimentos públicos ${ }^{8}$ desestimula decisões de investimento, porém estimula o crescimento. Este trabalho não consegue informar com precisão qual o efeito

\footnotetext{
7 Isso será feito nas Conclusões.

8 Toda referência a política fiscal será feita nesse sentido.
} 
líquido sobre o crescimento, isso pois, como será argumentado em breve, o impacto de um real a mais em investimentos no setor privado gera efeitos significativos sobre o produto. Em outras palavras, existe, em tese, um efeito perverso da política fiscal sobre o crescimento quando se considera os efeitos indiretos dos investimentos privados. ${ }^{9}$

Figura 11 - Modelo 1: Funções de impulso resposta (choque em $I g$ )

(a) Intervalo de Confiança para o modelo linear
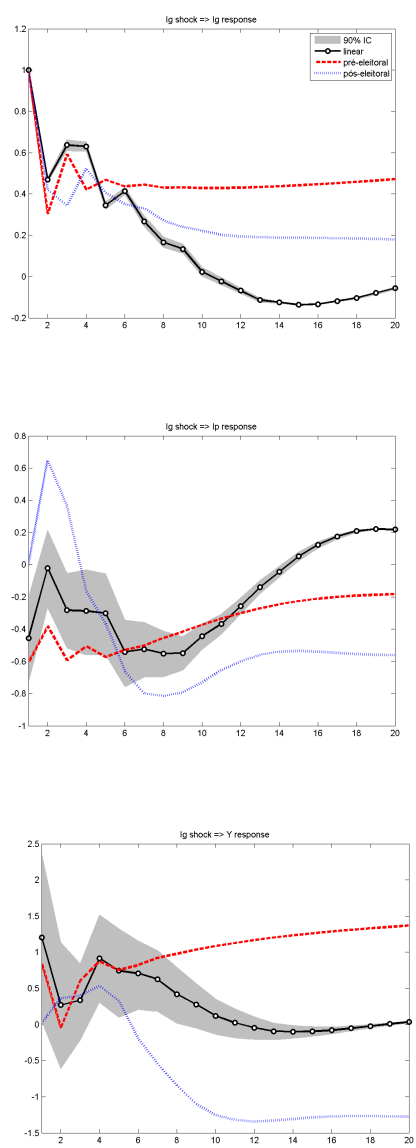

(b) Intervalo de Confiança para o regime pré-eleitoral
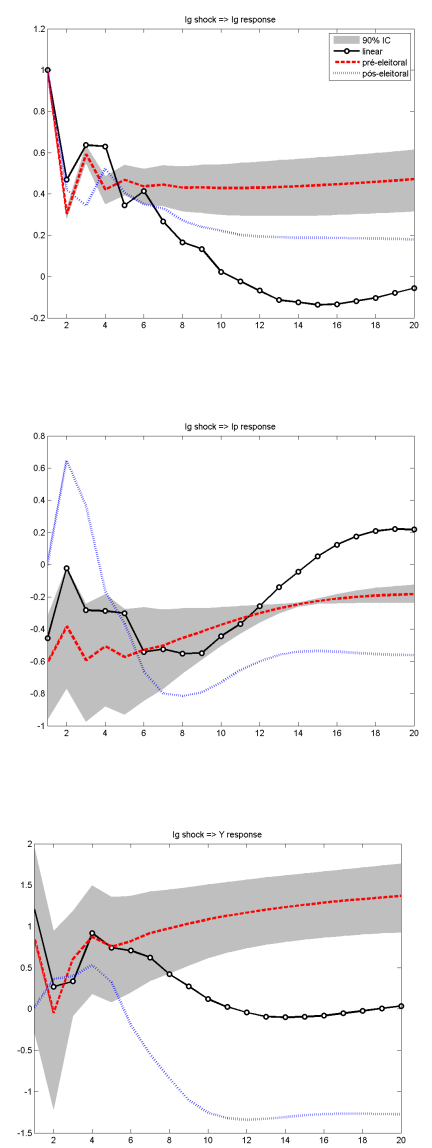

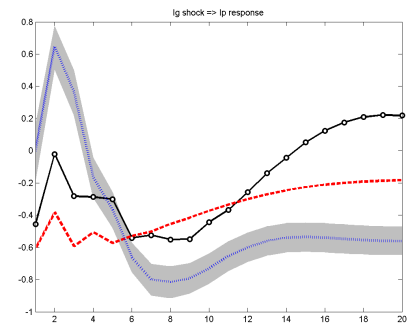

(c) Intervalo de Confiança para regime pós-eleitoral
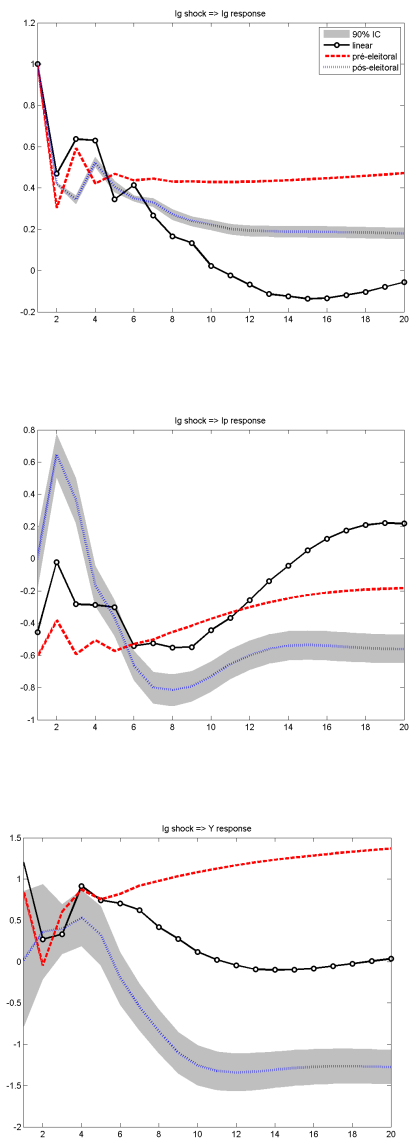

Fonte: Elaboração própria. As figuras mostam as funções de impulso resposta a um aumento de $\mathrm{R} \$ 1$ na variável de interesse. A região sombreada é o intervalo de confiança de $90 \%$.

Analisando as funções de impulso resposta para um choque no investimento privado, percebe-se que seus efeitos sobre o investimento público não são economicamente significantes. Por outro lado, o impacto sobre o produto é forte, partindo de um patamar três vezes superior ao choque e convergindo para zero depois de vinte meses. Cabe ressaltar que não há distinções pré e pós eleitorais do impacto do investimento privado sobre o PIB: é sempre positivo e significativo.

O ajuste de todos os modelos ${ }^{10}$ estimados apresentaram-se qualitativamente

9 Há um certo grau de abstração nesse argumento, por isso, este será melhor detalhado no próximo capítulo.

10 Exceto para o modelo com amostra truncada. 
Figura 12 - Modelo 1 Funções de impulso resposta (choque em Ip)

(a) Intervalo de Confiança para o modelo linear
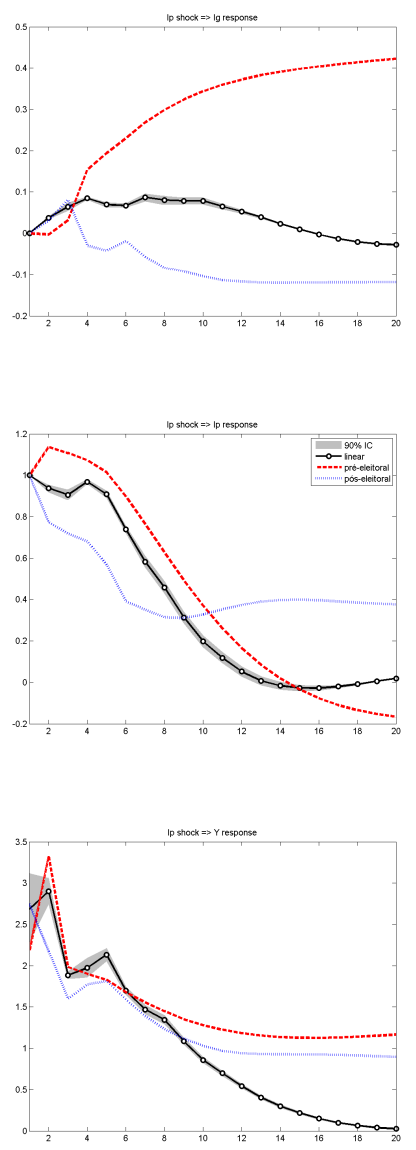

(b) Intervalo de Confiança para o regime pré-eleitoral
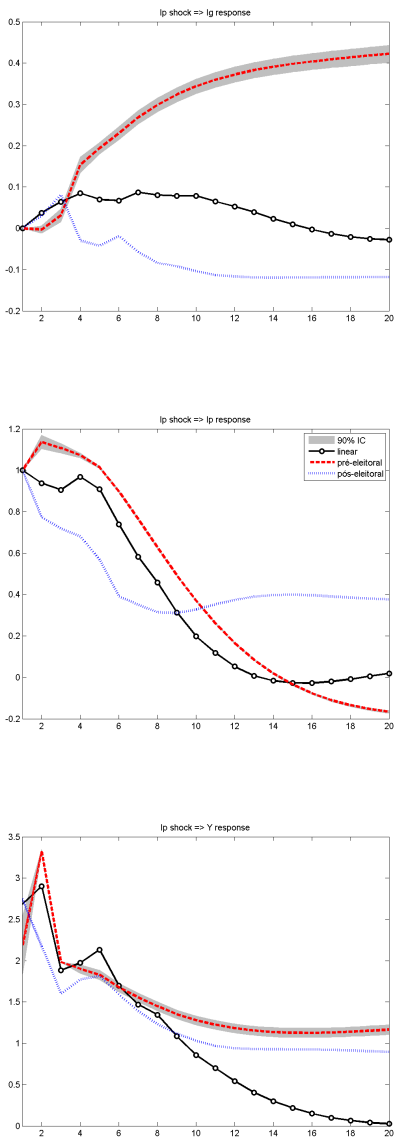

(c) Intervalo de Confiança para regime pós-eleitoral
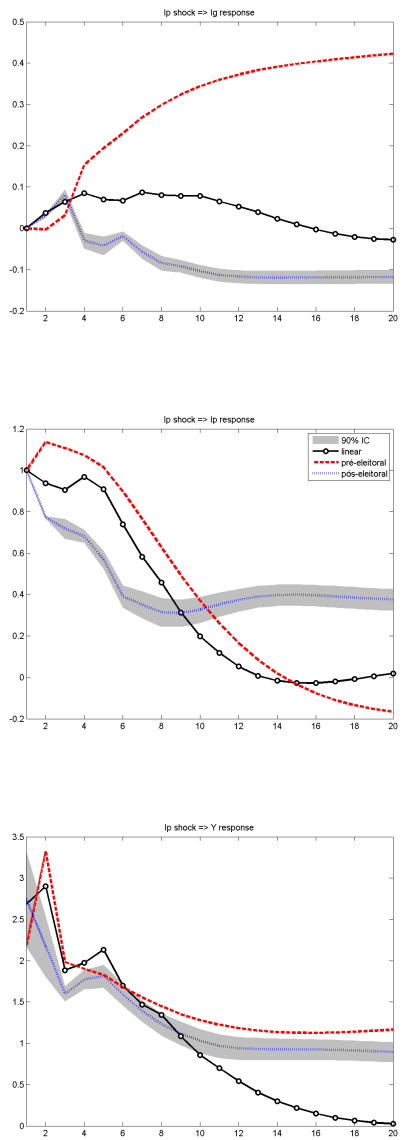

Fonte: Elaboração própria. As figuras mostam as funções de impulso resposta a um aumento de $\mathrm{R} \$ 1$ na variável de interesse. A região sombreada é o intervalo de confiança de $90 \%$.

satisfatórios: as cadeias de Markov simuladas convergem para distribuições estacionárias e os parâmetros simulados são consistentes com uma boa identificação dos mesmos. Os testes de robustez serão apresentados a seguir, com o propósito de ver quão sensíveis são os resultados do Modelo 1 frente diferentes especificações. Como o objetivo do trabalho é verificar os efeitos da política fiscal, apenas as respostas frente a um choque em $I g$ foram reportadas nos testes de robustez.

\section{Teste de robustez 1 : PIB residual}

Sob a ótica da demanda o PIB pode ser desmembrado em consumo, investimento, gastos do governo e exportações líquidas. As duas primeiras variáveis endógenas do VAR somam uma parcela considerável e relativamente estável ao longo do tempo do produto, desse modo, faz sentido em retirá-las da terceira entrada do vetor como checagem. A resposta do PIB no período pré-eleitoral obteve um aumento, o formato hump-shaped da resposta do modelo linear se alterou, apresentado pico no sétimo mês, ao passo que a 
resposta da fase de ajuste fiscal não se alterou.

Figura 13 - Teste de Robustez 1: Funções de impulso resposta (choque em $I g$ )

(a) Intervalo de Confiança para o modelo linear
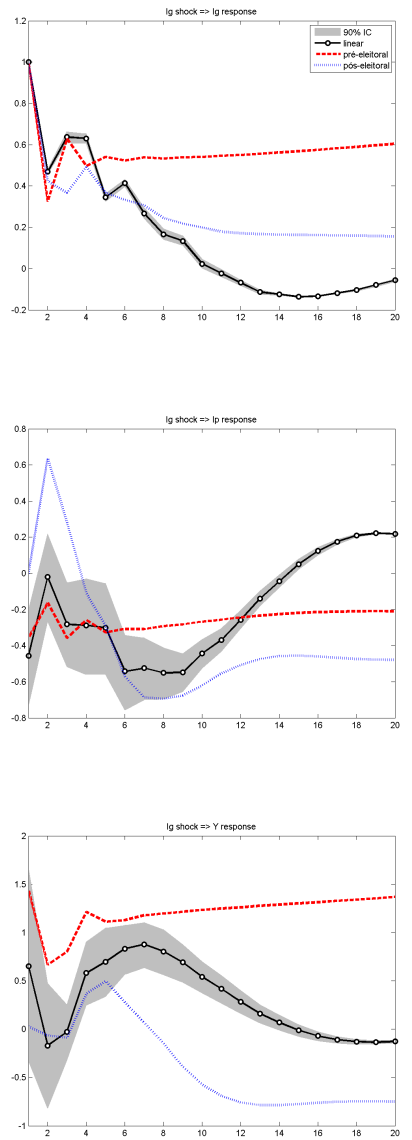

(b) Intervalo de Confiança para o regime pré-eleitoral
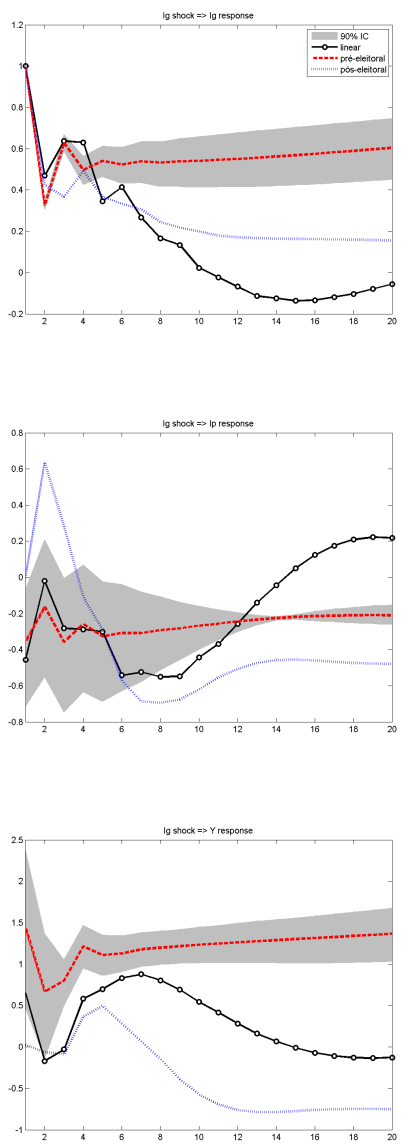

(c) Intervalo de Confiança para regime pós-eleitoral
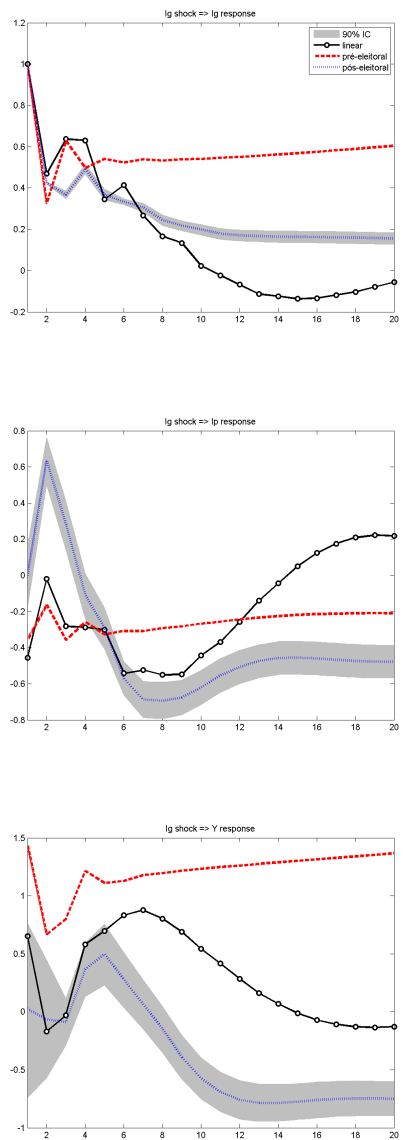

Fonte: Elaboração própria. As figuras mostam as funções de impulso resposta a um aumento de $\mathrm{R} \$ 1$ na variável de interesse. A região sombreada é o intervalo de confiança de $90 \%$.

\section{Teste de robustez 2 : Priors alternativas para os parâmetros}

As priors dos parâmetros de estimação bayesiana do VAR foram alteradas para checar a sensibilidade do modelo. Os resultados apontam que não há grandes mudanças. Alguns modelos foram estimados, reporta-se neste trabalho apenas um: para o caso em que o parâmetro do controle da resposta entre variáveis é 1,5 e o parâmetro de controle da resposta própria é 1 (esses parâmetros são 1 e 0,5, respectivamente, para o modelo principal).

Na verdade, para a diferenciação entre os regimes, o valor de $\gamma$ não traz grandes diferenças, uma vez que, utilizando a primeira diferença do componente cíclico, o ponto de inflexão não se altera, $\log \mathrm{o}, P(F(z)>0,5) \approx 0,5$ sempre.

No trabalho de Auerbach e Gorodnichenko (2012), o regime de recessão tem relativamente poucas observações. Neste trabalho, o número de observações é quase idêntico 
para ambos regimes, implicando em ganhos em termos de estabilidade paramétrica.

Figura 14 - Teste de Robustez 2: Funções de impulso resposta (choque em $I g$ )

(a) Intervalo de Confiança para o

modelo linear
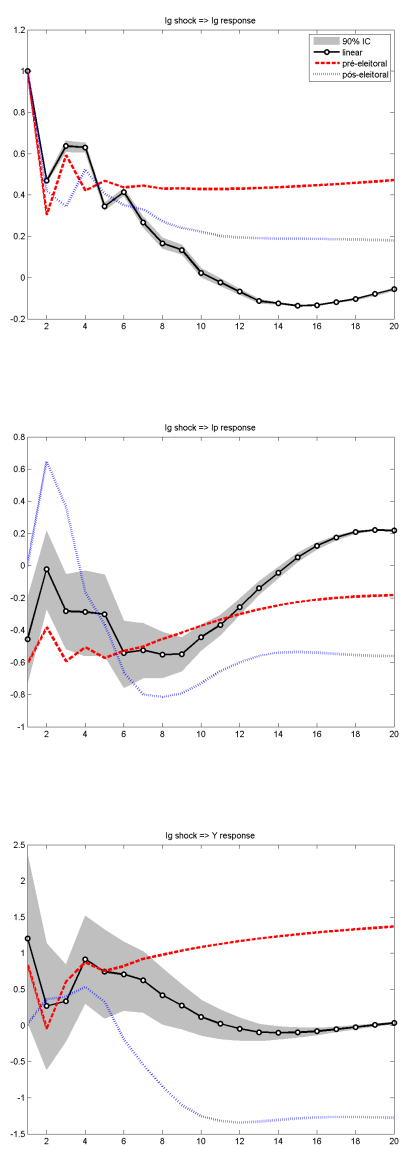

(b) Intervalo de Confiança para o

regime pré-eleitoral
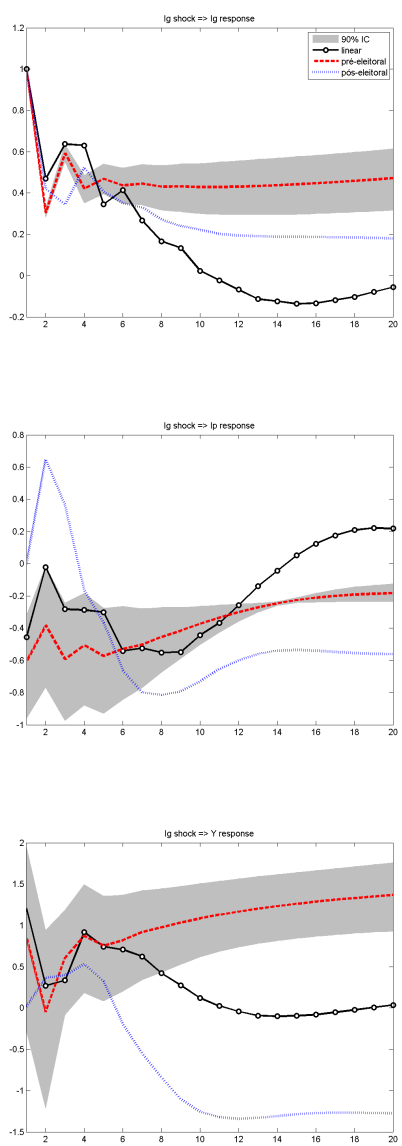

(c) Intervalo de Confiança para regime pós-eleitoral
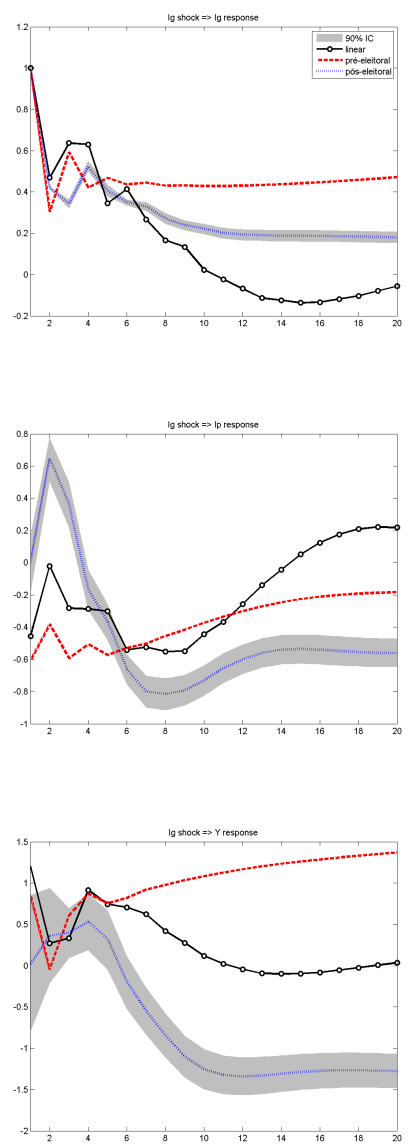

Fonte: Elaboração própria. As figuras mostam as funções de impulso resposta a um aumento de $\mathrm{R} \$ 1$ na variável de interesse. A região sombreada é o intervalo de confiança de $90 \%$.

\section{Teste de robustez 3 : Período truncado}

Um objetivo secundário deste trabalho seria determinar se os efeitos do ciclo político seriam maiores em determinados governos. Esse tipo de conclusão não pôde ser feita, uma vez que o modelo estimado para o período truncado (até 12/2009) não obteve convergência. Com a redução da amostra, os graus de liberdade caem suficientemente, prejudicando o ajuste do modelo. 
Figura 15 - Teste de Robustez 3: Funções de impulso resposta (choque em Ig)

(a) Intervalo de Confiança para o modelo linear
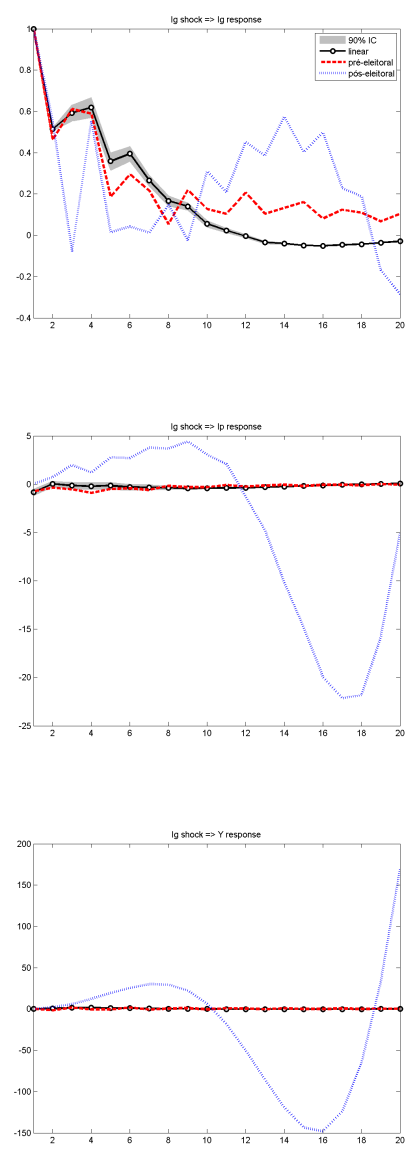

(b) Intervalo de Confiança para o regime pré-eleitoral
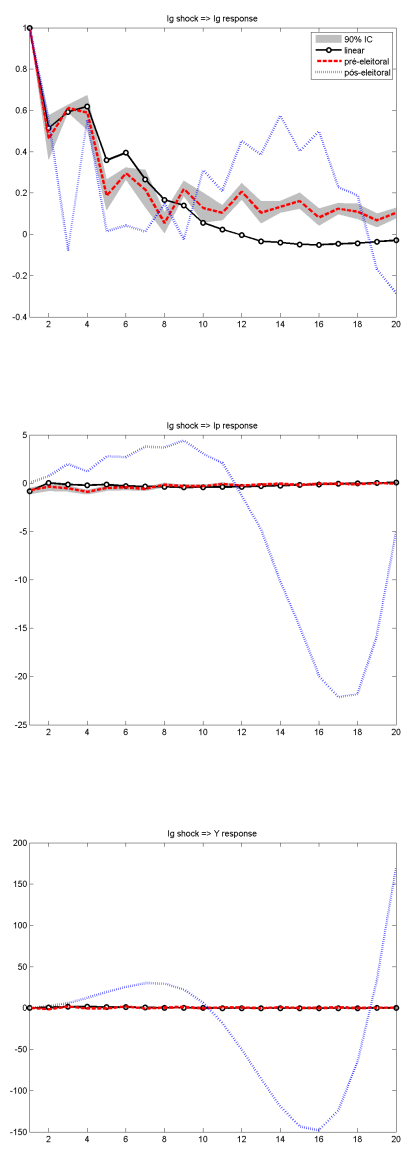

(c) Intervalo de Confiança para regime pós-eleitoral
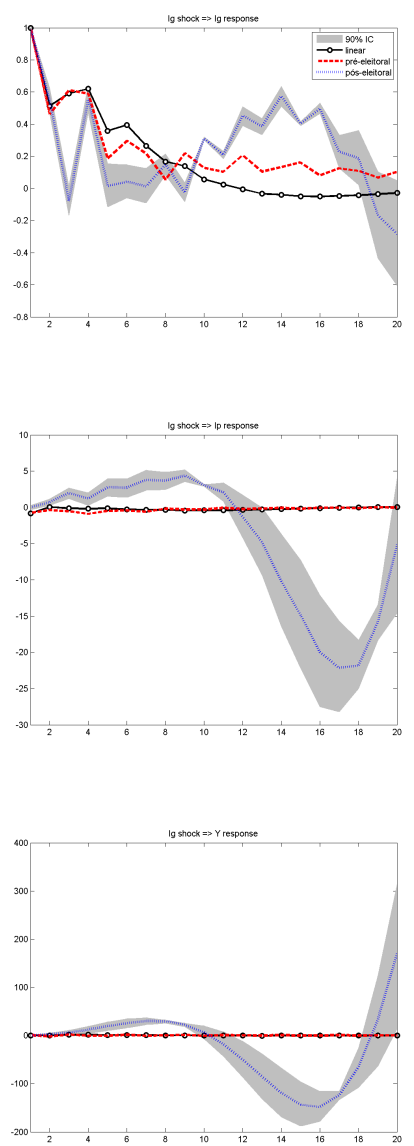

Fonte: Elaboração própria. As figuras mostam as funções de impulso resposta a um aumento de $\mathrm{R} \$ 1$ na variável de interesse. A região sombreada é o intervalo de confiança de $90 \%$.

Teste de Robustez 4: Empresas Estatais.

Os investimentos das empresas estatais correspondem a uma participação considerável do produto brasileiro. No período em análise, a média da razão entre investimento das estatais e PIB foi de 1,3\%, ao passo que esse dado para os investimentos da Administração Pública é $2 \%$.

O primeiro questionamento, antes de tudo, é: existe um componente de ciclo político para o investimento público, quando se considera investimento de empresas estatais? A resposta é não, outra estimação do Modelo Estrutural foi realizada com essa nova série de investimento e o que se observa é que o componente cíclico desaparece ${ }^{11}$. O segundo é se os resultados do Modelo 1 diferem ao fazer essa incorporação.

Com relação ao modelo linear, ainda pode-se dizer de crowding-out sobre o in-

11 O mesmo exercício foi feito para a série de investimento privado: tampouco se observa componente cíclico. 
vestimento privado; ademais, o efeito do investimento público sobre crescimento diminui e deixa de ser significativo. Concernente ao modelo não-linear, nota-se que, no período pré-eleitoral, a resposta de $I p$ frente a um choque em $I g$ se torna positiva após oito meses, as outras respostas tendo tendência similares, porém com magnitudes maiores.

Figura 16 - Teste de Robustez 4: Funções de impulso resposta (choque em $I g$ )

(a) Intervalo de Confiança para o modelo linear
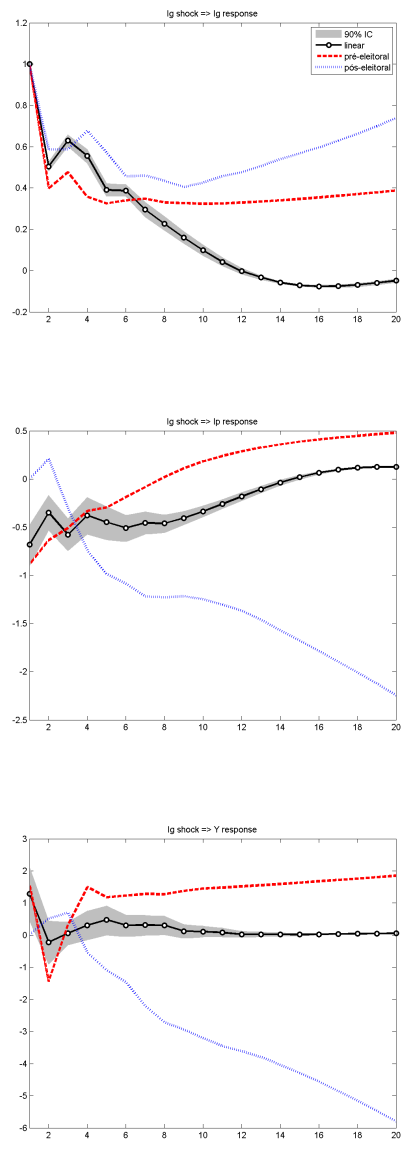

(b) Intervalo de Confiança para o regime pré-eleitoral
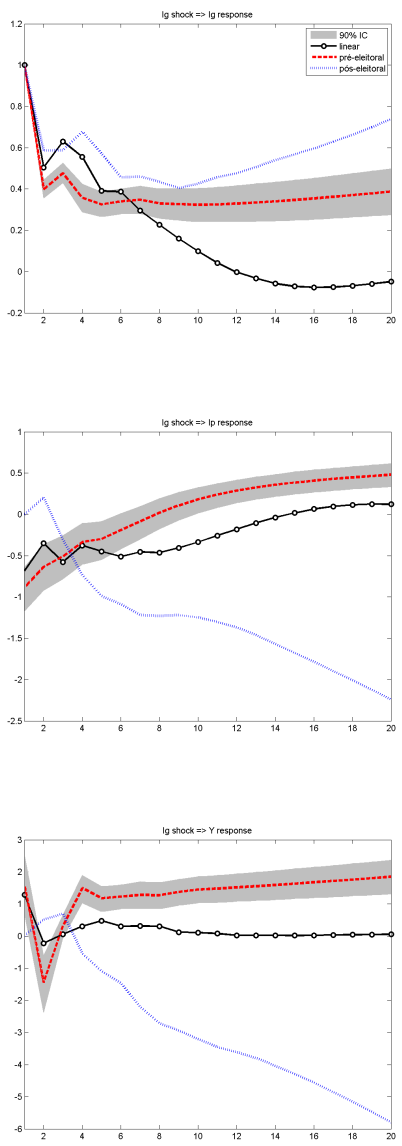

(c) Intervalo de Confiança para regime pós-eleitoral
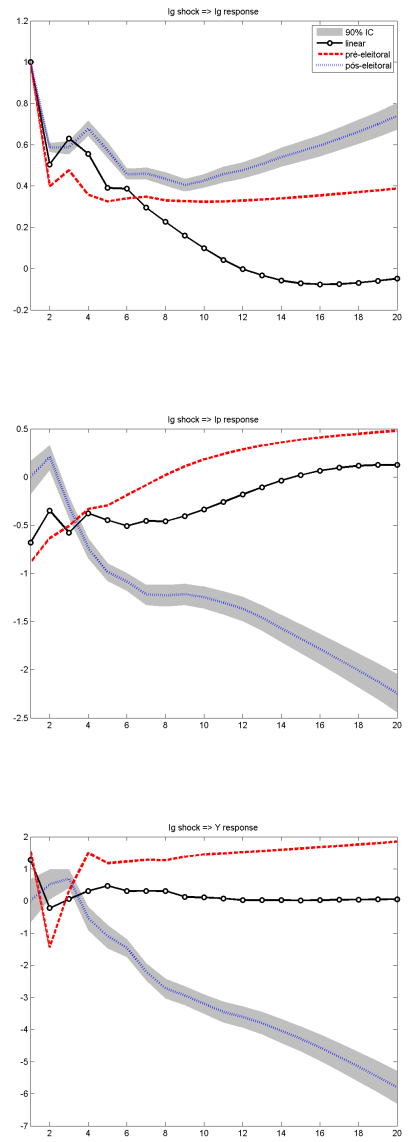

Fonte: Elaboração própria. As figuras mostam as funções de impulso resposta a um aumento de $\mathrm{R} \$ 1$ na variável de interesse. A região sombreada é o intervalo de confiança de $90 \%$.

Percebe-se da Tabela (10) que os multiplicadores são de fato distintos de período para período: maiores no período pré-eleitoral, tanto com relação aos parâmetros do modelo linear quanto aos referentes do período pós-eleitoral.

As mudanças dos multiplicadores quando se desconsidera os investimentos do produto são marginais: o valor máximo no modelo linear cai de 1,2 para 0,9, o que era de se esperar uma vez que o choque de um real no investimento público necessariamente implica em um aumento da mesma proporção no PIB contemporaneamente e pela característica autoregressiva das equações; apenas o multiplicador acumulado no período pós-eleitoral tem uma mudança significativa. 
Tabela 10 - Multiplicadores fiscais

\begin{tabular}{lllll}
\hline & \multicolumn{3}{c}{$\max _{h=1, \ldots, 20} Y_{h}$} & \multicolumn{2}{c}{$\sum_{h=1}^{20} Y_{h} / \sum_{h=1}^{20} I g_{h}$} \\
& Estimativa pontual & Erro padrão & Estimativa pontual & Erro padrão \\
\hline \hline Modelo 1 & & & & \\
linear & 1.2055 & 0.5632 & 1.6585 & 0.1698 \\
pré & 1.3695 & 0.3213 & 2.1767 & 0.2995 \\
pós & 0.5328 & 0.2468 & -2.5468 & 0.1921 \\
TR 1 & & & & \\
linear & 0.8768 & 0.2785 & 1.8603 & 0.1115 \\
pré & 1.4456 & 0.4126 & 2.1299 & 0.1729 \\
pós & 0.4976 & 0.204 & -1.3574 & 0.1472 \\
TR 2 & & & & 0.1698 \\
linear & 1.2055 & 0.5632 & 1.6585 & 0.2995 \\
pré & 1.3695 & 0.3213 & 2.1767 & 0.1921 \\
pós & 0.5328 & 0.2468 & -2.5468 & 0.1816 \\
TR 3 & & & & 0.0934 \\
linear & 1.5075 & 0.5183 & 1.3645 & 2.7054 \\
pré & 1.828 & 0.2961 & 1.0035 & \\
pós & 169.496 & 87.0402 & -79.4529 & 0.1224 \\
TR 4 & & & & 0.2729 \\
linear & 1.2842 & 0.4569 & 0.9162 & 0.2476 \\
pré & 1.8486 & 0.3556 & 3.3966 & $\mathrm{R} \$ 1$ \\
pós & 0.7006 & 0.1944 & -5.0493 & \\
\hline Nota: A & & & & \\
\hline
\end{tabular}

Nota: A tabela mostra os multiplicadores do produto para um choque de $\mathrm{R} \$ 1$ no investimento público.

O Teste de Robustez 2 apenas confirma que houve convergência na estimativa dos parâmetros ao alterar as priors. Os resultados são exatamente os mesmos. O Testes de Robustez 3, por sua vez, indica posição contrária, não houve convergência e os multiplicadores estimados não são consistentes.

Incorporar investimentos das estatais na definição de setor público faz com que a magnitude dos multiplicadores fiscais seja maior em todos os casos (com a exceção da resposta acumulada pós-eleitoral) 



\section{Conclusões}

Os resultados levam à conclusão de que investimentos públicos impulsionam o produto mas contraem investimento privado. Independentemente de ciclo político, olhando apenas para os resultados do modelo linear, o choque de $\mathrm{R} \$ 1$ em $I_{g}$ causa uma retração média de $0,5^{1}$ em $I_{p}$ em um período de 11 meses. ${ }^{2}$ Ao passo que o mesmo choque gera uma expansão média de 0,68 em $Y$ no período de 5 meses. Ou seja, o tempo de impacto significativo no segundo caso é aproximadamente a metade do primeiro enquanto que seu impacto médio é $36 \%$ maior. Por outro lado, observou-se que o choque em $I_{p}$ gera impactos altos, persistentes e significantes sobre o produto, tendo uma média de 1,06 e sendo significante durante todo o período analisado.

Antes de prosseguir com o raciocínio, cabe destacar que esses argumentos são traçadas a partir de simples contas das FIRs, logo, não se pretende designar a esses valores importância além do que se sugere: uma análise das relações macroeconômicas evidenciadas no modelo econométrico.

Resumindo, o que se pretende defender é que, aparentemente, os benefícios da política fiscal são menores que seus custos diretos e indiretos. Os benefícios são os efeitos positivos sobre o crescimento, que duram um pouco mais de 5 meses. Os custos diretos são, principalmente, a concorrência por recursos que se insere junto ao mercado, o denominado crowding-out, cuja resposta é significativa por 11 meses. O custo indireto é, em última instância, um custo de oportunidade: como o "multiplicador privado é maior que o multiplicador fiscal (evidenciado pela magnitude das respostas frente a um mesmo choque), para cada real a mais aplicado pelo governo, há menos recursos a serem investidos pelo setor privado e, portanto, menos potencial de crescimento através da relação entre essas variáveis.

Não obstante, vale ressaltar que os investimentos da Administração Pública correspondem, em média, a apenas $11,6 \%$ da FBCF total ${ }^{3}$, logo, na tual conjuntura, essa variável já não tem grandeza suficiente para surtir impactos significativos sobre a renda. Ou seja, em média, cerca de apenas $2 \%$ da renda corresponde a investimentos da APU. Assim sendo, a capacidade do investimento público de puxar o crescimento já é reduzida por uma simples questão de magnitude.

Expostos esses argumentos, surge o questionamento sobre qual a política fiscal ótima. Este trabalho sugere que a resposta deve ser elaborada tendo em consideração dois pontos principais: características do processo orçamentário e ciclo político.

$\overline{1}$ Não se pode confundir esses valores com multiplicadores fiscais, esses são apenas uma representação das respostas estimadas.

2 Análise da trajetória da função de impulso resposta considerando apenas o intervalo de significância estatística.

3 Esta historicamente baixa no Brasil. Média de 18,8\% do PIB de 2000 a 2014, de acordo com as CNTs do IBGE. 
Se o conceito de restrição orçamentária fosse levado a sério no setor público brasileiro, faria sentido reduzir o investimento público para o nível mínimo, focando principalmente nos projetos de infraestrutura que não podem ser conduzidos pelo mercado, pois necessitam de um amparo estatal. E isso seria uma decisão baseada no conceito de eficiência, independente de viés político.

O contra-argumento é que, mesmo menos eficiente do que aqueles provindo do setor privado, os gastos públicos em despesas de capital ainda são mais justificáveis, do ponto de vista social, do que diversos outros gastos que os governos federal, estadual e municipal incorrem. Há custos de oportunidade na relação entre gasto privado e gasto público mas também na relação entre os tipos de gasto do governo. Este trabalho não analisa a eficiência de outros gastos governamentais, tampouco consegue diferenciar os diversos tipos de investimento. A extensão dessa pesquisa poderia ser feita explorando esses pontos.

Mesmo que este trabalho não tenha analisado outros dados da despesa pública, pode-se afirmar que o investimento público é uma variável de ajuste, mais volátil que outros tipos de gastos e mais vulnerável a decisões de política econômica cunhadas em fatores políticos. É inevitável que, sob essa linha de raciocínio, se associe os resultados encontrados aos modelos teóricos de ciclos políticos oportunistas. Nordhaus (1975) salienta que pode haver uma correspondência entre investimentos governamentais e a existência de interesses oportunistas da classe política.

Denominou-se aqui o termo ajuste fiscal institucionalizado (que será melhor discutido adiante), que é o fenômeno de penalização dos investimentos em momentos póseleitorais de maneira sistemática. A legislação vigente protege determinados gastos, as despesas de capital, entretanto, não gozam dessa proteção.

A característica de expansão pré-eleitoral das despesas de capital encontrada neste trabalho também é evidenciada por outros estudos, como Schuknecht (2000), Khemani (2004) e Eslava (2006), para um painel de países em desenvolvimento, Índia e Colômbia, respectivamente. Com relação ao segundo ponto, tanto os resultados do Modelo Estrutural quanto do STVAR indicam que a volatilidade advinda do ciclo político piora o clima de negócios e, por conseguinte, o desenvolvimento econômico. Desse modo, medidas devem ser tomadas para que o investimento público não seja vítima do ajuste fiscal pós-eleitoral que se instalou no país.

Antes de analisar os resultados do modelo não-linear, vale chamar a atenção para os dois gráficos abaixo. O primeiro se refere à variável de transição $z$ do modelo STVAR, que é a primeira diferença do componente agregado dos ciclos obtido pelo Modelo Estrutural. O segundo diz respeito à variável de investimento público da APU, a mesma que se utilizou no VAR, defasada uma vez de ano para ano. 
Figura 17 - Variável de transição

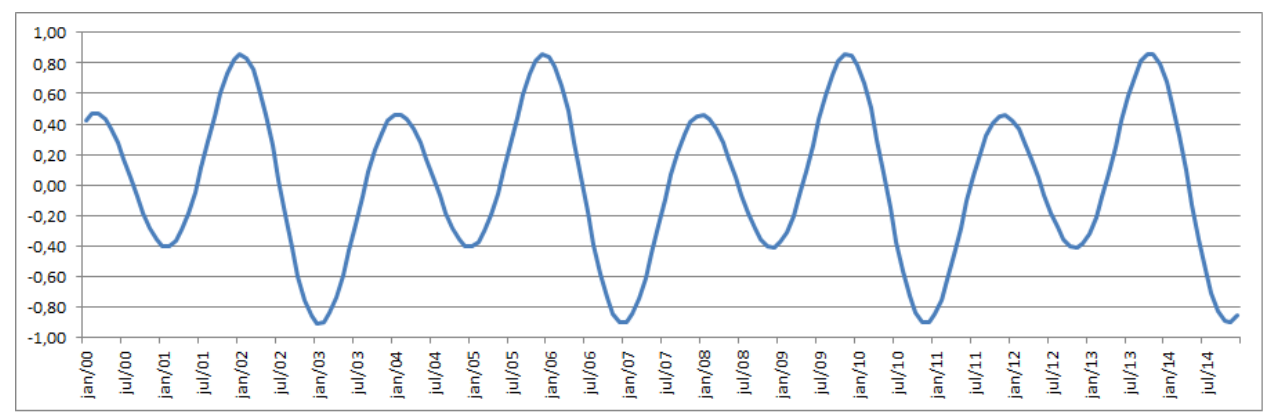

Fonte: Elaboração própria.

Figura 18 - Investimento da APU

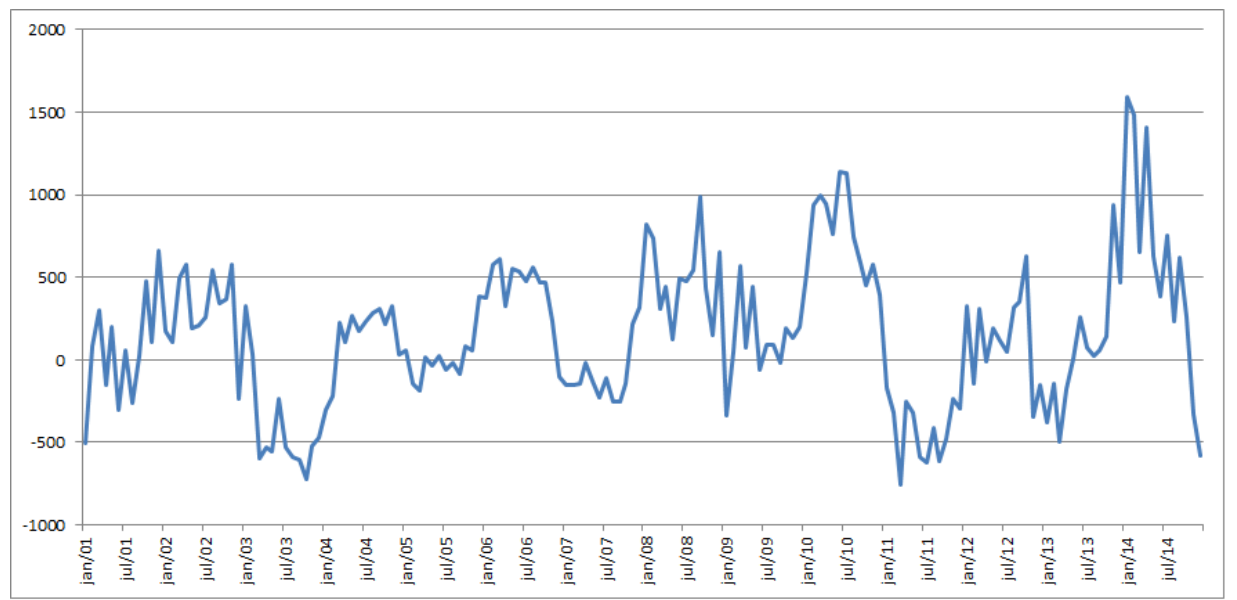

Fonte: IBGE, Contas Nacionais Trimestrais; Dimac/Ipea. Série defasada.

Note que, no primeiro gráfico, os intervalos nos quais a função apresenta valores positivos são os denominados períodos pré-eleitorais, de expansão do ciclo, o análogo valendo para o período pós-eleitoral. Os períodos de expansão fiscal se encerram um pouco antes das eleições, em média entre junho e julho. Em contrapartida, pelo segundo gráfico, observa-se um padrão claro de expansão do investimento público ${ }^{4} \mathrm{em}$ anos pares e contração em anos ímpares. Em média, o ritmo dessa expansão começa a cair entre os meses de outubro e novembro, sendo que o ponto de inflexão ocorre, em média, entre novembro e dezembro. Note que o ano de 2009 foi um dos únicos na história recente em que não houve um ajuste fiscal sobre o investimento público ${ }^{5}$. Inclusive, essa variável atingiu níveis recordes, alcançando aproximadamente $4 \%$ do PIB, considerando os investimentos da APU e também de empresas estatais. A decisão de não cortar os investimentos públicos foi motivada pela percepção do governo federal de que era necessário estimular a economia diante da crise internacional. Como foi um período atípico, refletindo nos dados de despesa e produção, inclui-se no VAR uma variável dummy como controle. Em suma, os dois gráficos não podem ser justapostos uma vez que o primeiro é a primeira diferença dos componentes

4 A série analisada é aquele cujos componentes sazonais já foram expurgados pelo ajuste ARIMA X13.

$5 \quad$ Além de 2009, apenas 2005. 
cíclicos do mês $t$ em relação ao mês $t-1$ do mesmo ano. No segundo, por sua vez, a defasagem é realizada comparando o mês $t$ do ano $T$ com o mesmo mês do ano $T-1$.

No regime pré-eleitoral, a resposta do investimento privado frente a um choque em $I_{g}$ é sempre negativa e significante durante todo o intervalo. Note que, com a exceção dos meses de 6 a 11, a resposta é inferior a obtida pelo modelo linear. Ou seja, os investimentos públicos puxam o investimento privado para baixo, há uma relação de substituição entre as variáveis, comprometendo a FBCF como um todo.

No regime pós-eleitoral, a resposta do $I_{p}$ frente a um choque de $\mathrm{R} \$ 1$ no $I_{g}$ começa positiva e depois de um trimestre se torna negativa, sendo significativa em todo o intervalo. Conclui-se, portanto, pelo fenômeno de crowding-out, pelo diagnóstico das FIRs. O período pós-eleitoral, contudo, deve ser estudado com ressalvas: esse período é caracterizado por ajuste fiscal, sendo que os choques provindos do setor público quanto a despesas de capital são, na verdade, negativos. Isto é, deve-se olhar para a FIR no período pós-eleitoral com o sinal invertido, projetando uma função simétrica ao eixo X. Fazendo isso, tem que o investimento privado, apesar de cair no primeiro trimestre, responde positivamente ao ajuste fiscal em $I_{g}$. Em outras palavras, a expansão fiscal é contracionista, enquanto o ajuste fiscal é expansionista, sob o ponto de vista da FBCF. Por outro lado, a resposta do PIB a um choque do $I_{g}$ é positiva e significante a partir do $3^{\circ}$ mês do período pré-eleitoral, indicando que a política fiscal é eficiente na promoção do crescimento nesse tipo de regime. Entretanto, no período pós-eleitoral (o raciocínio análogo à FIR do investimento privado é aqui aplicado), o ajuste fiscal não causa recessão, pelo contrário, este é expansionista.

Esse tipo de conclusão é condizente com os resultados encontrados por Giavazzi e Pagano (1990) e Alesina e Ardagna (2012), que encontram episódios de ajustes fiscais expansionistas. Acredita-se que o principal canal pelo qual o fenômeno ocorre seria a confiança transmitida a consumidores e investidores.

Deve-se ter em mente que não se pretende atribuir aos multiplicadores fiscais estimados no modelo não-linear importância maior que os do modelo linear. O objetivo é testar a sensibilidade das relações macroeconômicas frente ao ciclo político e entender como que as mesmas políticas tomadas em tempos distintos geram diferentes resultados. Assim sendo, este trabalho conclui que a política fiscal exerce diferentes impactos na economia quando se considera o cenário político.

A FBCF do setor privado no Brasil parece ser altamente influenciada por questões políticas de curto prazo (quem será o novo presidente da República, por exemplo), uma vez que investigadas as consequências de choques fiscais sobre o investimento privado sob o ponto de vista pré e pós eleitoral.

Teoricamente, o Estado, ao realizar investimentos, aumenta a capacidade produtiva, melhora o ambiente de negócios, reduz os custos de produção das empresas e projeta 
para o futuro ganhos difusos mais que proporcionais à despesa incorrida. Entretanto, é imprescindível que esses investimentos governamentais sejam produtivos, caso contrário, os empresários não terão incentivos para expandir suas atividades. Os resultados deste trabalho indicam que tampouco parece haver confiança do setor privado no governo, nesse sentido.

Em suma, a execução dos investimentos públicos no Brasil é altamente influenciada pelo calendário eleitoral implicando em consequências para a formação de capital do país como um todo assim como para o crescimento econômico. Há uma clara assimetria dos multiplicadores fiscais nos períodos antes e depois das eleições, indicando que questões políticas estão influenciando resultados econômicos em uma magnitude a nível nacional.

Cabe ressaltar que o impacto do investimento do setor privado sobre o produto nacional não apresenta essa clivagem, pelo contrário, as três respostas estimadas têm uma mesma tendência e indicam que a capacidade dos investimentos privados em alavancar o crescimento econômico é consideravelmente elevada (ver Figura (12)). Pode-se dizer que a capacidade do investimento em gerar efeitos positivos sobre o produto é maior no setor privado do que no setor público. Os resultados indicam que existe o efeito keynesiano de multiplicador fiscal maior que a unidade, entretanto, este é instável perante o momento político. Por outro lado, a constatação de crowding-out dos investimentos privados é condizente com os modelos neoclássicos.

Pode-se concluir, portanto, que as implicações deste estudo para a elaboração de políticas públicas que pensem no desenvolvimento do país seria no sentido de pensar em um sistema que minimize o ciclo político. Uma alternativa seria separar o orçamento de capital do orçamento corrente, de modo que se garanta que os projetos sejam de fato executados sem descontinuidade e sem ciclicidade.

Isso pois se observa no Brasil uma espécie de "ajuste fiscal institucionalizado", caracterizado por expansões do investimento público no período pré-eleitoral e contrações no pós-eleitoral. Esses resultados vão de acordo com o modelo teórico de ciclos políticos orçamentários

Idealmente, se gostaria que prevalecesse o fenômeno de crowding-in, ou seja, investimentos do setor público e privado sendo complementares e gerando efeitos (diretos e indiretos) sempre positivos sobre crescimento. Aparentemente, esse não é o caso para a economia brasileira, na verdade, o que se pode concluir desta pesquisa é que o Brasil precisa de "mais mercado" e "menos Estado". 



\section{Referências}

AIDT, T. S.; VEIGA, F. J.; VEIGA, L. G. Election Results and Opportunistic Policies: An Integrated Approach. NIPE Working Papers. NIPE - Universidade do Minho, 2007.

AIYAGARI, S. R.; CHRISTIANO, L. J.; EICHENBAUM, M. The output, employment, and interest rate effects of government consumption. Journal of Monetary Economics, v. 30, n. 1, p. 73-86, 1992.

ALESINA, A.; FAVERO, C.; GIAVAZZI, F. The Output Effect of Fiscal Consolidations. NBER Working Papers. National Bureau of Economic Research, Inc, 2012.

ALESINA, A.; ROUBINI, N. Political Cycles in OECD Economies. Review of Economic Studies, v. 59, n. 4, p. 663-88, 1992.

ALESINA, A. F.; ARDAGNA, S. The design of fiscal adjustments. NBER Working Papers. National Bureau of Economic Research, Inc, 2012.

AlEsina, N. R. A.; COHEN, G. Political Cycles and the Macroeconomy. Cambridge, MA: MIT Press, 1997.

ALMUNIA, M. et al. From Great Depression to Great Credit Crisis: Similarities, Differences and Lessons. The Institute for International Integration Studies Discussion Paper Series. IIIS, 2009.

AUERBACH, A. J.; GORODNICHENKO, Y. Fiscal Multipliers in Recession and Expansion. NBER Working Papers. National Bureau of Economic Research, Inc, 2011.

AUERBACH, A. J.; GORODNICHENKO, Y. Measuring the Output Responses to Fiscal Policy. American Economic Journal: Economic Policy, v. 4, n. 2, p. 1-27, 2012.

AUERBACH, A. J.; GORODNICHENKO, Y. Fiscal Multipliers in Japan. NBER Working Papers. National Bureau of Economic Research, Inc, 2014.

BACHMANN, R.; SIMS, E. R. Confidence and the transmission of government spending shocks. Journal of Monetary Economics, v. 59, n. 3, p. 235-249, 2012.

BARRO, R. J. Are Government Bonds Net Wealth? Journal of Political Economy, v. 82, n. 6, p. 1095-1117, 1974.

BARRO, R. J. Output Effects of Government Purchases. Journal of Political Economy, v. 89, n. 6, p. 1086-1121, 1981.

BARRO, R. J. Government spending, interest rates, prices, and budget deficits in the United Kingdom, 1701-1918. Journal of Monetary Economics, v. 20, n. 2, p. 221-247, 1987.

BARRO, R. J. The Ricardian Approach to Budget Deficits. Journal of Economic Perspectives, v. 3, n. 2, p. 37-54, 1989.

BAUM, A.; POPLAWSKI-RIBEIRO, M.; WEBER, A. Fiscal Multipliers and the State of the Economy. IMF Working Papers. International Monetary Fund, 2012.

BAXTER, M.; KING, R. G. Fiscal Policy in General Equilibrium. American Economic Review, v. 83, n. 3, p. 315-34, 1993. 
BLANCHARD, O.; PEROTTI, R. An Empirical Characterization Of The Dynamic Effects Of Changes In Government Spending And Taxes On Output. The Quarterly Journal of Economics, v. 117, n. 4, p. 1329-1368, 2002.

BLOCK, S. A. Political business cycles, democratization, and economic reform: the case of Africa. Journal of Development Economics, v. 67, n. 1, p. 205-228, 2002.

BOnOMO, M.; TERRA, C. The Political Economy of Exchange Rate Policy in Brazil: 1964-199\%. Research Department Publications. Inter-American Development Bank, Research Department, 1999.

BRENDER, A.; DRAZEN, A. Political budget cycles in new versus established democracies. Journal of Monetary Economics, v. 52, n. 7, p. 1271-1295, 2005.

BURNSIDE, C.; EICHENBAUM, M.; FISHER, J. D. M. Fiscal shocks and their consequences. Journal of Economic Theory, v. 115, n. 1, p. 89-117, 2004.

BURRIEL, P. et al. Fiscal Multipliers in the Euro Area. Revista de Economía y Estadística, v. 0, n. 2, p. 727, 2010.

CAVAlCANTI, M. A.; SILVA, N. L. Dívida pública, política fiscal e nível de atividade: uma abordagem var para o brasil no período 1995-2008. Economia Aplicada, v. 14, p. 391-418, 2010.

CHERNOZHUKOV, V.; HONG, H. An MCMC approach to classical estimation. Journal of Econometrics, v. 115, n. 2, p. 293-346, 2003.

CHOLETTE, P. A. Adjusting sub-annual series to yearly benchmarks. Survey Methodology, v. 10, p. 35-49, 1984.

CHRISTIANO, L.; EICHENBAUM, M.; REBELO, S. When Is the Government Spending Multiplier Large? Journal of Political Economy, v. 119, n. 1, p. 78 - 121, 2011.

CLOYNE, J. What are the Effects of Tax Changes in the United Kingdom? New Evidence from a Narrative Evaluation. CESifo Working Paper Series. CESifo Group Munich, 2011.

COEnen, G.; STRAUB, R.; TRABAnDT, M. Fiscal Policy and the Great Recession in the Euro Area. American Economic Review, v. 102, n. 3, p. 71-76, 2012.

CORSETTI, G.; MEIER, A.; MLLER, G. J. What determines government spending multipliers? Economic Policy, v. 27, n. 72, p. 521-565, 2012.

COS, P. H. de; MORAL-BENITO, E. Fiscal multipliers in turbulent times: the case of Spain. Banco de Espaa Working Papers. Banco de Espaa, 2013.

DENTON, F. Adjustment of montly or quarterly series to annual totals: An approach based on quadratic minimization. Journal of the American Statistical Association, v. 66, n. 333, p. 99-102, 1971.

DRAZEN, A. The Political Business Cycle After 25 Years. In: NBER Macroeconomics Annual 2000, Volume 15. [S.l.]: National Bureau of Economic Research, Inc, 2001, (NBER Chapters). p. 75-138. 
DURBIN, J.; KOOPMAN, S. An efficient and simple simulation smoother for state space time series analysis. Computing in Economics and Finance. Society for Computational Economics, 2001.

EBEKE, C.; LCER, D. ã. Fiscal Policy over the Election Cycle in Low-Income Countries. IMF Working Papers. International Monetary Fund, 2013.

EDELBERG, W.; EICHENBAUM, M.; FISHER, J. D. Understanding the Effects of a Shock to Government Purchases. Review of Economic Dynamics, v. 2, n. 1, p. 166-206, 1999.

EGGERTSSON, G. B.; KRUGMAN, P. Debt, Deleveraging, and the Liquidity Trap: A Fisher-Minsky-Koo Approach. The Quarterly Journal of Economics, v. 127, n. 3, p. 1469-1513, 2012.

ENDERS, W. Applied econometric time series. 3. ed. New Jersey: Wiley, 2010.

ESLAVA, M. Ciclos políticos de la política fiscal con votantes opuestos al dficit. El caso colombiano. El Trimestre Económico, v. 0, n. 290, p. 289-336, 2006.

FATÁS, A.; MIHOV, I. Fiscal Policy and Business Cycles:An Empirical Investigation. CEPR Discussion Papers, 2001.

FATÁS, A.; MIHOV, I. The Effects of Fiscal Policy on Consumption and Employment: Theory and Evidence. CEPR Discussion Papers, 2001.

FATÁS, A.; MIHOV, I. The Case For Restricting Fiscal Policy Discretion. The Quarterly Journal of Economics, v. 118, n. 4, p. 1419-1447, 2003.

FAVERO, C. A.; GIAVAZZI, F. Reconciling VAR-based and Narrative Measures of the Tax-Multiplier. Working Papers. IGIER (Innocenzo Gasparini Institute for Economic Research), Bocconi University, 2010.

FRIEDMAN, M. A Theory of the Consumption Function. Princeton: Princeton University Press, 1957.

GALÍ, J.; LÓPEZ-SALIDO, J. D.; VALLS, J. Understanding the Effects of Government Spending on Consumption. Journal of the European Economic Association, v. 5, n. 1, p. 227-270, 2007.

GIAVAZZI, F.; PAGANO, M. Can Severe Fiscal Contractions Be Expansionary? Tales of Two Small European Countries. CEPR Discussion Papers, 1990.

GOBETTI, S. Estimativa dos investimentos públicos: um novo modelo de análise da execução orçamentária aplicado s contas nacionais. In: SECRETARIA DO TESOURO NACIONAL (STN). Finanças Públicas. XI Prêmio Tesouro Nacional de Monografias em 2006. Brasília: Editora da Universidade de Brasília, 2007.

GORDON, R. J.; KRENN, R. The End of the Great Depression 1939-41: Policy Contributions and Fiscal Multipliers. NBER Working Papers. National Bureau of Economic Research, Inc, 2010.

GRANGER, C. W.; TERASVIRTA, T.; ANDERSON, H. M. Modeling Nonlinearity over the Business Cycle. In: Business Cycles, Indicators and Forecasting. [S.l.]: National Bureau of Economic Research, Inc, 1993, (NBER Chapters). p. 311-326. 
HALL, R. E. By How Much Does GDP Rise If the Government Buys More Output? Brookings Papers on Economic Activity, v. 40, n. 2, p. 183-249, 2009.

HAMILTON, J. D. Historical Causes of Postwar Oil Shocks and Recessions. The Energy Journal, v. 0, n. 1, p. 97-116, 1985.

HANSEN, A. Monetary Theory and Fiscal Policy. New York: McGraw-Hill, 1949.

HANSEN, A. A Guide to Keynes. New York: New York, 1953.

HAYO, B.; UHL, M. The macroeconomic effects of legislated tax changes in Germany. Oxford Economic Papers, v. 66, n. 2, p. 397-418, 2014.

HIBBS, D. Political Parties and Macroeconomic Policy. The American Political Science Review, 1977.

HIBBS, D. Political Parties and Macroeconomic Policies and Outcomes in the United States. American Economic Reuiew Papers and Proceedings, v. 76, n. 2, p. 66-70, 1986.

HICKS, J. Mr. keynes and the classics: a suggested interpretation. Econometrica, 1937.

ILZETZKI, E.; MENDOZA, E. G.; VGH, C. A. How big (small?) are fiscal multipliers? Journal of Monetary Economics, v. 60, n. 2, p. 239-254, 2013.

JESUS, C. S. de. A Macroeconomia da Política Fiscal: modelo dinâmico e evidências para o Brasil. Tese (Doutorado) — UFPR, 2011.

KALECKI, M. Political aspects of full employment. Political Quarterly, v. 14, 1943.

KEYNES, J. M. A Teoria Geral do Emprego, do Juro e da Moeda. São Paulo: Atlas, 1936.

KHEMANI, S. Political cycles in a developing economy: effect of elections in the Indian States. Journal of Development Economics, v. 73, n. 1, p. 125-154, 2004.

KIRCHNER, M.; CIMADOMO, J.; HAUPTMEIER, S. Transmission of government spending shocks in the euro area: Time variation and driving forces. Working Paper Series. European Central Bank, 2010.

KRUEGER, A.; TURAN, I. The politics and economics of turkish policy reform in the 1980's. In: BATES, R.; KRUEGER, A. (Ed.). Political and Economic Interactions in Economic Policy Reform: Evidence from Eight Countries. Oxford: Basil Blackwell, 1993.

LEIGH, D.; PESCATORI, A.; GUAJARDO, J. Expansionary Austerity New International Evidence. IMF Working Papers. International Monetary Fund, 2011.

LIPPI, M.; REICHLIN, L. VAR analysis, non-fundamental representations, Blashke matrices. ULB Institutional Repository. ULB - Universite Libre de Bruxelles, 1994.

LONG, J. B. D.; SUMMERS, L. H. Equipment Investment and Economic Growth. The Quarterly Journal of Economics, v. 106, n. 2, p. 445-502, 1991.

LUCAS, R. J. Expectations and the neutrality of money. Journal of Economic Theory, v. 4, n. 2, p. 103-124, 1972.

MANKIW, N. G. The Savers-Spenders Theory of Fiscal Policy. American Economic Review, v. 90, n. 2, p. 120-125, 2000. 
MCCALLUM, B. The political business cycle: an empirical test. Southern Journal of Economics, v. 44, p. 504-15, 1978.

MERTENS, K.; RAVN, M. O. A reconciliation of SVAR and narrative estimates of tax multipliers. Journal of Monetary Economics, v. 68, n. 68 (S), p. S1-S19, 2014.

MODIGLIANI, F. Liquidity preference and the theory of interest and money. Econometrica, v. 12, p. 45-88, 1944.

MONACELLI, T.; PEROTTI, R.; TRIGARI, A. Unemployment fiscal multipliers. Journal of Monetary Economics, v. 57, n. 5, p. 531-553, 2010.

MONOKROUSSOS, P.; THOMAKOS, D. Fiscal multipliers in deep economic recessions and the case for a 2?year extension in Greeces austerity programme. Economy 8 Markets, VIII, n. 4, 2012.

MOUNTFORD, A.; UHLIG, H. What are the effects of fiscal policy shocks? Journal of Applied Econometrics, v. 24, n. 6, p. 960-992, 2009.

NORDHAUS, W. D. The Political Business Cycle. Review of Economic Studies, v. 42, n. 2, p. 169-90, 1975.

OHLSSON, H.; VREDIN, A. Political Cycles and Cyclical Policies. Scandinavian Journal of Economics, v. 98, n. 2, p. 203-18, 1996.

ONU. System of National Accounts. New York: [s.n.], 1993.

ORAIR, R. O.; GOUVÊA, R. R.; LEAL sio M. Ciclos políticos eleitorais e investimentos das Administrações Públicas. Texto para Discussão 1999 Ipea. Brasília, 2014.

PAIVA, C. Interesses eleitorais e flutuações de preços em mercados regulados. Rei;isfa de Economia PoMca,, v. 4, n. 56, p. 31 -4, 1994.

PERES, M. A. F. Os efeitos dinâmicos da política fiscal sobre a atividade econômica: um estudo para o caso brasileiro. Brasília: XII Prêmio do Tesouro Nacional. Secretaria do Tesouro Nacional, 2007.

PERES, M. A. F. Dinâmica dos Choques Fiscais no Brasil. Tese (Doutorado) Universidade de Brasília, 2012.

PEROTTI, R. Estimating the effects of fiscal policy in OECD countries. Working Papers. IGIER (Innocenzo Gasparini Institute for Economic Research), Bocconi University, 2004.

Persson, T.; TABELlini, G. Macroeconomic Policy, Credibility, and Politics. Switzerland: Harwood Academic Publishers, 1990.

PIRES, M. Política fiscal e ciclos econômicos no brasil. Economia Aplicada, v. 18, n. 1, p. 69-90, 2014.

PREUSSLER, A.; PORTUGAL, M. Um estudo empírico dos ciclos político-econômicos no brasil. Análise Econômica, v. 40, 2003.

QAZIZADA, W.; STOCKHAMMER, E. Government spending multipliers in contraction and expansion. International Review of Applied Economics, v. 29, n. 2, p. 238-258, 2015. 
RAMEY, V. A. Identifying Government Spending Shocks: It's all in the Timing. The Quarterly Journal of Economics, v. 126, n. 1, p. 1-50, 2011.

RAMEY, V. A.; SHAPIRO, M. D. Costly capital reallocation and the effects of government spending. Carnegie-Rochester Conference Series on Public Policy, v. 48, n. 1, p. $145-194,1998$.

RAMEY, V. A.; ZUBAIRY, S. Government Spending Multipliers in Good Times and in Bad: Evidence from U.S. Historical Data. NBER Working Papers. National Bureau of Economic Research, Inc, 2014.

RAVNIK, R.; ZILIC, I. The use of svar analysis in determining the effects of fiscal shocks in croatia. Financial Theory and Practice, v. 35, p. 25-58, 2011.

ROGOFF, K. Equilibrium Political Budget Cycles. American Economic Review, v. 80, n. 1, p. 21-36, 1990.

ROGOFF, K.; SIBERT, A. Elections and Macroeconomic Policy Cycles. Review of Economic Studies, v. 55, n. 1, p. 1-16, 1988.

ROMER, C. D. What Ended the Great Depression? The Journal of Economic History, v. 52, n. 04 , p. $757-784,1992$.

ROMER, C. D.; ROMER, D. H. New Evidence on the Monetary Transmission Mechanism. Brookings Papers on Economic Activity, v. 21, n. 1, p. 149-214, 1990.

ROMER, C. D.; ROMER, D. H. The Macroeconomic Effects of Tax Changes: Estimates Based on a New Measure of Fiscal Shocks. American Economic Review, v. 100, n. 3, p. 763-801, 2010.

SAKURAI, S.; MENEZES-FILHO, N. Opportunistic and partisan election cycles in Brazil: new evidence at the municipal level. Public Choice, v. 148, n. 1, p. 233-247, 2011.

SAKURAI, S. N.; GREMAUD, A. P. Political Business Cycles: Evidências Empíricas Para Os Municípios Paulistas (1989 - 2001). Anais do XXXII Encontro Nacional de Economia [Proceedings of the 32th Brazilian Economics Meeting]. ANPEC - Associação Nacional dos Centros de Pósgraduação em Economia [Brazilian Association of Graduate Programs in Economics], 2004.

SANTOS, C. H. M. dos et al. Uma metodologia de estimação da formação bruta de capital fixo das administrações públicas brasileiras em níveis mensais para o período 2002-2010. Texto para Discussão 1660 Ipea. Brasília, 2011.

SCHETTINI, B. P. et al. Resultado estrutural e impulso fiscal: uma aplicação para as administrações públicas no Brasil, 1997-2010. Texto para Discussão 1650 Ipea. Brasília, 2011.

SCHUKNECHT, L. Political Business Cycles and Fiscal Policies in Developing Countries. Kyklos, v. 49, n. 2, p. 155-70, 1996.

SCHUKNECHT, L. Fiscal policy cycles and public expenditure in developing countries. Public Choice, v. 102, n. 1-2, p. 115-30, 2000. 
SHI, M.; SVEnSSON, J. Conditional Political Budget Cycles. CEPR Discussion Papers, 2002 .

SNOWDOW, B.; VANE, H. Modern macroeconomics: its origins, development and current state. Northampton: Edward Elgar, 2005.

SQUEFF, G. Dinâmica Macrosetorial Brasileira. Brasília: Ipea, 2015.

UHLIG, H. What are the effects of monetary policy on output? Results from an agnostic identification procedure. Journal of Monetary Economics, v. 52, n. 2, p. 381-419, 2005.

UNAL, U. Rethinking the Effects of Fiscal Policy on Macroeconomic Aggregates: A Disaggregated SVAR Analysis. Working Papers. Florida International University, Department of Economics, 2011.

VERGNE, C. Democracy, elections and allocation of public expenditures in developing countries. European Journal of Political Economy, v. 25, n. 1, p. 63-77, 2009.

WARMEDINGER, T.; WESTPHAL, C. C.; COS, P. Hernández de. Fiscal multipliers and beyond. Working Paper Series. European Central Bank, 2015.

WOODFORD, M. Simple Analytics of the Government Expenditure Multiplier. American Economic Journal: Macroeconomics, v. 3, n. 1, p. 1-35, 2011. 



\section{Apêndices}

\subsection{Testes de Raiz Unitária}

Os testes de raiz unitária foram feitos para os métodos Dickey-Pantula, Augmented Dickey-Fuller, DF-GLS, NG-Perron e KPSS. Por questões de espaço, a totalidade dos testes não foi reportada, optando por manter apenas o modelo final estimado. Seguiu-se o roteiro convencional de especificação da forma funcional.

A tabela (11) resume as estatísticas dos testes de raiz unitária, ressalta-se que, em todos os testes, não se pode rejeitar a hipótese de raiz unitária para as séries de investimento público, investimento privado e produto interno bruto. Antes da realização destes, realizou-se o teste Dickey-Pantula, com a hipótese nula de duas raízes unitárias ${ }^{1}$. Rejeitou-se a presença de duas raízes unitárias, mas não de uma.

Tabela 11 - Resumo dos testes de raiz unitária

\begin{tabular}{rrlrr}
\hline & ADF & DF-GLS & NG-Perron & KPSS \\
\hline Investimento Público & 0.146019 & -2.15253 & -2.35502 & 1.549494 \\
Investimento Privado & -0.90509 & -2.3997 & -2.09838 & 1.615165 \\
Produto Interno Bruto & -0.36732 & -1.58705 & -1.58904 & 1.716732 \\
\hline
\end{tabular}

$\overline{1}$ Séries temporais econômicas têm, em geral, no máximo duas raízes unitárias, por isso optou-se por essa especificação. 
Tabela 12 - ADF Investimento público

Null Hypothesis: IG has a unit root

Exogenous: None

Lag Length: 3 (Automatic based on SIC, MAXLAG=12)

\begin{tabular}{llll}
\hline \hline & t-Statistic & Prob. $^{*}$ \\
\hline \hline Augmented Dickey-Fuller test statistic & 0.146019 & 0.7272 \\
Test critical values: $\quad 1 \%$ level & -2.57817 & \\
& $5 \%$ level & -1.94265 & \\
& $10 \%$ level & -1.6155 & \\
\hline \hline
\end{tabular}

*MacKinnon (1996) one-sided p-values.

Augmented Dickey-Fuller Test Equation

Dependent Variable: D(IG)

Method: Least Squares

Sample (adjusted): 2000M05 2014M12

Included observations: 176 after adjustments

\begin{tabular}{lllll}
\hline \hline & Coefficient & Std. Error & t-Statistic & Prob. \\
\hline \hline IG(-1) & 0.001202 & 0.008234 & 0.146019 & 0.8841 \\
$\mathrm{D}(\mathrm{IG}(-1))$ & -0.50405 & 0.078329 & -6.43496 & 0 \\
$\mathrm{D}(\mathrm{IG}(-2))$ & -0.09907 & 0.088803 & -1.11559 & 0.2662 \\
$\mathrm{D}(\mathrm{IG}(-3))$ & 0.172972 & 0.077177 & 2.241226 & 0.0263 \\
\hline \hline R-squared & 0.252957 & Mean dependent var & 7.220198 \\
Adjusted R-squared & 0.239928 & S.D. dependent var & 248.7044 \\
S.E. of regression & 216.8258 & Akaike info criterion & 13.61853 \\
Sum squared resid & 8086312 & Schwarz criterion & 13.69059 \\
Log likelihood & -1194.43 & Hannan-Quinn criter. & 13.64776 \\
Durbin-Watson stat & 1.905587 & & & \\
\hline
\end{tabular}


Tabela 13 - DF-GLS Investimento Público

\begin{tabular}{|c|c|}
\hline \multicolumn{2}{|c|}{$\begin{array}{l}\text { Null Hypothesis: IG has a unit root } \\
\text { Exogenous: Constant, Linear Trend } \\
\text { Lag Length: } 3 \text { (Automatic based on SIC, MAXLAG=13) }\end{array}$} \\
\hline & t-Statistic \\
\hline Elliott-Rothenberg-Stock DF-GLS test statistic & -2.3997 \\
\hline Test critical values: $1 \%$ level & -3.4888 \\
\hline $5 \%$ level & -2.954 \\
\hline $10 \%$ level & -2.664 \\
\hline
\end{tabular}

*Elliott-Rothenberg-Stock (1996, Table 1)

Tabela 14 - NG-Perron Investimento Público

Null Hypothesis: IG has a unit root

Exogenous: Constant, Linear Trend

Lag length: 3 (Spectral GLS-detrended AR based on SIC, MAXLAG=13)

Sample: 2000M01 2014M12

Included observations: 180

\begin{tabular}{llllll}
\hline \hline & & MZa & MZt & MSB & \multicolumn{1}{c}{ MPT } \\
\hline \hline Ng-Perron test statistics & & -11.3344 & -2.35502 & 0.20778 & 8.17598 \\
Asymptotic critical values*: & $1 \%$ & -23.8 & -3.42 & 0.143 & 4.03 \\
& $5 \%$ & -17.3 & -2.91 & 0.168 & 5.48 \\
& $10 \%$ & -14.2 & -2.62 & 0.185 & 6.67 \\
\hline \hline \multirow{2}{*}{ Ng-Perron (2001, Table 1) } & & & \\
\hline HAC corrected variance (Spectral GLS-detrended AR) & & 26113.79 \\
\hline
\end{tabular}

Tabela 15 - KPSS Investimento Público

Null Hypothesis: IG is stationary

Exogenous: Constant

Bandwidth: 10 (Newey-West using Bartlett kernel)

\begin{tabular}{lcc}
\hline \hline & LM-Stat. \\
\hline \hline Kwiatkowski-Phillips-Schmidt-Shin test statistic & 1.549494 \\
Asymptotic critical values*: & 1\% level & 0.739000 \\
& $5 \%$ level & 0.463000 \\
& $10 \%$ level & 0.347000 \\
\hline \hline
\end{tabular}

*Kwiatkowski-Phillips-Schmidt-Shin (1992, Table 1)

Os testes de raiz unitária foram todos realizados no EViews. Os que tiveram os resultados aqui reportados têm a implementação direta no software, os testes de Dickey- 
Tabela 16 - ADF Investimento Privado

Null Hypothesis: IP has a unit root

Exogenous: Constant

Lag Length: 0 (Automatic based on SIC, MAXLAG=12)

\begin{tabular}{llcc}
\hline \hline & t-Statistic & Prob. $^{*}$ \\
\hline \hline Augmented Dickey-Fuller test statistic & -0.90509 & 0.7849 \\
Test critical values: $\quad$ 1\% level & -3.46699 & \\
& $5 \%$ level & -2.87754 & \\
$10 \%$ level & -2.57538 & \\
\hline \hline
\end{tabular}

*MacKinnon (1996) one-sided p-values.

Augmented Dickey-Fuller Test Equation

Dependent Variable: D(IP)

Method: Least Squares

Sample (adjusted): 2000M02 2014M12

Included observations: 179 after adjustments

\begin{tabular}{lllll}
\hline \hline & Coefficient & Std. Error & t-Statistic & Prob. \\
\hline \hline IP(-1) & -0.00859 & 0.009494 & -0.90509 & 0.3667 \\
C & 175.2026 & 146.4134 & 1.19663 & 0.2331 \\
\hline \hline R-squared & 0.004607 & Mean dependent var & 46.13132 \\
Adjusted R-squared & -0.00102 & S.D. dependent var & 443.5401 \\
S.E. of regression & 443.7656 & Akaike info criterion & 15.03958 \\
Sum squared resid & 34856234 & Schwarz criterion & 15.07519 \\
Log likelihood & -1344.04 & Hannan-Quinn criter. & 15.05402 \\
F-statistic & 0.819178 & Durbin-Watson stat & 2.22669 \\
Prob(F-statistic) & 0.366651 & & & \\
\hline
\end{tabular}

Tabela 17 - DF-GLS Investimento Privado

Null Hypothesis: IP has a unit root

Exogenous: Constant, Linear Trend

Lag Length: 0 (Automatic based on SIC, MAXLAG=13)

\begin{tabular}{lll}
\hline \hline & t-Statistic \\
\hline \hline \multicolumn{2}{l}{ Elliott-Rothenberg-Stock DF-GLS test statistic } & -2.15253 \\
Test critical values: $1 \%$ level & -3.4852 \\
& $5 \%$ level & -2.951 \\
& $10 \%$ level & -2.661 \\
\hline \hline
\end{tabular}

*Elliott-Rothenberg-Stock (1996, Table 1) 
Tabela 18 - NG-Perron Investimento Privado

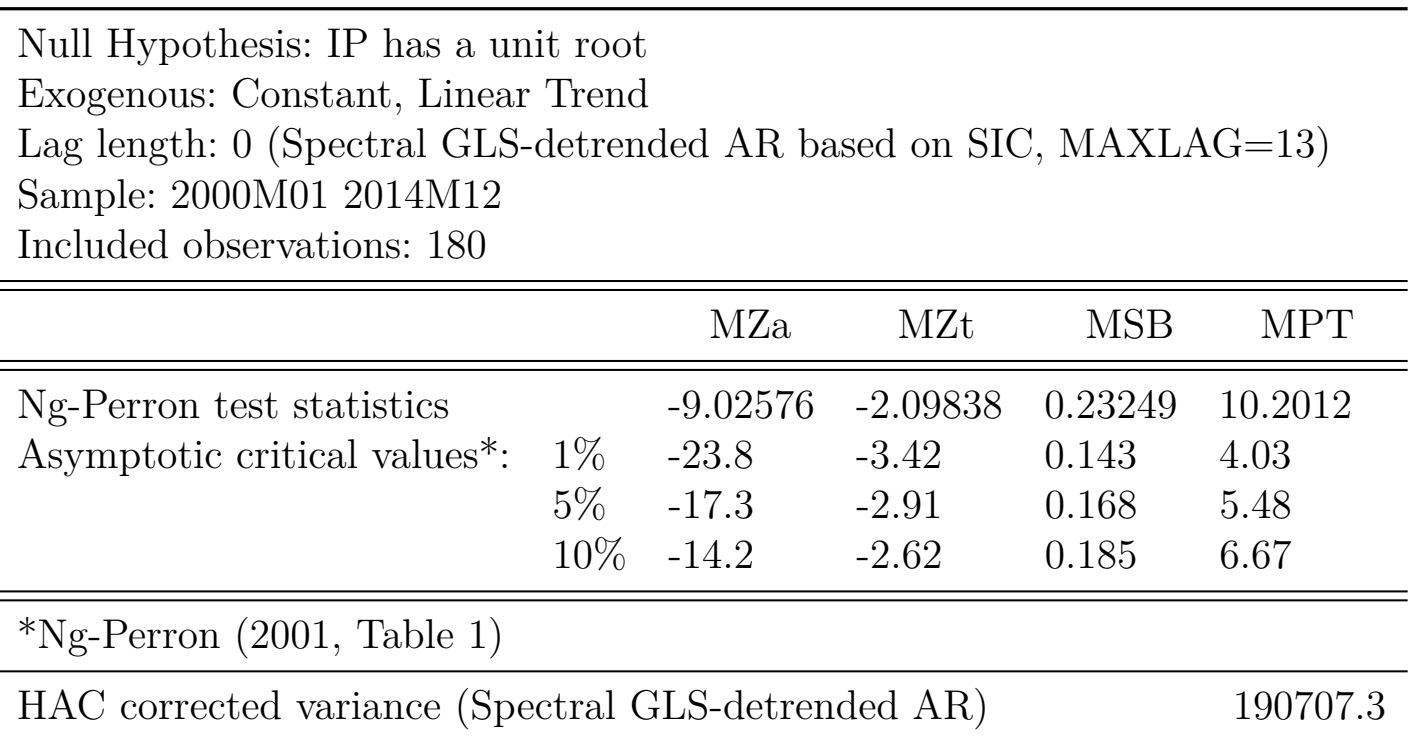

Tabela 19 - KPSS Investimento Privado

Null Hypothesis: IP is stationary

Exogenous: Constant

Bandwidth: 10 (Newey-West using Bartlett kernel)

\begin{tabular}{|c|c|}
\hline & LM-Stat. \\
\hline Kwiatkowski-Phillips-Schmidt-Shin test statistic & 1.615165 \\
\hline \multirow{3}{*}{$\begin{array}{ll}\text { Asymptotic critical values*: } & 1 \% \text { level } \\
& 5 \% \text { level } \\
& 10 \% \text { level }\end{array}$} & 0.739000 \\
\hline & 0.463000 \\
\hline & 0.347000 \\
\hline
\end{tabular}

*Kwiatkowski-Phillips-Schmidt-Shin (1992, Table 1)

Pantula foram feitos passo a passo.

Como foi ressaltado em capítulos anteriores, todas as séries analisadas têm fortes indícios de apresentarem raiz unitária. Desse modo, os exercícios econométricos foram realizados para as séries em primeira diferença. 
Tabela 20 - ADF Produto Interno Bruto

Null Hypothesis: Y has a unit root

Exogenous: Constant

Lag Length: 2 (Automatic based on SIC, MAXLAG=12)

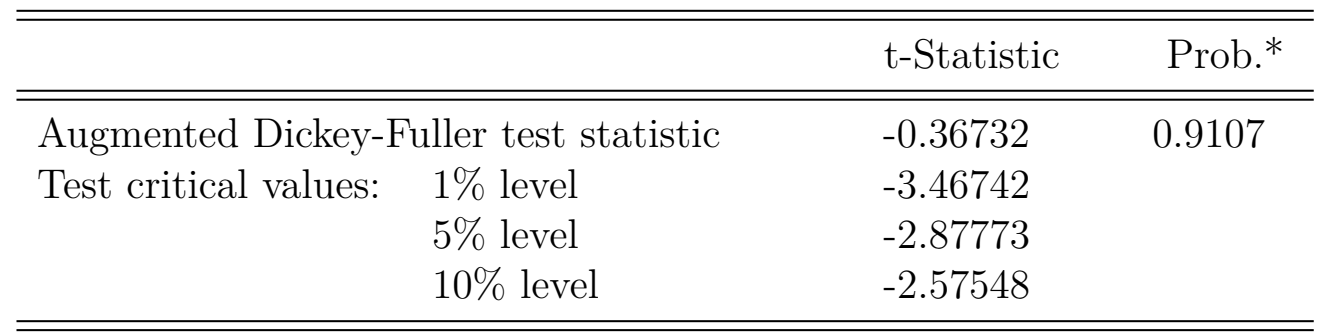

*MacKinnon (1996) one-sided p-values.

Augmented Dickey-Fuller Test Equation

Dependent Variable: D(Y)

Method: Least Squares

Sample (adjusted): 2000M04 2014M12

Included observations: 177 after adjustments

\begin{tabular}{lllll}
\hline \hline & Coefficient & Std. Error & t-Statistic & Prob. \\
\hline \hline $\mathrm{Y}(-1)$ & -0.00227 & 0.006185 & -0.36732 & 0.7138 \\
$\mathrm{D}(\mathrm{Y}(-1))$ & -0.3 & 0.0732 & -4.09829 & 0.0001 \\
$\mathrm{D}(\mathrm{Y}(-2))$ & -0.25916 & 0.073106 & -3.54497 & 0.0005 \\
$\mathrm{C}$ & 740.8332 & 569.1467 & 1.301656 & 0.1948 \\
\hline \hline R-squared & 0.122937 & Mean dependent var & 349.0318 \\
Adjusted R-squared & 0.107728 & S.D. dependent var & 1792.11 \\
S.E. of regression & 1692.83 & Akaike info criterion & 17.72853 \\
Sum squared resid & $4.96 \mathrm{E}+08$ & Schwarz criterion & 17.80031 \\
Log likelihood & -1564.98 & Hannan-Quinn criter. & 17.75764 \\
F-statistic & 8.083094 & Durbin-Watson stat & 1.969473 \\
Prob(F-statistic) & 0.000045 & & & \\
\hline
\end{tabular}

Tabela 21 - DF-GLS Produto Interno Bruto

\begin{tabular}{|c|c|}
\hline $\begin{array}{l}\text { Null Hypothesis: Y has a unit root } \\
\text { Exogenous: Constant, Linear Trend } \\
\text { Lag Length: } 2 \text { (Automatic based on SIC, MAXI }\end{array}$ & $A G=13)$ \\
\hline & t-Statistic \\
\hline Elliott-Rothenberg-Stock DF-GLS test statistic & -1.58705 \\
\hline Test critical values: $1 \%$ level & -3.4876 \\
\hline $5 \%$ level & -2.953 \\
\hline $10 \%$ level & -2.663 \\
\hline
\end{tabular}

*Elliott-Rothenberg-Stock (1996, Table 1) 
Tabela 22 - NG-Perron Produto Interno Bruto

Null Hypothesis: Y has a unit root

Exogenous: Constant, Linear Trend

Lag length: 2 (Spectral GLS-detrended AR based on SIC, MAXLAG=13)

Sample: 2000M01 2014M12

Included observations: 180

\begin{tabular}{llllll}
\hline \hline & & MZa & MZt & MSB & \multicolumn{1}{c}{ MPT } \\
\hline \hline Ng-Perron test statistics & & -5.11385 & -1.58904 & 0.31073 & 17.7769 \\
Asymptotic critical values*: & $1 \%$ & -23.8 & -3.42 & 0.143 & 4.03 \\
& $5 \%$ & -17.3 & -2.91 & 0.168 & 5.48 \\
& $10 \%$ & -14.2 & -2.62 & 0.185 & 6.67 \\
\hline \hline \multirow{2}{*}{ Ng-Perron (2001, Table 1) } & & & \\
\hline HAC corrected variance (Spectral GLS-detrended AR) & & 1201772. \\
\hline
\end{tabular}

Tabela 23 - KPSS Produto Interno Bruto

Null Hypothesis: Y is stationary

Exogenous: Constant

Bandwidth: 10 (Newey-West using Bartlett kernel)

\begin{tabular}{llc}
\hline \hline & LM-Stat. \\
\hline \hline Kwiatkowski-Phillips-Schmidt-Shin test statistic & 1.716732 \\
Asymptotic critical values*: & 1\% level & 0.739000 \\
& $5 \%$ level & 0.463000 \\
& $10 \%$ level & 0.347000 \\
\hline \hline
\end{tabular}

*Kwiatkowski-Phillips-Schmidt-Shin (1992, Table 1) 


\subsection{Modelo linear}

Esta subseção se concentra em reportar os resultados do VAR linear para o seguinte vetor: $(d(I g) d(I p) d(y))$, em que Ig é o investimento da Administração pública (federal, estadual e municipal), Ip é o investimento privado residual, obtido pela subtração da FBCF mensal estimada por Ig e y é o produto interno bruto. A operação $d()$ é a primeira diferença de meses semelhantes para um ano defasado.

Primeiramente, verificou-se o critério do número de defasagens a serem usadas no modelo. A tabela (24) indica que a melhor quantidade é 4. Analisando os parâmetros estimados e seus desvios-padrão, conclui-se que o modelo deve incluir uma constante. Analisando a estabilidade do VAR pela Figura (19), constata-se que todas as raízes inversas do polinômio característico se encontram dentro do círculo unitário. Pelos testes de autocorrelação dos resíduos de Portmanteau (Tabela (25)) e LM (Tabela (26)), não há esse tipo de problema para a maioria das defasagens analisadas, com a exceção da $12^{\mathrm{a}}$. $\mathrm{O}$ teste de normalidade, por sua vez, indica que os resíduos são relativamente simétricos mas apresentam problemas de curtose. Separadamente, os resíduos de $I g$ e $y$ se aproximam de uma distribuição normal, com relação à distribuição conjunta, entretanto, não se pode tirar as mesmas conclusões (Tabela (27)). Pela Figura (20), percebe-se que a decomposição da variância se comporta distintamente para cada variável. Enquanto que para os investimentos público e privado, a quase totalidade da sua variação é originada pelos choques da própria variável (basta observar as duas primeiras curvas perto de 100\% na diagonal principal) ${ }^{2}$, para o PIB, choques do investimento público não explicam quase nada das variações do produto. Ademais, choques em investimento privado explicam grande parcela da variância do PIB, chegando inclusive à marca de $70 \%$.

Os resultados aqui reportados sobre o modelo linear foram feitos no software EViews, contudo, as funções de impulso resposta, assim como seus intervalos de confiança, e os multiplicadores fiscais foram feitos no MatLab.

2 Como a decomposição da variância é sensível à decomposição de Cholesky, é de se esperar que a primeira variável do VAR tenha o comportamento acima descrito, justamente pelo fato de seus choques estruturais serem contemporaneamente independentes dos demais. 
Tabela 24 - Critério do número de defasagens

\begin{tabular}{|c|c|c|c|c|c|c|}
\hline \multicolumn{7}{|c|}{$\begin{array}{l}\text { VAR Lag Order Selection Criteria } \\
\text { Endogenous variables: D_IG D_IP D_Y } \\
\text { Exogenous variables: C } \\
\text { Sample: } 1168 \\
\text { Included observations: } 156\end{array}$} \\
\hline Lag & $\log L$ & LR & FPE & AIC & $\mathrm{SC}$ & HQ \\
\hline 0 & -3940.11 & $\mathrm{NA}$ & $1.81 \mathrm{e}+18$ & 50.55275 & 50.61140 & 50.57657 \\
\hline 1 & -3716.44 & 435.8880 & $1.15 \mathrm{e}+17$ & 47.80045 & $48.03505^{*}$ & 47.89573 \\
\hline 2 & -3700.09 & 31.23184 & $1.05 \mathrm{e}+17$ & 47.70622 & 48.11678 & 47.87297 \\
\hline 3 & -3683.04 & 31.90304 & $9.47 \mathrm{e}+16$ & 47.60309 & 48.18960 & $47.84131^{*}$ \\
\hline 4 & -3668.75 & 26.20604 & $8.86 \mathrm{e}+16^{*}$ & $47.53522^{*}$ & 48.29768 & 47.84490 \\
\hline 5 & -3666.73 & 3.624017 & $9.70 \mathrm{e}+16$ & 47.62472 & 48.56313 & 48.00586 \\
\hline 6 & -3661.38 & 9.395055 & $1.02 \mathrm{e}+17$ & 47.67152 & 48.78589 & 48.12413 \\
\hline 7 & -3654.32 & 12.12414 & $1.05 \mathrm{e}+17$ & 47.69643 & 48.98675 & 48.22050 \\
\hline 8 & -3646.21 & 13.63068 & $1.06 \mathrm{e}+17$ & 47.70776 & 49.17404 & 48.30330 \\
\hline 9 & -3639.4 & 11.17574 & $1.09 \mathrm{e}+17$ & 47.73584 & 49.37807 & 48.40284 \\
\hline 10 & -3633.37 & 9.648948 & $1.14 \mathrm{e}+17$ & 47.77403 & 49.59221 & 48.51250 \\
\hline 11 & -3617.62 & 24.64824 & $1.05 \mathrm{e}+17$ & 47.68738 & 49.68152 & 48.49731 \\
\hline 12 & -3600.78 & $25.67863^{*}$ & $9.58 \mathrm{e}+16$ & 47.58698 & 49.75707 & 48.46837 \\
\hline
\end{tabular}

* indicates lag order selected by the criterion

LR: sequential modified LR test statistic (each test at 5\% level)

FPE: Final prediction error

AIC: Akaike information criterion

SC: Schwarz information criterion

HQ: Hannan-Quinn information criterion

Figura 19 - Análise de estabilidade do VAR linear

Inverse Roots of AR Characteristic Polynomial

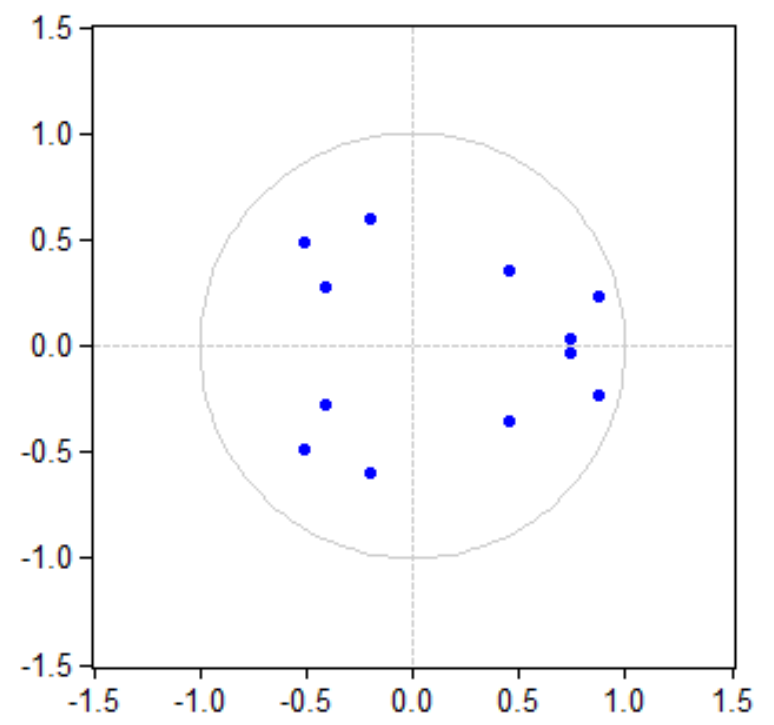


Tabela 25 - Teste de Autocorrelação Portmanteau

VAR Residual Portmanteau Tests for Autocorrelations

Null Hypothesis: no residual autocorrelations up to lag $h$

Sample: 1168

Included observations: 164

\begin{tabular}{llllll}
\hline \hline Lags & Q-Stat & Prob. & Adj Q-Stat & Prob. & df \\
\hline \hline 1 & 0.148497 & NA* $^{*}$ & 0.149408 & NA* $^{*}$ & NA* $^{*}$ \\
2 & 1.141048 & NA* $^{*}$ & 1.154213 & NA* $^{*}$ & NA* $^{*}$ \\
3 & 2.231705 & NA* $^{*}$ & 2.265193 & NA* $^{*}$ & NA* $^{*}$ \\
4 & 6.343710 & NA* $^{*}$ & 6.479998 & NA* $^{*}$ & NA* $^{*}$ \\
5 & 11.71993 & 0.2296 & 12.02528 & 0.2119 & 9 \\
6 & 15.07838 & 0.6566 & 15.51127 & 0.6266 & 18 \\
7 & 28.86856 & 0.3673 & 29.91630 & 0.3179 & 27 \\
8 & 42.83284 & 0.2014 & 44.59670 & 0.1540 & 36 \\
9 & 45.46269 & 0.4527 & 47.37925 & 0.3758 & 45 \\
10 & 52.82362 & 0.5198 & 55.21815 & 0.4284 & 54 \\
11 & 60.31628 & 0.5726 & 63.2495 & 0.4675 & 63 \\
12 & 133.8946 & 0 & 142.6366 & 0 & 72 \\
\hline \hline
\end{tabular}

*The test is valid only for lags larger than the VAR lag order.

$\mathrm{df}$ is degrees of freedom for (approximate) chi-square distribution

Tabela 26 - Teste de Autocorrelação LM

VAR Residual Serial Correlation LM Tests

Null Hypothesis: no serial correlation at lag order h

Sample: 1168

Included observations: 164

\begin{tabular}{lll}
\hline \hline Lags & LM-Stat & Prob \\
\hline \hline 1 & 2.672656 & 0.9759 \\
2 & 6.516634 & 0.6873 \\
3 & 5.46013 & 0.7925 \\
4 & 8.111064 & 0.523 \\
5 & 6.168943 & 0.7229 \\
6 & 3.882301 & 0.919 \\
7 & 16.75208 & 0.0527 \\
8 & 14.78317 & 0.0971 \\
9 & 2.889611 & 0.9685 \\
10 & 8.11501 & 0.5226 \\
11 & 8.108715 & 0.5232 \\
12 & 91.14531 & 0 \\
\hline \hline
\end{tabular}

Probs from chi-square with $9 \mathrm{df}$. 
Tabela 27 - Teste de Normalidade

VAR Residual Normality Tests

Orthogonalization: Cholesky (Lutkepohl)

Null Hypothesis: residuals are multivariate normal

Sample: 1168

Included observations: 164

\begin{tabular}{ccccc}
\hline \hline Component & Skewness & Chi-sq & df & Prob. \\
\hline \hline 1 & 0.057491 & 0.090343 & 1 & 0.7637 \\
2 & -0.37794 & 3.904214 & 1 & 0.0482 \\
3 & 0.148199 & 0.600320 & 1 & 0.4385 \\
Joint & & 4.594877 & 3 & 0.2040
\end{tabular}

\begin{tabular}{ccccc}
\hline \hline Component & Kurtosis & Chi-sq & df & Prob. \\
\hline \hline 1 & 2.819212 & 0.223344 & 1 & 0.6365 \\
2 & 5.567727 & 45.05367 & 1 & 0.0000 \\
3 & 3.682792 & 3.185732 & 1 & 0.0743 \\
Joint & & 48.46275 & 3 & 0.0000
\end{tabular}

\begin{tabular}{cccc}
\hline \hline Component & Jarque-Bera & df & Prob. \\
\hline \hline 1 & 0.313686 & 2 & 0.8548 \\
2 & 48.95789 & 2 & 0.0000 \\
3 & 3.786052 & 2 & 0.1506 \\
Joint & 53.05762 & 6 & 0.0000 \\
\hline
\end{tabular}


Figura 20 - Decomposição da variância

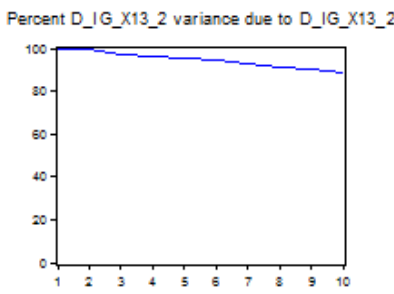

Percent $D_{-} \mid P_{-} X 13{ }_{-} 2$ variance due to $D_{-} \mid G_{-} X 13{ }_{-} 2$

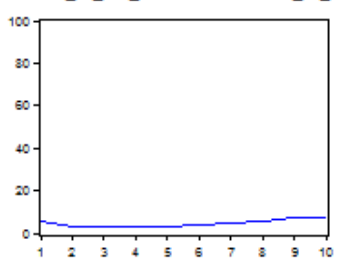

Percent $D_{-} Y_{-} X 13{ }_{-} 2$ variance due to $D_{-} \mid G_{-} X 13{ }_{-} 2$

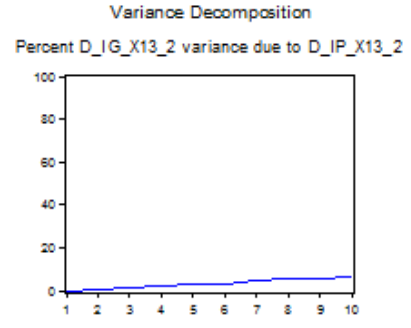

Percent $D_{-} \mid G_{-} X 13 \_2$ variance due to $D_{-} Y_{-} X 13{ }_{-} 2$

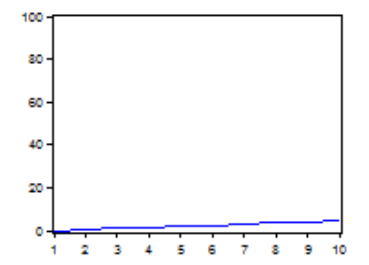

Percent $D_{-} \mid P_{-} X 13{ }_{-} 2$ variance due to $D_{-} \mid P_{-} X_{13}{ }_{-} 2$

Percent $D_{-} I P_{-} X 13{ }_{-} 2$ variance due to $D_{-} Y_{-} X 13{ }_{-} 2$
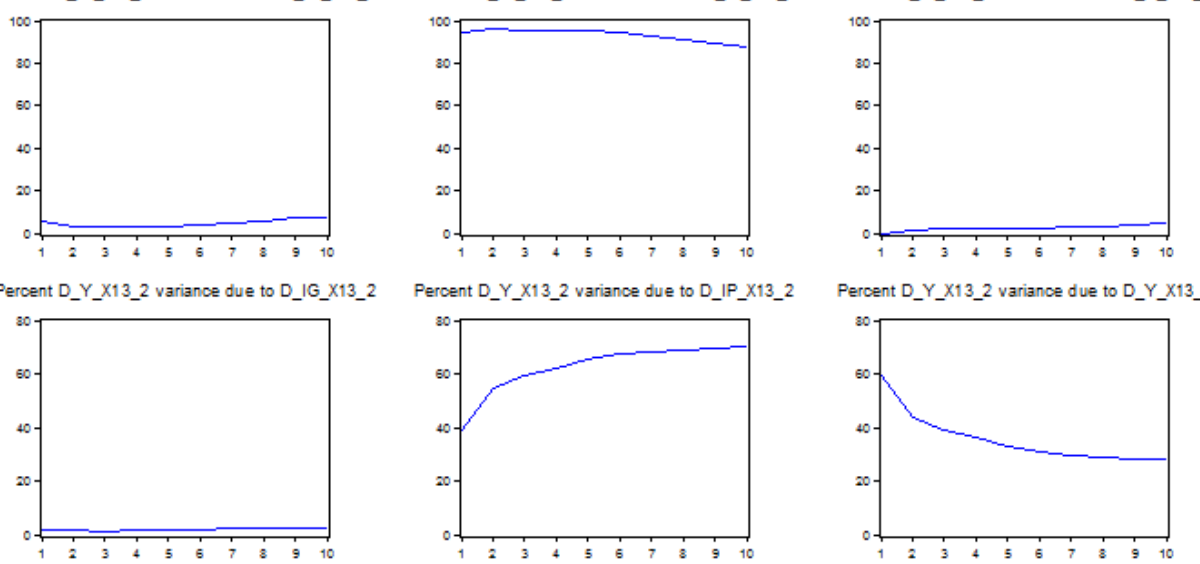

Percent $D_{-} Y_{-} X 133_{-} 2$ variance due to $D_{-} \mid P_{-} X 13_{-} 2$

Percent $D_{-} Y_{-} X 13 \_2$ variance due to $D_{-} Y_{-} X 13{ }_{-} 2$
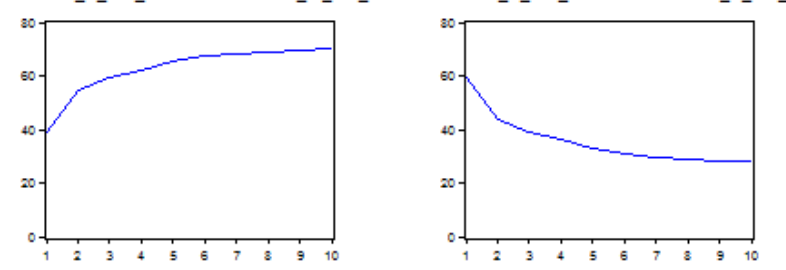


\subsection{Modelo não-linear}

Esta subseção reporta apenas alguns dos outputs gerados pelo software na estimação do modelo principal do trabalho. Seguem abaixo os critérios de informação, as matrizes de variância e covariância do modelo inicialmente estimado para a geração de resíduos e também dos períodos analisados (pré e pós-eleitoral).

Tabela 28 - Critérios de Informação (Modelo não-linear)

$\begin{array}{r}\hline \text { AICnonlin: } 38.6149 \\ \hline \text { BICnonlin: } 39.1608 \\ \text { AIClin: } 38.8872 \\ \text { BIClin: } 39.0567 \\ \hline\end{array}$

Tabela 29 - Covariância dos Resíduos

\begin{tabular}{ccc}
\hline \multicolumn{3}{c}{ Omega (covariância dos resíduos) } \\
\hline 66047.81 & -30837.3 & 100711.5604 \\
-30837.3 & 249941.9 & 527817.5299 \\
100711.6 & 527817.5 & 4221233.513 \\
\hline
\end{tabular}

Tabela 30 - Omega (pré-eleitoral)

\begin{tabular}{ccc}
\hline \multicolumn{3}{c}{$\Omega_{E}$} \\
\hline 52990.17 & -33111.9 & 43447.81227 \\
-33111.9 & 329704.9 & 644578.6594 \\
43447.81 & 644578.7 & 4073969.069 \\
\hline
\end{tabular}

Tabela 31 - Omega (pós-eleitoral)

\begin{tabular}{lrr}
\hline \multicolumn{3}{c}{$\Omega_{R}$} \\
\hline 79184.61 & 20.94739 & 10.3286149 \\
20.94739 & 155120.3 & 426754.5601 \\
10.32861 & 426754.6 & 3849108.42 \\
\hline
\end{tabular}


Tabela 32 - Resumo do Modelo 1

\begin{tabular}{l}
\hline sample0: [1x168 double] \\
\hline VARlags: 3 \\
Nvar: 3 \\
irf_hor: 20 \\
Igpos: 1 \\
T: 165 \\
Omega_length_cov: 6 \\
\hline
\end{tabular}

